\title{
First Row Transition Metal Mediated Redox Reactions of Hydrazines and Isonitriles
}

\author{
John Riedesel
}

Follow this and additional works at: https://researchrepository.wvu.edu/etd

\section{Recommended Citation}

Riedesel, John, "First Row Transition Metal Mediated Redox Reactions of Hydrazines and Isonitriles" (2016). Graduate Theses, Dissertations, and Problem Reports. 6505.

https://researchrepository.wvu.edu/etd/6505

This Thesis is protected by copyright and/or related rights. It has been brought to you by the The Research Repository @ WVU with permission from the rights-holder(s). You are free to use this Thesis in any way that is permitted by the copyright and related rights legislation that applies to your use. For other uses you must obtain permission from the rights-holder(s) directly, unless additional rights are indicated by a Creative Commons license in the record and/ or on the work itself. This Thesis has been accepted for inclusion in WVU Graduate Theses, Dissertations, and Problem Reports collection by an authorized administrator of The Research Repository @ WVU. For more information, please contact researchrepository@mail.wvu.edu. 


\title{
First Row Transition Metal Mediated Redox Reactions of Hydrazines and Isonitriles
}

\author{
John Riedesel \\ Thesis submitted \\ to the Eberly College of Arts and Sciences \\ at West Virginia University
}

in partial fulfillment of the requirements for the degree of

Master of Science in

Chemistry

\author{
Jessica Hoover, Ph.D., Chair \\ Brian Popp, Ph.D. \\ Björn Söderberg, Ph.D. \\ Carsten Milsmann, Ph.D. \\ C. Eugene Bennett Department of Chemistry \\ Morgantown, West Virginia \\ 2016
}

Keywords: isonitrile, hydrazine, vanadium, cobalt, redox, coupling Copyright 2016 John Riedesel 


\section{ABSTRACT \\ First Row Transition Metal Mediated Redox Reactions of Hydrazines and Isonitriles}

\section{John Riedesel}

Over the past 50 years, there has been an explosion in the progress of transition-metal mediated reaction design, allowing chemists to perform a vast array of organic and inorganic transformations. While first-row transition-metals play a role in many reactions that have been known for some time, second- and third-row transition-metals have been key for the discovery and success of many of the most well-known and utilized reactions in homogeneous catalysis existing today. However, developing reactions utilizing first-row transition-metals has re-gained in popularity over recent years, in part due to the general expense of heavier metals. Also, the ability of first-row transition-metals to perform unique transformations or tolerate different functional groups in substrates is often a motivation to explore their applications in synthetic reactions.

Inspiration for the design of many catalyst systems is often drawn from biological processes, namely enzyme catalysis. Various transition-metals are found within enzymes, being necessary for most of their functions. Enzymes are highly refined catalysts for performing reactions essential to life, which are often found to be difficult to accomplish synthetically. Among these is the nitrogenase enzyme, named for its primary biological function, the reduction of dinitrogen to ammonia. In addition to dinitrogen reduction, nitrogenases can perform reduction reactions on a wide range of small molecules. Of particular interest is the recently discovered ability of vanadium nitrogenase to perform the complete deoxygenative reductive coupling of carbon monoxide to form small-chain hydrocarbons, a reaction not yet accomplished in a homogeneous model system.

The unique ability of the vanadium nitrogenase variant to perform the reductive coupling of carbon monoxide provided an inspiration to develop new homogeneous vanadium systems capable of mimicking the reactivity observed with nitrogenase enzymes. Hydrazines were chosen to investigate in place of dinitrogen due to its weaker nitrogen-nitrogen bond. Isonitriles were chosen to investigate for reductive coupling reactions in place of carbon monoxide due to their 
ease of handling. Additionally, the coupling of isonitriles with bisnucleophiles was investigated using iron and cobalt sources as an alternative to palladium catalysts. 


\section{ACKNOWLEDGMENTS}

I would like to thank my advisor Dr. Jessica Hoover for help and support throughout my graduate campaign. Her knowledge of chemistry and enthusiasm for teaching have made her a great asset to me while performing my studies and conducting research. Moreover, her patience and support have been key to my success as I have made my way through the graduate program.

Additionally, I would like to thank the other members of my committee, Dr. Brian Popp, Dr. Björn Söderberg, and Dr. Carsten Milsmann, for their kindness and helpfulness while I have worked my way through the program, and especially while preparing my thesis.

I would also like to thank all of my groupmates, Dr, Anitha Shankara Linge Gowda, Dr. Minghoa Li, Dr. Bhasker Radaram, Dr. Andreas Baur, Aaron Honeycutt, Rob Crovak, and Jiaqi Liu, for all of their help with revising my thesis.

Finally, I would like to thank my significant other, Kateryna Konstantynova, for her endless love and support. Without it, none of this would have been possible. 


\section{Table of Contents}

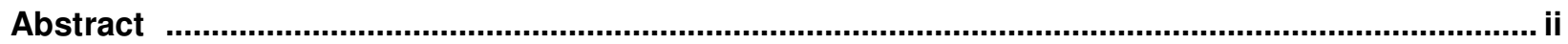

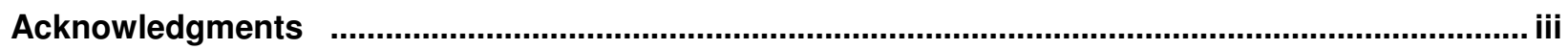

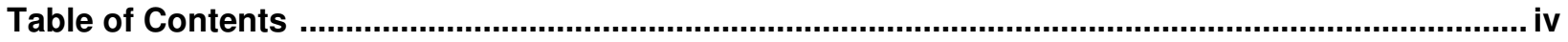

LIST OF FIGURES

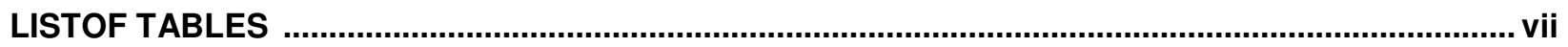

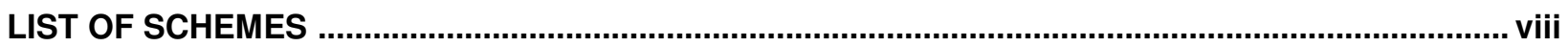

CHAPTER I. Synthesis of Vanadium-Tris(methimizolyl)borate Complexes as Vanadium Nitrogenase Mimics

1.1. Introduction

1.1.1. Reduction of Small Molecules by Nitrogenase Enzymes

1.1.2. Catalytic Reduction of Hydrazines by Homogeneous Transition-Metal Complexes …......... 3

1.1.3. Homogeneous Reductive Coupling of Carbon Monoxide and Isonitriles …......................... 7

1.1.4. Tris(methimizolyl)borate as a Ligand in Transition-Metal Chemistry .................................. 14

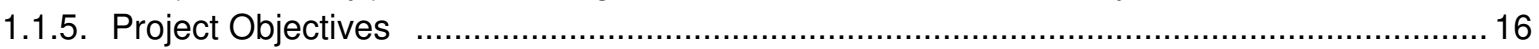

1.1.5.1. Tris(methimizolyl)borate as a Ligand for Nitrogenase Structural Mimics ................... 16

1.1.5.2. Vanadium-Tris(methimizolyl)borate Complexes for the Reductive Coupling of

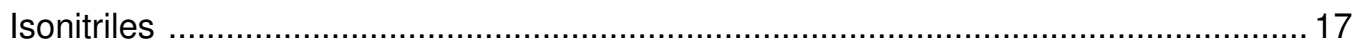

1.1.5.3. Vanadium-Tris(methimizolyl)borate-Hydrazine Complexes and their Reduction

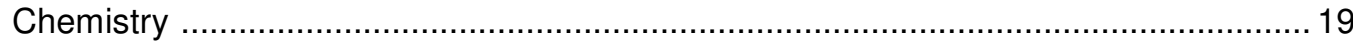

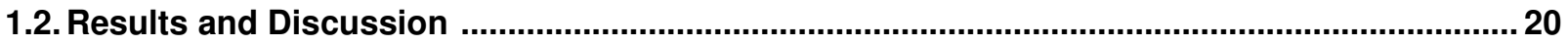

1.2.1. Synthesis of Vanadium-Tris(imidazole-2-thione)borate Sandwich Complexes ...................20

1.2.2. Attempts at Synthesizing Vanadium-Tris(methimizolyl)borate-Isonitrile Complexes ..........25

1.2.3. Attempts at Synthesizing Vanadium-Tris(methimizolyl)borate-Hydrazine Complexes and

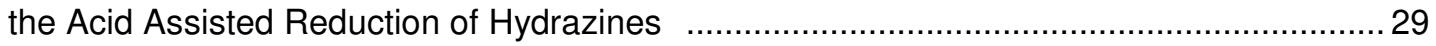

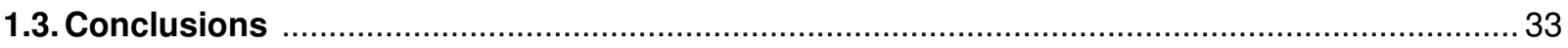

CHAPTER II. Coupling of Isonitriles with Bisnucleophiles Mediated by Iron and Cobalt ..........................34

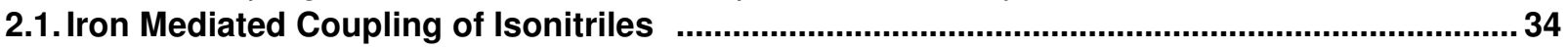

2.1.1. Isonitrile Coupling Mediated by Iron-Tris(methimizolyl)borate Complexes to Form Ureas .34

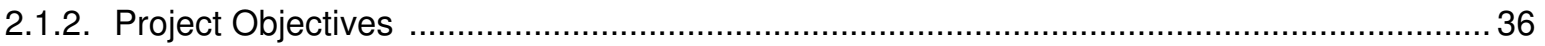

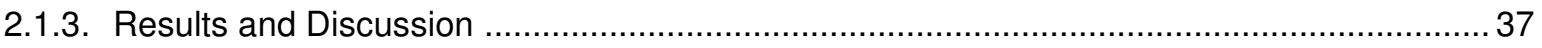

2.2. Oxidative Transition-Metal Catalyzed Coupling of Isonitriles and Nucleophiles ...................41

2.2.1. Palladium-Catalyzed Coupling of Isonitriles and Nucleophiles ....................................... 42

2.2.2. Oxidative First-Row Transition-Metal Catalyzed Coupling Reactions of Isonitriles with

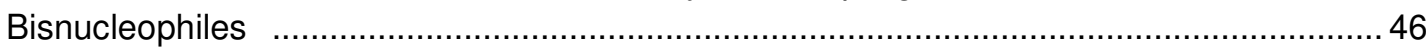

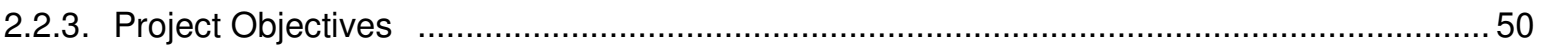

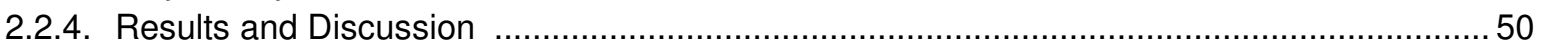

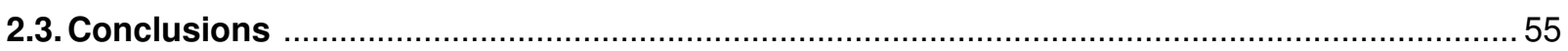

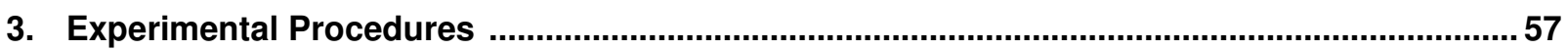

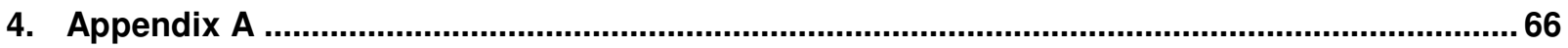

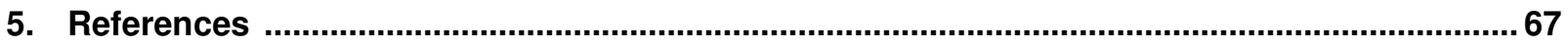




\section{List of Figures}

Figure 1. Examples of homogeneous complexes capable of the catalytic reduction of N2 to ammonia .... 3

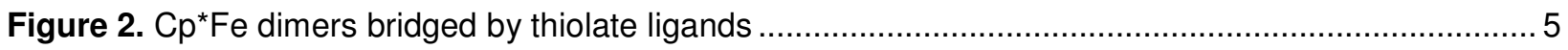

Figure 3. $\mathrm{MFe}_{3} \mathrm{~S}_{4}$ cubane complexes capable of the catalytic reduction of hydrazines .......................... 6

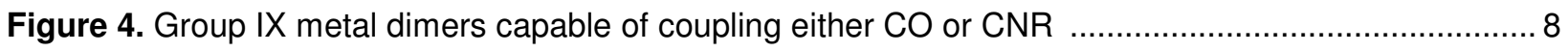

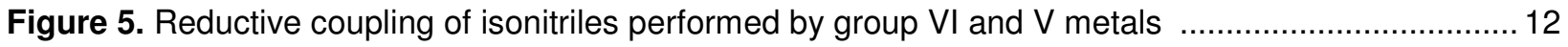

Figure 6. Displacement of a belt-sulfur with $\mathrm{CO}$ molecule in the active sit of Nase .............................. 13

Figure 7. Tris(methimizolyl)borate $(\mathrm{Tm})$ and its coordination as a ligand on transition-metals .............. 14

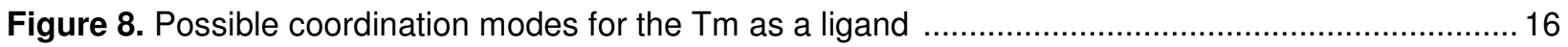

Figure 9. $\mathrm{k}^{3}-\mathrm{S}, \mathrm{S}, \mathrm{S}$ coordination of the Tm ligand as a motif for mimicking the active site of Nase $\ldots . . . . .17$

Figure 10. Examples of vanadium complexes capable of performing the reductive coupling of $\mathrm{CO}$ or

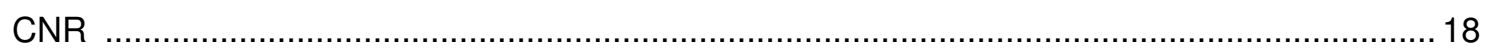

Figure 11. Examples of sulfur-ligated vanadium complexes with hydrazines .................................... 19

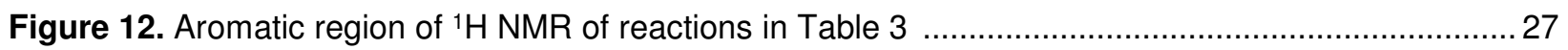

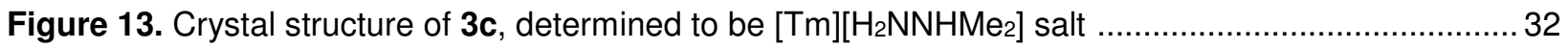

Figure 14. Currently marketed drugs containing a 2-aminoqunazoline moiety .................................... 51 


\section{List of Tables}

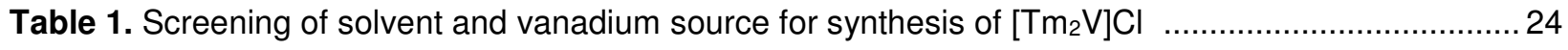

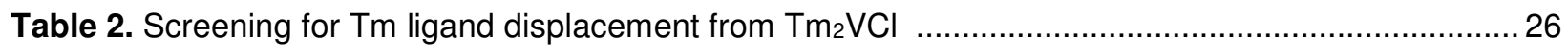

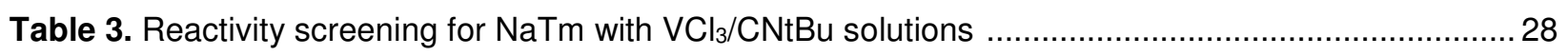

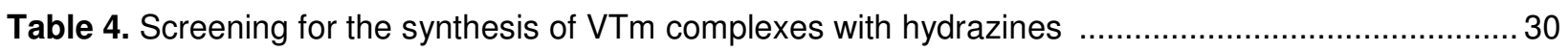

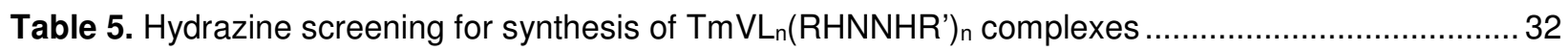

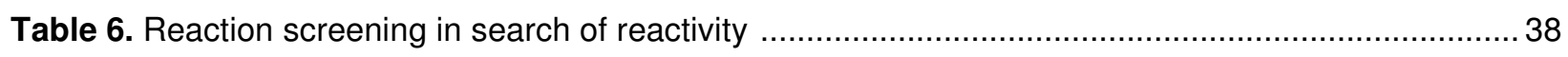

Table 7. Iron screening for the coupling of 2-aminophenol and tert-butyl isonitrile ................................ 39

Table 8. Condition screening for the coupling of 2-aminophenol and tert-butyl isonitrile ........................ 39

Table 9. Reductant screening for the coupling of 2-aminophenol and tert-butyl isonitrile .................... 40

Table 10. Cobalt screening for the coupling of 2-aminophenol and tert-butyl isonitrile ......................... 41

Table 11. Cobalt and oxidant screening for the coupling of 2-aminobenzylamine and tert-butyl isonitrile

Table 12. Temperature screening for coupling of 2-aminobenzylamine and tert-butyl isonitrile 53

Table 13. Isonitrile screening for the coupling with 2-aminobenzylamine 54

Table 14. Projected scope of isonitriles to be investigated .54

Table 15. Projected scope of 2-aminobenzylamines to be investigated .55

Table 16. Recent attempts for reproducing the cobalt-catalyzed coupling of 2-aminobenzylamine and tert-butyl isonitrile. 66 


\section{List of Schemes}

Scheme 1. Reduction of $\mathrm{N}_{2}$ to ammonia by Nase

Scheme 2. Catalytic ammonia production from hydrazine using molybdenum and tungsten $\mathrm{Cp}^{*}$ complexes

Scheme 3. Catalytic conversion of hydrazine to ammonia by a Mo dimer complex 4

Scheme 4. Vanadium and iron tris(thiolato)phosphine precatalysts for the reduction of hydrazine to ammonia

Scheme 5. Pendant Lewis acid-assisted reductive coupling of $\mathrm{CO}$ at a single rhenium center

Scheme 6. Iron-mediated reductive coupling of $\mathrm{CO}$

Scheme 7. CO coupling by $\mathrm{Cp}^{*} 2 \mathrm{Zr}(\mathrm{H})(\mathrm{CO})$ to form an enedioxy-bridged dimer 10

Scheme 8. Reductive coupling of $\mathrm{CO}$ by anionic group $\mathrm{V}$ metal complexes induced by silylation 11

Scheme 9. Deoxygenative reductive coupling of $\mathrm{CO}$ to generate silylated-C2 products at a single molybdenum site

Scheme 10. Molybdenum and chromium complexes capable of coupling isonitriles 12

Scheme 11. Synthesis of Tm-salts from the reactions of methimazole with borohydride 15

Scheme 12. Plausible route towards accessing $\operatorname{TmV}(\mathrm{CNR})_{\mathrm{n}}$ complexes and generating possible C-C coupled products

Scheme 13. Plausible route towards accessing VTm complexes with hydrazines and performing reductive cleavage of the $\mathrm{N}-\mathrm{N}$ bond

Scheme 14. NaTm synthesis 20

Scheme 15. $\mathrm{NaTm}^{\mathrm{Ph}}$ synthesis 21

Scheme 16. $\mathrm{NaTm}^{\mathrm{R}}$ synthesis

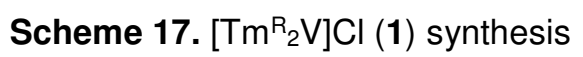
22

Scheme 18. $\left[\mathrm{Tm}_{2} \mathrm{~V}\right](\mathrm{OTf})(\mathbf{1 c})$ synthesis 23

Scheme 19. $\mathrm{Tm}_{2} \mathrm{~V}(2)$ synthesis via reduction of $\mathbf{1 a}$ 25 
Scheme 20. Subsequent addition of a reductant and an acid generates aniline as a product

Scheme 21. Addition of a reductant and an acid $3 \mathbf{a}$ generates aniline as a product 31

Scheme 22. [Tm $\left.{ }^{\mathrm{R} F e}\left(\mathrm{CNR}^{\prime}\right)_{3}\right](\mathrm{OTf})$ complexes isolated by the Hoover group 34

Scheme 23. Reactions of FeTm-CNR complexes to produce ureas 35

Scheme 24. Possible pathway for the production of urea from $\left[\mathrm{Tm}^{\mathrm{Me}} \mathrm{Fe}(\mathrm{CNtBu})_{3}\right]^{+}$ 36

Scheme 25. Desired coupling of 2-aminophenol with isonitriles to produce 2-aminobenzoxazoles, mediated by iron under reductive conditions 37

Scheme 26. Isolation of 2-amino- $N$-tert-butylbenzoxazole

Scheme 27. Palladium-catalyzed coupling of tert-butyl isonitrile with amino alcohols and amino thiols

Scheme 28. Palladium-catalyzed coupling of tert-butyl isonitrile with phenyl bromide and organotin reagents

Scheme 29. Typical catalytic cycle for redox-neutral palladium-catalyzed coupling of isonitriles with an aryl halide and a nucleophile

Scheme 30. Oxidative palladium-catalyzed coupling of isonitriles with amines to produce carbodiimides

Scheme 31. Oxidative palladium-catalyzed coupling of isonitriles with $\mathrm{N}$-aryl amidines to produce 4aminoquinazolines

Scheme 32. Palladium catalyzed coupling of isonitriles with aniline-based bisnucleophiles 44

Scheme 33. Catalytic cycle for palladium-catalyzed coupling of isonitriles with bisnucleophiles 45

Scheme 34. Optimized conditions for obtaining 2-aminobenzoxazoles and 3-amino-2H-benzoxazines .46

Scheme 35. Cobalt-catalyzed coupling of isonitriles with aniline-based bisnucleophiles 47

Scheme 36. Nickel-catalyzed coupling of isonitriles with aniline-based bisnucleophiles 47

Scheme 37. Proposed mechanistic pathways for cobalt-catalyzed coupling of isonitriles with anilinebased bisnucleophiles 48

Scheme 38. Cobalt-catalyzed coupling of isonitriles with amines under ultrasound irradiation 49 
Scheme 39. Goal for the optimization of the coupling between isonitriles and 2-aminobenzylamines to produces 2-aminoquinazolines

Scheme 40. Reaction conditions for screening the coupling of bisnucleophiles with tert-butyl isonitrile mediated by cobalt under oxidative conditions

Scheme 41. Reduction of 2-aminobenzonitriles to 2-aminobenzylamines 


\section{CHAPTER I.}

\section{Synthesis of Vanadium-Tris(methimizolyl)borate Complexes as Vanadium Nitrogenase}

Mimics

\subsection{Introduction}

\subsubsection{Reduction of Small Molecules by Nitrogenase Enzymes}

Nitrogenase enzymes (Nase) are responsible for all known biological dinitrogen $\left(\mathrm{N}_{2}\right)$ fixation, providing over half of the world's nitrogen supply. ${ }^{1,2}$ These enzymes exist only in bacterial and archaeal species, reducing $\mathrm{N}_{2}$ as their primary function. There are three main categories of Nases based on the metal composition of the cofactor responsible for mediating $\mathrm{N}_{2}$ reduction (Scheme 1). While consuming 16 molecules of ATP, the overall throughput of 8 protons and 8 electrons produces two equivalents of ammonia and one of dihydrogen $\left(\mathrm{H}_{2}\right)$ from each $\mathrm{N}_{2}$ molecule. Molybdenum nitrogenases (MoNase) are the most commonly found versions, as well as most the catalytically active for $\mathrm{N}_{2}$ reduction. Because of their reduction activity, it is not surprising that vanadium and iron nitrogenases (VNase and FeNase, respectively) are found less frequently in nature. Due to this incredible ability to reduce $\mathrm{N}_{2}$, an inert molecule in most contexts, Nases have received significant attention in order to try to elucidate the mechanisms involved in its reduction to ammonia. ${ }^{3,4}$

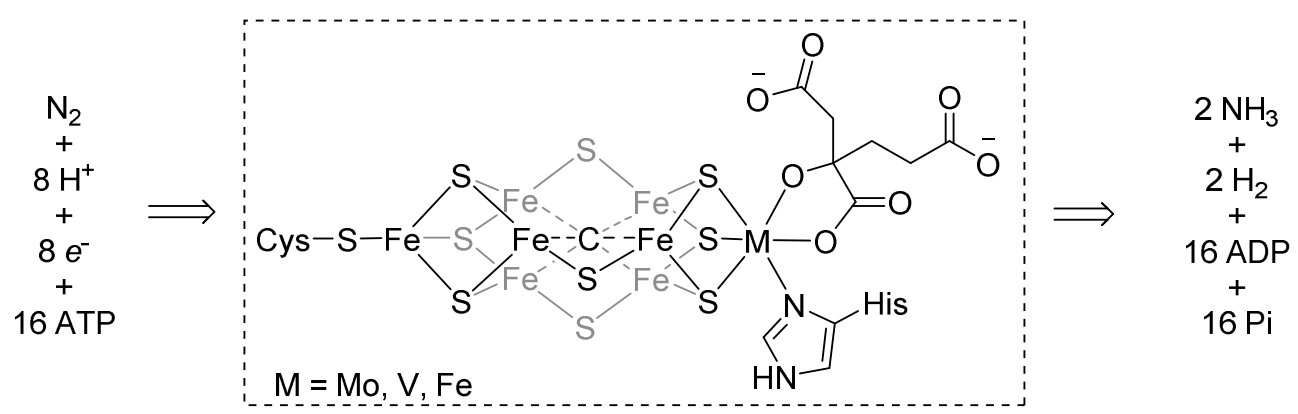

Scheme 1. Reduction of $\mathrm{N}_{2}$ to ammonia by Nase. Depicted is the Nase active site responsible for $\mathrm{N}_{2}$ fixation and reduction, consisting of $\mathrm{Mo}, \mathrm{V}$, and $\mathrm{Fe}$ variants. 
The Haber-Bosch (HB) process has been developed industrially to help satisfy the world's needs for nitrogenous fertilizers through $\mathrm{N}_{2}$ reduction to ammonia. Elucidating the pathways involved in Nase or HB catalysis has been aided by the development of homogeneous transition-metal systems. $\mathrm{N}_{2}$ reduction using homogeneous complexes has been one of the most difficult synthetic challenges of modern chemistry due to the high energy input requirement, with complexes capable of catalytic reduction of $\mathrm{N}_{2}$ to ammonia emerging only recently (Figure 1) ${ }^{5-9}$ Instead, homogeneous studies over the years have focused on related transformations ranging from simple $\mathrm{N}_{2}$ fixation to catalytic ammonia production from known $\mathrm{N}_{2}$ reduction intermediates. These intermediates include the 2 and 4 electron reduction products diazine and hydrazine, which have been confirmed to be intermediates through extensive investigations probing the activity of Nases. ${ }^{10}$ Although attention has been given to diazines, their general instability has resulted in a greater focus on the reduction of hydrazines in homogeneous transition-metal systems.

Nases have been demonstrated to reduce a wide range of different small molecules in addition to $\mathrm{N}_{2}$. Intermediates such as diazine and hydrazine have also been shown to be reduced to the corresponding amines when submitted as substrates to Nase. ${ }^{11,12}$ Nitrite, another major source in the biogeochemical nitrogen cycle, has also been shown to be reducible to ammonia by Nase. ${ }^{13}$ Likewise, its reduction intermediate hydroxylamine has also been demonstrated as a compatible substrate. Numerous reports of the reduction of other small nitrogen containing compounds by Nase exist, including azide, cyanide, and nitriles, among others. ${ }^{14,15}$

Beyond nitrogen containing molecules, Nases have been shown to reduce several classes of compounds containing C-C, C-O, and C-S multiple-bonds. ${ }^{14}$ Among them, acetylene has proven to be the second most favorable substrate for catalytic reduction by Nases, following $\mathrm{N}_{2} \cdot{ }^{16-18} \mathrm{In}$ fact, it's the only other substrate reducible by FeNase. However, only 2 or 4 electron reductions to alkenes and alkanes can occur, with ethylene as the favored product. Likewise, select alkenes are reducible to the corresponding alkanes. ${ }^{19,20}$ Aside from the ring-opening of cyclopropenes, ${ }^{21}$ Nases are incapable of the complete cleavage of a C-C bond. On the other hand, C-O and C-S multi-bonds can be reduced by MoNase and VNase to release water and hydrogen sulfide, respectively. ${ }^{22,23}$ 
While carbon dioxide has been a known substrate for over two decades, carbon monoxide (CO) has long been considered to be an inhibitor of Nases. Due to competitively binding to the active site of Nase, $\mathrm{CO}$ can effectively prevent $\mathrm{N}_{2}$ reduction, diverting electrons towards $\mathrm{H}_{2}$ production instead. However, Ribbe and coworkers reported in 2010 that the VNase analog is capable not only of reducing $\mathrm{CO}$, but also of coupling multiple molecules to yield small hydrocarbons. ${ }^{24}$ Immediately following this discovery, Seefeldt and coworkers reported a similar result for an $\alpha$ $\mathrm{Val}^{70}$ substituted MoNase variant, although the wild-type enzyme shows no reductive activity towards $\mathrm{CO} .{ }^{25}$ While methane is the predominant reduction product, these two Nase examples are capable of coupling up to four $\mathrm{CO}$ molecules to generate various alkanes and alkenes. Besides the Fischer-Tropsch process described in the section 1.1.3., no other systems exist, either natural or synthetic, that are capable of the complete deoxygenative reductive coupling of $\mathrm{CO}$ to release hydrocarbon products.

\subsubsection{Catalytic Reduction of Hydrazines by Homogeneous Transition-Metal Complexes}

Industrially, $\mathrm{N}_{2}$ reduction is performed rather efficiently with heterogeneous metal catalysts through the Haber-Bosch process. ${ }^{26,27}$ However, there is a strong demand for the development of homogeneous TM systems towards the reduction of $\mathrm{N}_{2}$ in order to help elucidate the mechanism of nitrogen reduction in systems such as nitrogenase enzymes or the Haber-Bosch process. With this in mind, there has been a considerable amount of work performed on homogenous systems involving not only the reduction of $\mathrm{N}_{2}$, but also that of known $\mathrm{N}_{2}$ reduction intermediates, namely hydrazines.

Figure 1. Examples of homogeneous complexes capable of the catalytic reduction of $\mathrm{N}_{2}$ to ammonia.
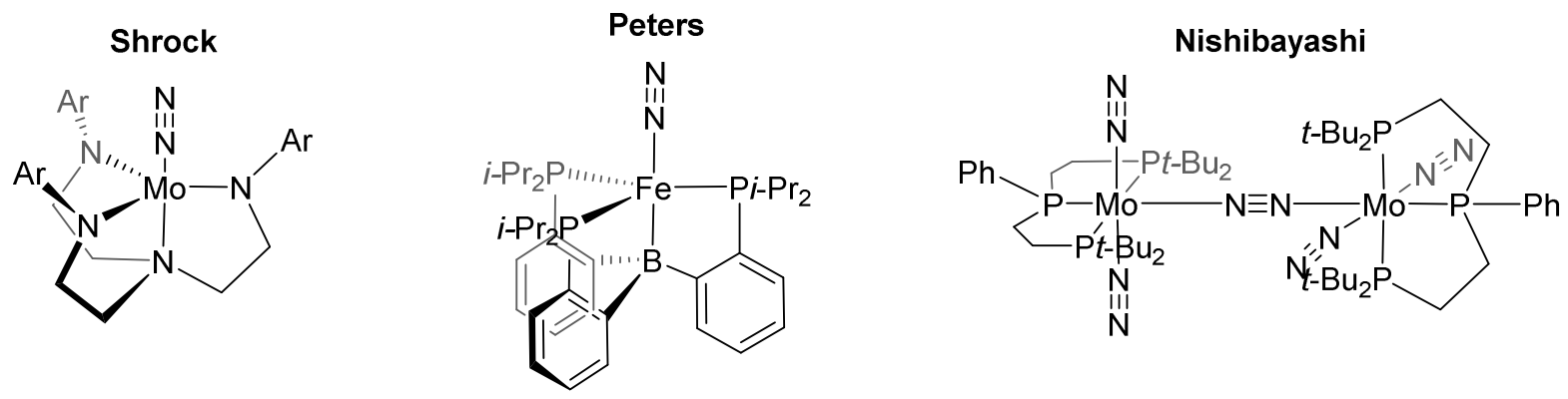
Many examples of $\mathrm{N}_{2}$ reduction by homogeneous transition-metal systems have been reported to date, although only a few have displayed catalytic activity (Figure 1) ${ }^{5-9}$ These catalysts all utilize either molybdenum or iron. Similarly, limited examples of catalytic hydrazine reduction have been reported despite its much weaker N-N single bond ( $38 \mathrm{kcal} / \mathrm{mol} \mathrm{vs.} 226 \mathrm{kcal} / \mathrm{mol}) .{ }^{28-40}$ Most of these examples utilize the metals found in the Nase active site, iron, molybdenum, and vanadium. Early systems developed were based primarily on molybdenum, following Schrock's 1991 report of a molybdenum-pentamethylcyclopentadienyl $\left(\mathrm{Cp}^{*}\right)$ catalyst (Scheme 2). ${ }^{29}$ Hydrazine complexes of molybdenum and tungsten both showed not only the conversion of the hydrazine ligand to ammonia with either a zinc amalgam or cobaltocene, but also catalytic turnover with added hydrazine.

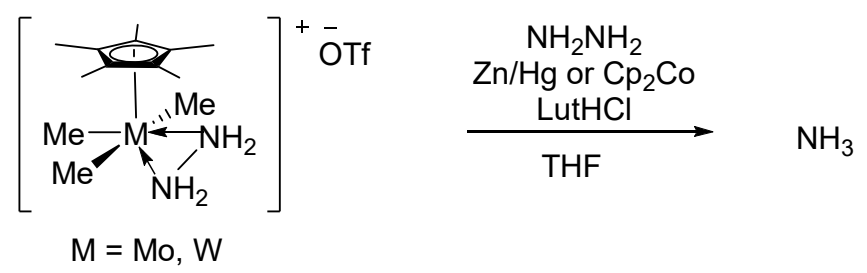

Scheme 2. Catalytic ammonia production from hydrazine using molybdenum and tungsten $\mathrm{Cp}^{*}$ complexes.
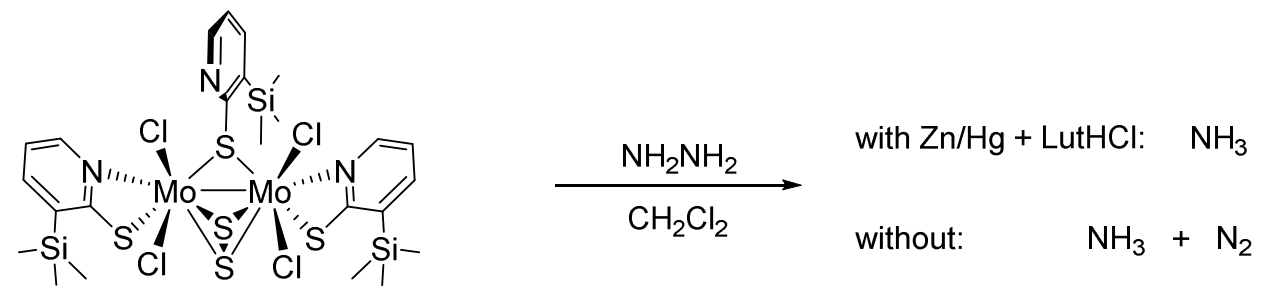

Scheme 3. Catalytic conversion of hydrazine to ammonia with either the addition of reductant and acid, or through disproportionation of hydrazine.

Block and Zubieta soon followed with a thiolate-bridged molybdenum dimer capable of the catalytic conversion of hydrazine to ammonia (Scheme 3). ${ }^{30}$ Catalysis was found to occur in the presence of zinc and 2,6-lutidinium chloride $(\mathrm{LutHCl})$, but could also proceed through a disproportionation reaction producing $\mathrm{N}_{2}$ as well. More recently, multiple examples of iron systems have combined the two strategies, achieving catalytic reductions of substituted hydrazines with thiolate-bridged $\mathrm{FeCp}{ }^{*}$ dimers (Figure 2). ${ }^{31,32}$ 
Figure 2. $\mathrm{Cp} * \mathrm{Fe}$ dimers bridged by thiolate ligands, capable of catalytic conversion of hydrazines to ammonia and the corresponding amine in the presence of reductant and acid.
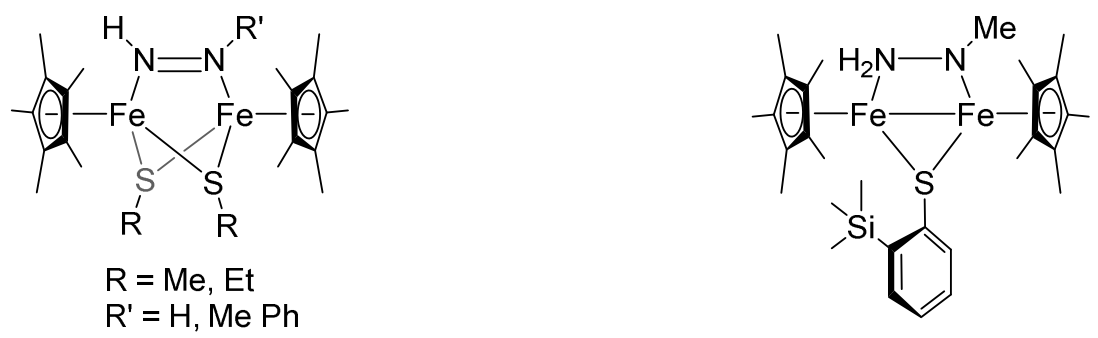

Thiolate-ligated monomers have also been effective at reducing hydrazine, with examples capable of catalytic reduction using iron, molybdenum, and vanadium. ${ }^{33-35}$ Most notably are Hsu's iron and vanadium tris(thiolato)phosphine catalysts, capable of ammonia production from hydrazine with added reductant and acid (Scheme 4). ${ }^{34,35}$ Although not catalytic, similar vanadium complexes developed by the Sanders group featuring a tris(thiolato)amine ligand are also capable of hydrazine reduction to ammonia. ${ }^{36,37}$ It is important to note the structural analogy of these thiolate-ligated complexes to the Nase active site, in addition to being functional mimics.

Similarly, a series of cubane complexes mimicking the structure of the Nase active site have been developed as well. ${ }^{38-40}$ The Coucouvanis group has developed iron-sulfur clusters incorporating either molybdenum or vanadium, providing structural mimics even more closely related to the Nase active site (Figure 3). ${ }^{39,40}$ Like many of the previous examples, these clusters are also capable of catalytic hydrazine reduction to ammonia.

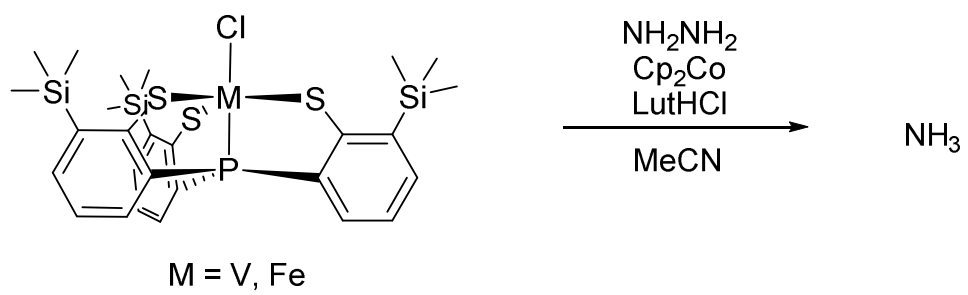

Scheme 4. Vanadium and iron tris(thiolato)phosphine precatalysts for the reduction of hydrazine to ammonia. 
Figure 3. $\mathrm{MFe}_{3} \mathrm{~S}_{4}$ cubane complexes featuring Mo or $\mathrm{V}$ are capable of the catalytic reduction of hydrazines.

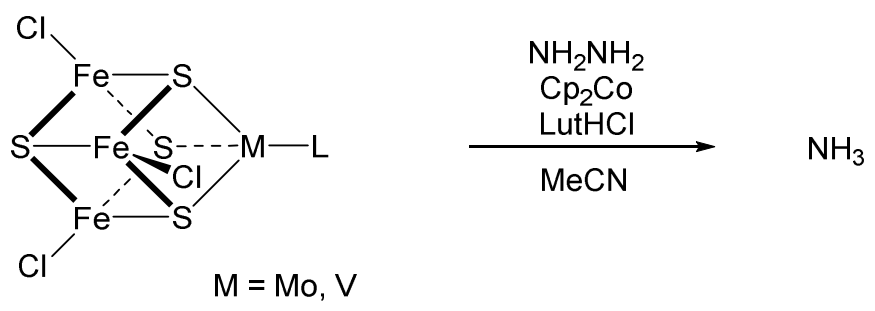

Enzymatic reduction of most substrates including $\mathrm{N}_{2}$ and hydrazine is believed to occur through the cooperation of multiple iron centers, based on studies involving modified Nases. ${ }^{3,4}$ Substitution of various amino acid residues surrounding the active site of MoNase, namely an $\alpha$ $70^{\mathrm{Val}}$ residue, allow the reduction of larger substrates. Proximity of these residues to the long side of the iron-sulfur cluster suggest coordination of the substrates to an iron-center is crucial. However, little is known about the role of the heterometal in these clusters other than the fact that they influence the enzymes effectiveness at performing reductions. To date there are several examples of catalytic reduction of $\mathrm{N}_{2}$ and hydrazines by iron and molybdenum systems. Vanadium examples, however, are rare. Considering the general reactivity trend of MoNase > VNase $>$ FeNase in the reduction of most substrates, information about the role of the heterometal has significant potential to be ascertained through future research involving vanadium systems. ${ }^{14,41}$ The fact that more vanadium systems capable of these reductions have yet to be developed suggests the heterometal may play an alternative role. Drawing insights about the function of the capping position could be more difficult to divulge from iron and molybdenum systems because the ability of these metals to perform catalytic reductions in homogeneous systems. A vanadium model is more likely to be tuned to reflect the function of the heterometal without performing additional reactions that could be misleading about its role.

Vanadium-based structural and functional models could inform us about the role of the heteroposition by demonstrating the reactions that can be performed at a vanadium center. Models involving hydrazines are particularly attractive to focus on due to the relative ease of $\mathrm{N}-\mathrm{N}$ bond cleavage as compared to $\mathrm{N}_{2}$. Understanding the requirements necessary for a vanadium mediated reduction will help determine how the heterometal functions. However, the limited number of vanadium systems developed thus far highlights the need for additional models. 


\subsubsection{Homogeneous Reductive Coupling of Carbon Monoxide and Isonitriles}

The reductive coupling of carbon monoxide $(\mathrm{CO})$ to produce hydrocarbon products has been practiced for nearly a century since Hans Fischer and Franz Tropsch first reported the reaction of $\mathrm{CO}$ and dihydrogen in 1922, using an iron catalyst under high pressures. ${ }^{42,43}$ Before long, this reaction was adapted for the large-scale production of hydrocarbons in what is known as the Fischer-Tropcsh (FT) process (Eq. 1).

$$
(2 n+1) \mathrm{H}_{2}+n \mathrm{CO} \stackrel{\text { cat. }}{\longrightarrow} \mathrm{C}_{n} \mathrm{H}_{(2 n+2)}+n \mathrm{H}_{2} \mathrm{O}
$$

However, continued development and modifications of the FT process are ongoing due to challenges controlling the size of the hydrocarbon products. While initially performed using an iron catalyst, several other late metals such as cobalt, ruthenium and rhodium have proved to be competent catalyst for this process. While ruthenium is the most active metal in the FT process, it is generally considered too expensive to be practical for industrial FT reactions. Likewise, rhodium is also relatively expensive, but is also less active than cobalt or iron. Therefore, typical FT catalysts employed today are based on iron or cobalt. Much attention has focused on the FT process in order to optimize the efficiency of $\mathrm{CO}$ coupling and to fine-tune the production of longer-chained hydrocarbons. Selective production of specific hydrocarbons, especially longchain hydrocarbons, is one of the challenges in FT catalysis and has led to the development of a variety of homogeneous catalyst systems. ${ }^{44}$

Unlike the heterogeneous catalysis in the FT process, reductive coupling mediated by homogeneous transition-metal systems to form $\mathrm{C}-\mathrm{C}$ bonds from $\mathrm{CO}$ has proven to be much more difficult. ${ }^{44}$ Not only are these examples few in number, but also systems capable of releasing the coupled products and/or breaking the $\mathrm{C}-\mathrm{O}$ bonds are very rare. Isonitriles (CNR) are isoelectronic to $\mathrm{CO}$ and are often studied in place of or alongside of $\mathrm{CO}$ when investigating reductive coupling reactions mediated by metal complexes because they are easier to handle and have electronic variability derived from the R-group. However, related examples of the reductive coupling of isonitriles by homogeneous transition-metal complexes to form $\mathrm{C}$ - $\mathrm{C}$ bonds 
are also relatively few in number. ${ }^{45-}$ Additionally, most homogeneous examples to date are not capable of coupling both $\mathrm{CO}$ and CNR.

While the FT process utilizes late transition-metal catalysts, reports of reductive coupling of CO and CNR by late transition-metals have been scarce until recently. The first examples of such reactions came in the late 1980's when a pair of group IX dimer complexes were each shown to mediate $\mathrm{C}-\mathrm{C}$ bond formation with reducing equivalents coming from the metals themselves. In 1988 the Kubiak group reported a bisiridium complex bearing two bridging isonitrile ligands that undergo a reductive cyclization when treated with triethylaluminum (Figure 4a). ${ }^{45}$ Concurrently, Wayland and coworkers developed a rhodium porphyrin dimer that spontaneously couples CO to form a bridging diketone ligand (Figure $4 \mathrm{~b}){ }^{55}$

Figure 4. Group IX metal dimers capable of coupling either CO or CNR: (a) iridium dimer capable of the coupling of two isonitriles when treated with triethylaluminum, (b) rhodium-porphyrin dimer that inserts two CO molecules to for bridged complex.

a)

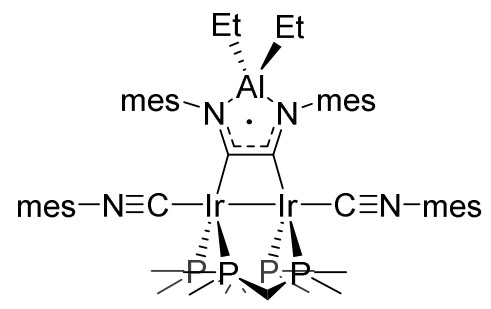

b)

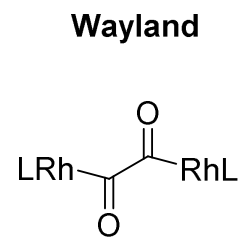

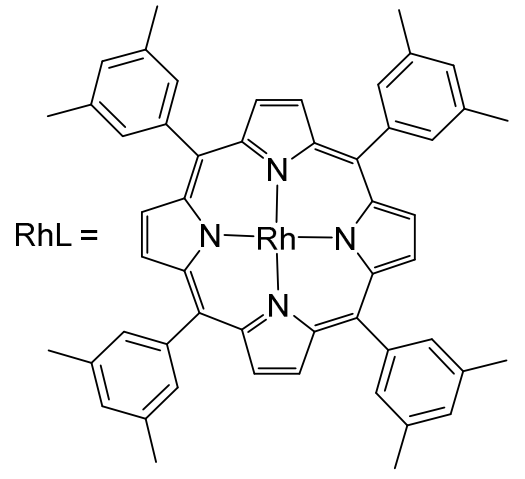

Two decades passed before the next report involving $\mathrm{CO}$ or $\mathrm{CNR}$ reductive coupling by a late transition-metal when in 2008 Bercaw and coworkers demonstrated CO coupling by a monomeric rhenium complex (Scheme 5). ${ }^{56}$ Carbon-carbon bond formation between two carbonyl ligands was induced upon addition of a hydride source with the assistance of two pendant borane groups. These boranes help activate the $\mathrm{CO}$, acting as Lewis acids by coordinating to the oxygen and weakening the $\mathrm{C}-\mathrm{O}$ bond. 

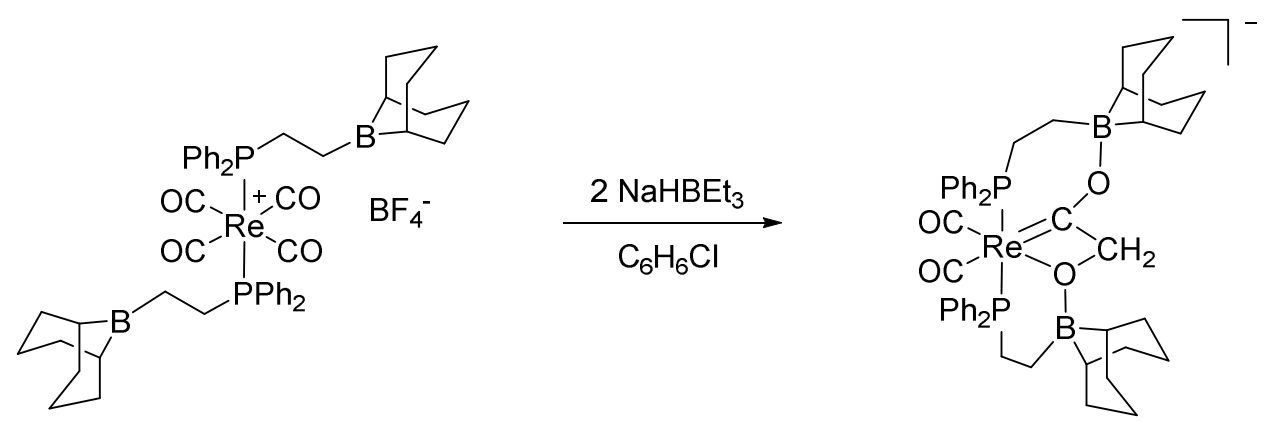

Scheme 5. Pendant Lewis acid-assisted reductive coupling of $\mathrm{CO}$ at a single rhenium center.

Following this work, several iron complexes have emerged that are capable of reductively coupling $\mathrm{CO}$ or $\mathrm{CNR}$. The Betley and Peters groups have both reported monomeric iron complexes capable of forming C-C bonds from two CO molecules (Scheme 6). Betley's anionic iron-tris(pyrrolide)ethane complex undergoes sequential $\mathrm{CO}$ insertions into the $\mathrm{C} 2$ position of one of the pyrrole rings, fragmenting the ligand (Scheme 6a). ${ }^{57}$ Alternatively, Peters' iron carbonyl complex bearing a diphosphineborane ligand generates a dicarbyne complex via reduction by potassium metal followed by silylation (Scheme $6 \mathrm{~b}) .{ }^{58}$ Hydrogenation under $1 \mathrm{~atm}$ of $\mathrm{H}_{2}$ induces $\mathrm{C}-\mathrm{C}$ coupling leading to the release of cis-disiloxyethene.

a)
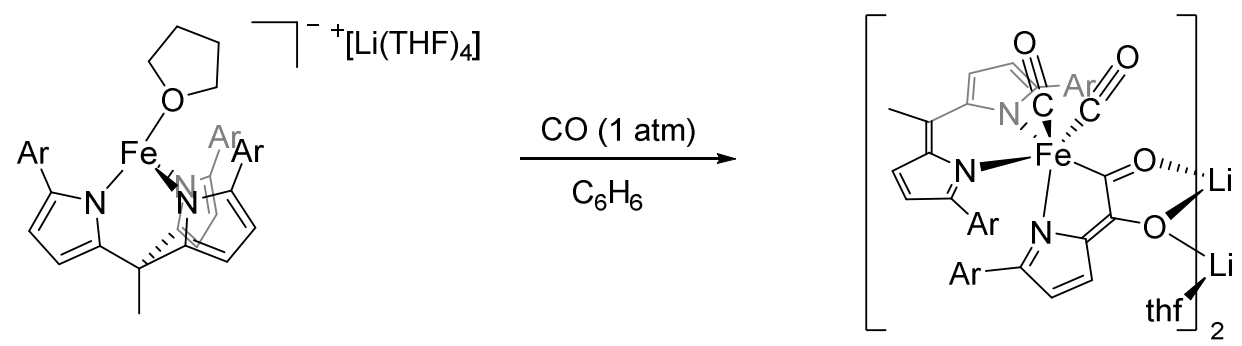

b)
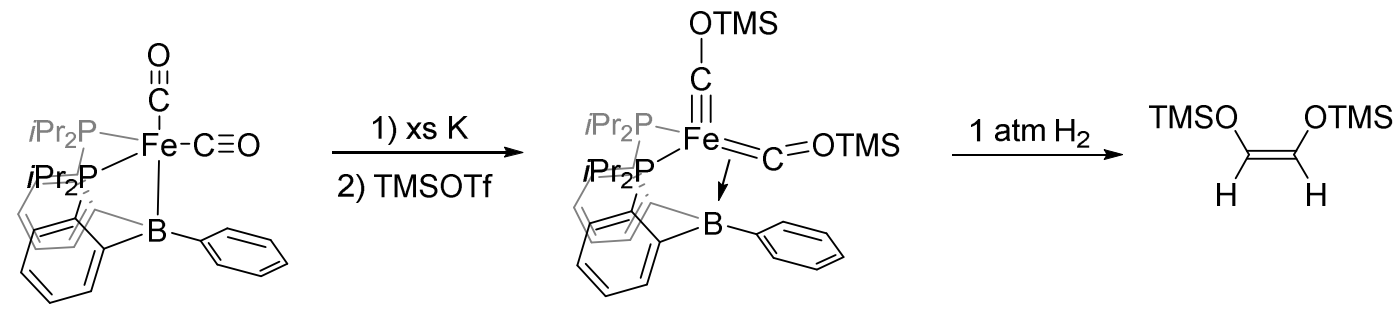

Scheme 6. Iron-mediated reductive coupling of CO. a) Tandem insertion of CO into a tris(pyrrolide)ethane ligand. b) Reduction and silylation of $\mathrm{CO}$ to form carbyne ligands, followed by hydrogenation-induced $\mathrm{C}-\mathrm{C}$ coupling. 
Examples of isonitrile coupling by iron complexes have also been reported recently. Okazaki and coworkers prepared iron-cyclopentadienyl $(\mathrm{Cp})$ clusters containing bridging isonitrile ligands that undergo $\mathrm{C}-\mathrm{C}$ bond formation and $\mathrm{C}-\mathrm{N}$ bond cleavage to form an acetylene ligand, following the addition of lithium aluminum hydride. ${ }^{46}$ The Zanotti group also designed CpFe complexes that experience $\mathrm{C}$-C coupling, through an insertion of an isonitrile into an $\mu$-aminocarbyne ligand when treated with sodium borohydride. ${ }^{47}$

Early transition-metals, however, have shown a much greater inclination towards the reductive coupling of carbonyl and isonitrile ligands. Bercaw's group was the first to report such coupling in 1976 when they were able to isolate a zirconium dimer containing a bridging enedioxy ligand following the treatment of a zirconium dihydride complex with $\mathrm{CO}$ (Scheme 7). ${ }^{59,60}$ Examples of group V metal-hydrides have also been reported to reductively couple CO ${ }^{61-63}$ However, all of these examples are incapable of releasing the coupled products without destroying them.
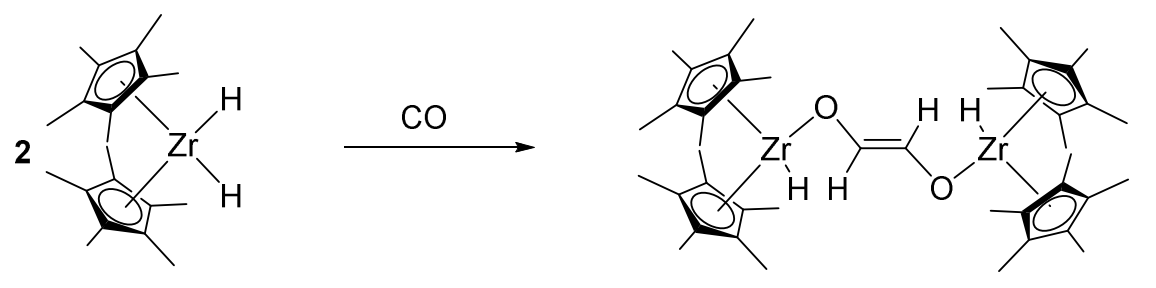

Scheme 7. $\mathrm{CO}$ coupling by $\mathrm{Cp}_{2}{ }_{2} \mathrm{Zr}(\mathrm{H})(\mathrm{CO})$ to form an enedioxy-bridged dimer.

In 1986, Lippard released the first of several publications reporting the reductive coupling of CO with by group $\mathrm{V}$ bis(diphosphinoethane) complexes (Scheme 8). ${ }^{64,65}$ Carbonyl-silylation of reduced complexes of tantalum, niobium, and vanadium resulted in $\mathrm{C}-\mathrm{C}$ bond formation to generate a disiloxyacetylene ligand. Hydrogenation of this ligand with $\mathrm{H}_{2}$ releases disiloxyethene from the tantalum and vanadium complexes, although a hydrogenation catalyst is required with the tantalum variant. Swapping out a carbonyl for an isonitrile ligand in the tantalum and niobium complexes allowed for the cross-coupling of $\mathrm{CO}$ and $\mathrm{CNR}$ as well. ${ }^{66}$ 


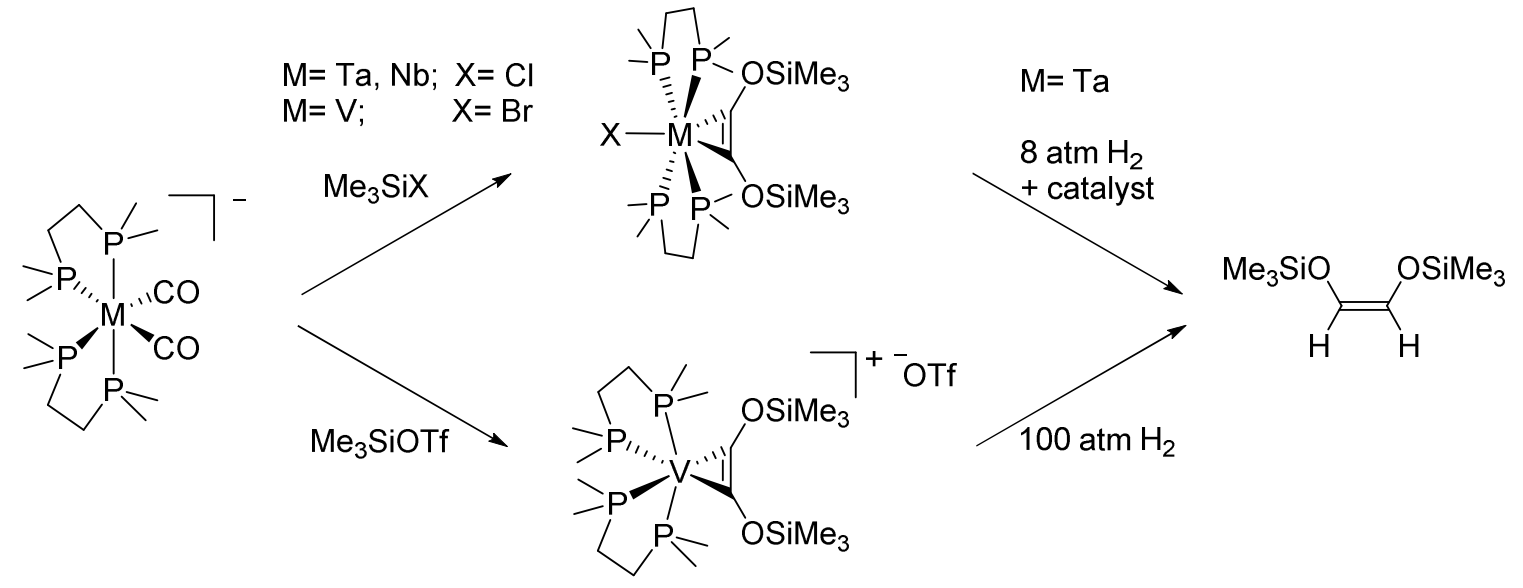

Scheme 8. Reductive coupling of CO by anionic group V metal complexes induced by silylation. Hydrogenation of resulting disiloxyacetylene complexes releases the C-C coupled product.

Earlier this year, the Agapie group established molybdenum's ability to reductively couple $\mathrm{CO}$ as well. ${ }^{67}$ Starting from a monomeric dicarbonyl-molybdenum complex supported by a terphenyldiphosphine ligand, $\mathrm{CO}$ was coupled to produce silylated $\mathrm{C}_{2}$ products (Scheme 9). Two different reduction pathways were proposed based on the varying products observed with different silyl reagents. Deoxygenation of a single $\mathrm{CO}$ is believed to occur prior to $\mathrm{C}-\mathrm{C}$ bond formation, releasing a disilyl ether as a byproduct. This is the first example of a deoxygenative $\mathrm{CO}$ reductive coupling performed by a single metal center.

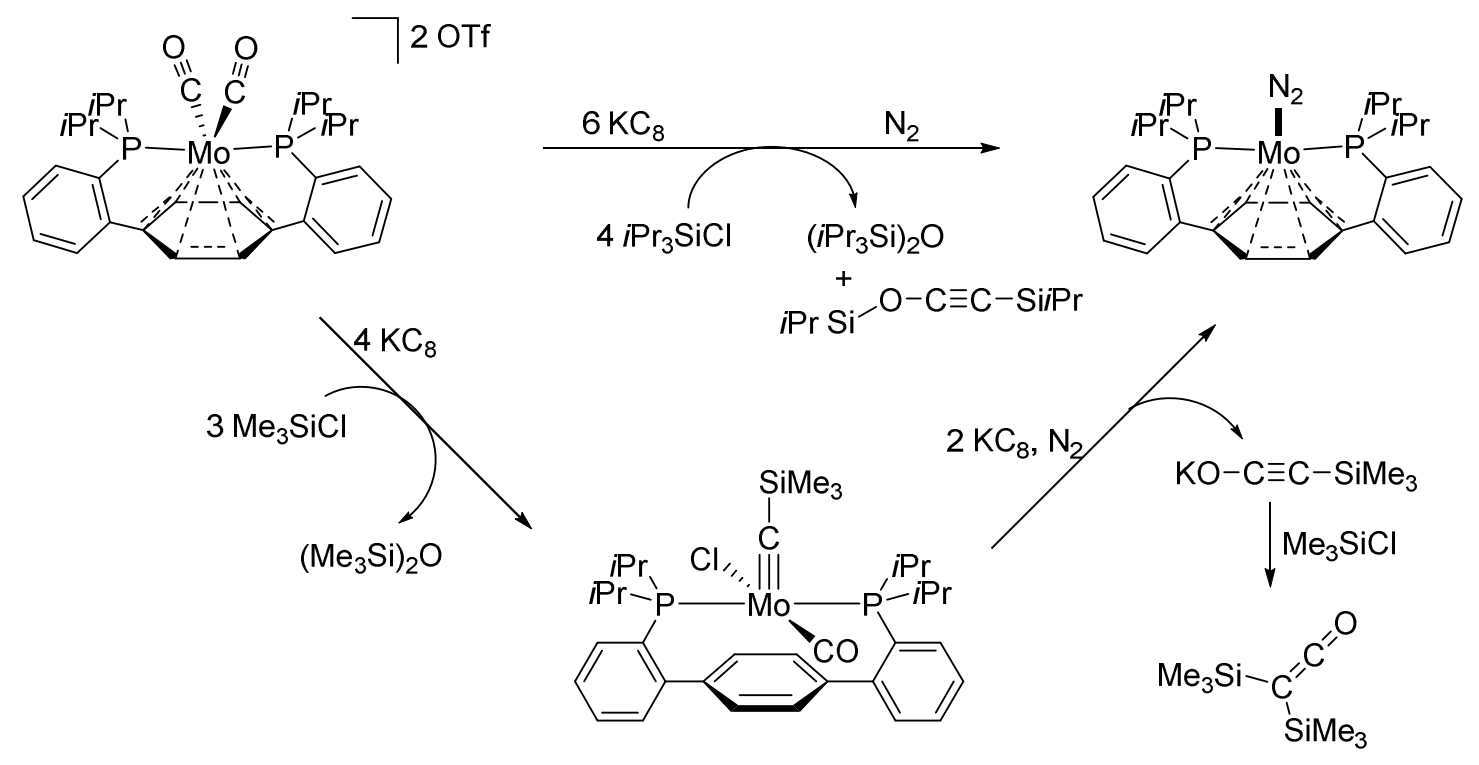

Scheme 9. Deoxygenative reductive coupling of $\mathrm{CO}$ to generate silylated- $\mathrm{C}_{2}$ products at a single molybdenum site. 
Figure 5. Reductive coupling of isonitriles performed by: a) group VI metals, b) group V metals.

a)

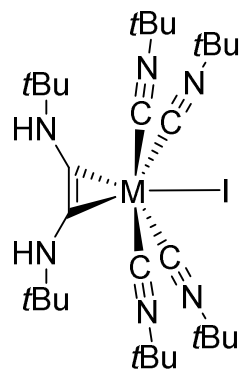

$\mathrm{M}=\mathrm{Mo}, \mathrm{W}, \mathrm{Cr}$ b)

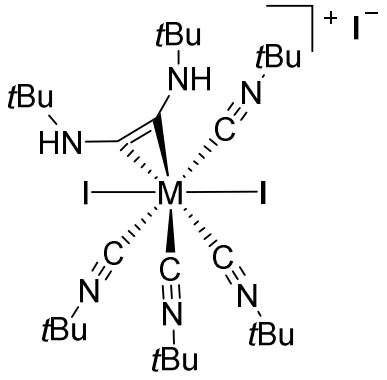

$\mathrm{M}=\mathrm{V}, \mathrm{Nb}$

In addition to his work with $\mathrm{CO}$, Lippard has also demonstrated the reductive coupling of isonitriles with group VI metals. When treating a hepta-coordinate molybdenum(II) complex $\left[\mathrm{Mo}(\mathrm{CN} t \mathrm{Bu})_{6} \mathrm{I}\right] \mathrm{I}$ with zinc dust, two isonitriles form a $\mathrm{C}-\mathrm{C}$ bond to generate a diaminoacetylene ligand (Figure 5a). ${ }^{48}$ Isonitrile coupling to generate the analogous tungsten and chromium complexes would later be achieved as well. ${ }^{49,50}$ Rehder and coworkers synthesized the analogous group V metal-isonitrile complexes, which were found to be capable of the same C-C coupling (Figure 5b). ${ }^{51,52}$ Similarly, they found the vanadium and niobium versions could mediate C-C bond formation to generate diaminoacetylene ligands.

a)

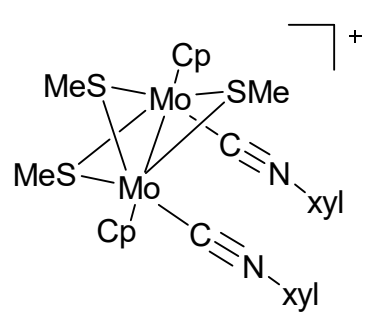

b)

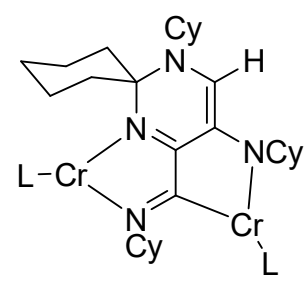

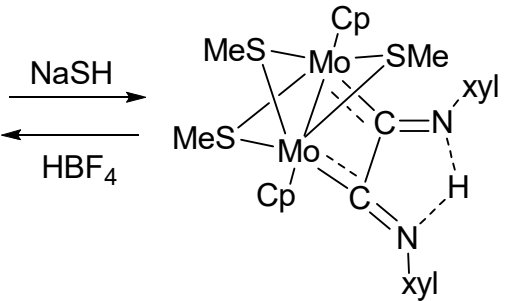

4 CNCy

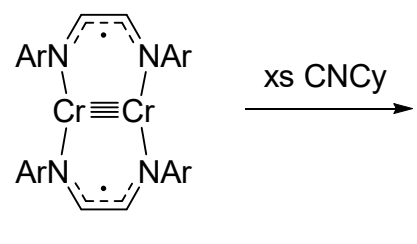

Scheme 10. a) A thiolate-bridged dimolybdenum complex capable of reversible C-C bond formation of isonitriles. b) A chromium dimer capable of several successive isonitrile insertions. 
Additional examples of early transition-metals facilitating the reductive coupling of isonitriles have emerged recently (Scheme 10). A dimolybdenum thiolate-bridged complex was shown to mediate reversible $\mathrm{C}-\mathrm{C}$ bond formation between two isonitrile ligands with the addition of sodium hydrosulfide $(\mathrm{NaSH})(\mathrm{Scheme} 10 \mathrm{a})$. Treating this product with fluoroboric acid $\left(\mathrm{HBF}_{4}\right)$ causes it to revert to its previous state. Alternatively, Theopold's quintuply-bound chromium dimer performs several successive isonitrile insertions to form products with up to five consecutive new C-C bonds (Scheme 10b). ${ }^{53,54}$

Despite the range of systems capable of mediating the reductive coupling of $\mathrm{CO}$ and $\mathrm{CNR}$ to form $\mathrm{C}-\mathrm{C}$ bonds, there is still much room for advancement in homogeneous systems for these coupling reactions. Unlike Nase and FT catalysis, no examples of homogeneous systems have been developed that are capable of the complete deoxygenative coupling of $\mathrm{CO}$ to release a product containing a new $\mathrm{C}-\mathrm{C}$ bond. The recent discovery of the ability of the wild-type VNase to reductively couple $\mathrm{CO}$ to generate hydrocarbon products presented the possibility that vanadium could be performing the reductive coupling of $\mathrm{CO} \cdot{ }^{23,24}$ However, it has recently been established that $\mathrm{CO}$ displaces a belt-sulfur atom in the active site of Nase through the trapping of the CO-bound intermediate (Figure 6). ${ }^{68}$ This intermediate produces ethylene and ethane when treated with additional $\mathrm{CO}$, demonstrating the likelihood of an iron-mediated coupling pathway. Prior to this new discovery, the larger selection of early transition-metal systems suggested the involvement of vanadium and molybdenum in the reductive coupling process in Nase.

Figure 6. Displacement of a belt-sulfur with CO molecule in the active sit of Nase.

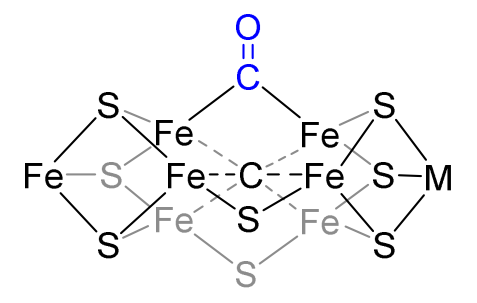




\subsubsection{Tris(methimizolyl)borate as a Ligand in Transition-Metal Chemistry}

Tris(methimizolyl)borate $(\mathrm{Tm})$ is an anionic tripodal ligand which typically prefers $\kappa^{3}-\mathrm{S}, \mathrm{S}, \mathrm{S}$ coordination to a metal through its three thione groups (Figure 7). ${ }^{69}$ Over the past two decades Tm has generated much interest as an alternative to the popular tris(pyrazolyl)borate (Tp) ligands due to their structural and electronic similarities. Like Tp, Tm is considered an analog to cyclopentadienyl (Cp) ligands. Comparisons of $\mathrm{CO}$ stretching frequencies in a series of $\left[\mathrm{LMo}(\mathrm{CO})_{3} \mathrm{I}\right]$ and $\mathrm{LW}(\mathrm{CO})_{2}\left(\eta^{3}\right.$-allyl $)$ complexes, where $\mathrm{L}=\mathrm{Cp}, \mathrm{Tp}$, and $\mathrm{Tm}$, revealed $\mathrm{Tm}$ to be the strongest electron-donor. ${ }^{70}$ Additionally, the homoleptic "sandwich" complex $\mathrm{Tm}_{2} \mathrm{Fe}$ was found to be high-spin, while $\mathrm{Cp}_{2} \mathrm{Fe}$ is low spin and $\mathrm{Tp}_{2} \mathrm{Fe}$ is a spin-crossover system. ${ }^{71,72}$ Thus, the argument is made for Tm as the strongest $\pi$-donor of the three. Considering the vast amount of studies performed employing $\mathrm{Cp}$ and $\mathrm{Tp}$ ligands, Tm has significant potential for application in organometallic chemistry.

Figure 7. Tris(methimizolyl)borate (Tm) and its typical coordination as a ligand on transition-metals.

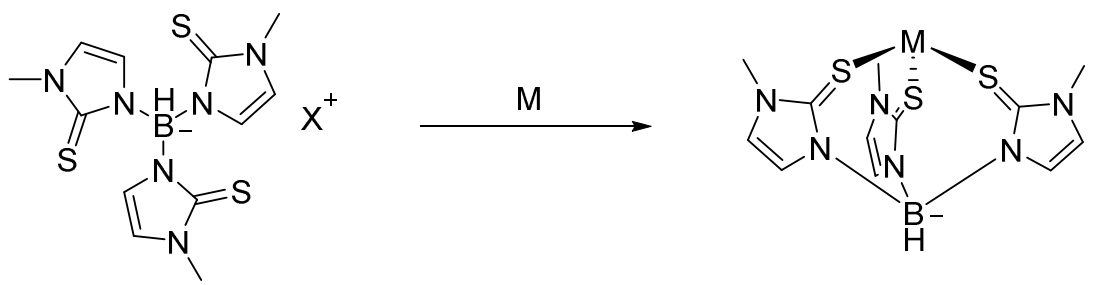

Sodium tris(methimizolyl)borate (NaTm) was first reported by Spicer and Reglinski in 1996, who synthesized it through a melt of methimazole (2-mercapto-1-methylimidazole) with sodium borohydride (Shceme 11). ${ }^{73,74}$ The resulting NaTm residue was then purified via Soxhlet extraction. Alternatively, other groups have preferred a synthesis involving heating of the two reagents in toluene or xylene, followed by recrystallization. ${ }^{75,76}$ Similarly, various groups have reported the preparation of mono and bis(methimizolyl)borate $(\mathrm{Bm})$ by lowering the reaction temperature. ${ }^{77,78}$ In addition to sodium, the lithium and potassium analogs have also been obtained through the same methods. ${ }^{75,79}$ 


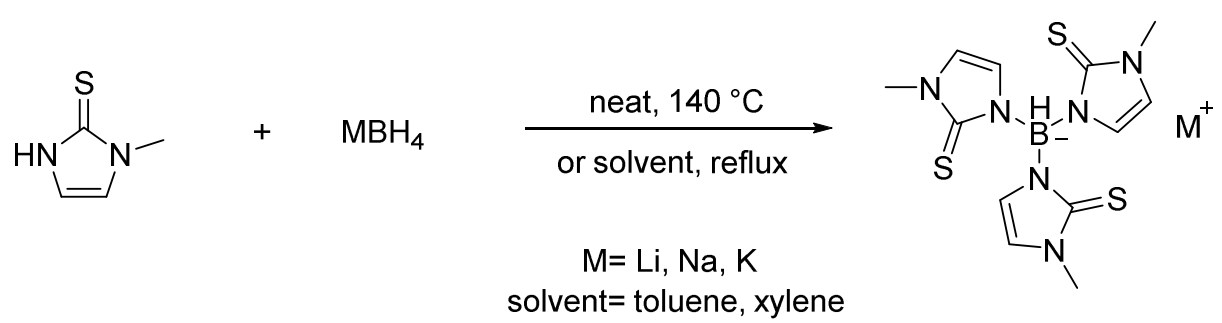

Scheme 11. Synthesis of Tm-salts from the reactions of methimazole with borohydride.

Other $\mathrm{N}$-substituted variants besides the parent $\mathrm{Tm}^{\mathrm{Me}}$ have been synthesized to alter the overall bulkiness of the ligand. A range of different alkyl ( $t \mathrm{Bu}, \mathrm{Bn}, \mathrm{Et}, \mathrm{Cy})$ and aryl (Ph, mesityl, $o$-tolyl, p-tolyl, xylyl, 2-biphenyl, 2,6-diisopropylphenyl) groups have been added to the series over the years by employing the corresponding imidazole-2-thione in place of methimazole. ${ }^{75,80-85}$ Such variations can influence the coordination-mode of the ligand when bound to metal centers. A variety of different $\kappa^{1}-, \kappa^{2}$-, or $\kappa^{3}$-motifs made up of the four potential coordinating groups, including an agnostic-coordination of the B-H bond, have been observed in isolated complexes (Figure 8). Tp, however, has a much greater preference for $\kappa^{3}-\mathrm{N}, \mathrm{N}, \mathrm{N}$ coordination. This flexibility is a key difference between the two ligands, attributed to the larger ring size of the chelated Tm-metallacycle. These different coordination-modes are found in both mono-metallic and metal-bridging structures, although the non-bridging $\kappa^{3}-\mathrm{S}, \mathrm{S}, \mathrm{S}$ motif is by far the most common. Included in the $\kappa^{3}-\mathrm{S}, \mathrm{S}, \mathrm{S}$ category are the homoleptic "sandwich" complexes $\left(\mathrm{Tm}_{2} \mathrm{M}\right)$, which have been isolated with the first-row transition-metals titanium, iron, cobalt, and nickel. ${ }^{71,86-88}$ Additionally, metallaboratranes have been synthesized for all of the group VIII, IV, and $\mathrm{V}$ metals through an activation of the hydride to form a metal-boron bond, ultimately achieving $\kappa^{4}-\mathrm{S}, \mathrm{S}, \mathrm{S}, \mathrm{B}$ coordination. ${ }^{89-96}$

Overall, examples of metal complexes bearing Tm or one of its derivatives exist with nearly every transition metal. However, there are only a handful of reports of these complexes mediating transformations with small molecules. A $\mathrm{Tm}^{t \mathrm{Bu}} \mathrm{Zn}$ complex was successfully applied as a catalyst for alcohol dehydrogenation. ${ }^{97} \mathrm{Cp}[\mathrm{Tm}] \mathrm{ZrCl}_{2}$ was found to be an effective precatalyst for olefin polymerization. ${ }^{98}$ Additionally, two different examples have been reported of $\mathrm{TmMo}(\mathrm{O})_{2} \mathrm{Cl}$ acting as an oxygen-atom transfer catalyst. ${ }^{99,100}$ Significant potential remains for reactivity to be discovered using Tm-complexes. Investigations into reactivity of vanadium and iron-Tm complexes will be discussed in the following sections. 
Figure 8. Possible coordination modes for the Tm as a ligand.

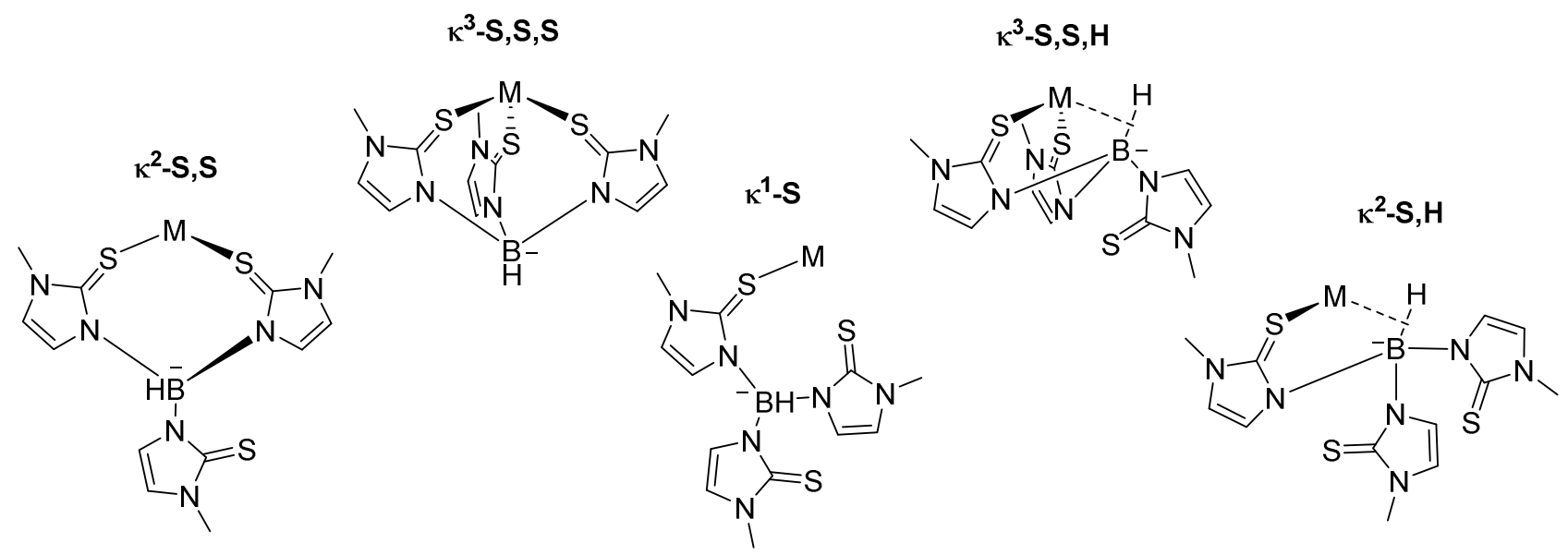

\subsubsection{Project Objectives}

\subsubsection{Tris(methimizolyl)borate as a Ligand for Nitrogenase Structural Mimics}

As discussed in the previous sections, nitrogenase enzymes (Nase) are capable of performing reductive transformations of small molecules, many of which have proven to be rather difficult to accomplish with synthetic homogeneous transition-metal systems. The goal of research in our group has been to design first-row transition-metal complexes capable of mimicking the reactivity of Nase. Not only do we desire to perform similar transformations, but we also hope to obtain mechanistic information that helps us understand the requirements for such reactivity. Tripodal ligands have been commonly used in the design of Nase mimics towards the activation of small molecules such as carbon monoxide (CO) and hydrazines. ${ }^{5,6,57,58}$ Tris(methimizolyl)borate $(\mathrm{Tm})$ is an attractive ligand for this purpose because its $\kappa^{3}-\mathrm{S}, \mathrm{S}, \mathrm{S}$ coordination mode presents a structural mimic of the Nase active site (Figure 9). ${ }^{4}$ 
Figure 9. $\kappa^{3}-\mathrm{S}, \mathrm{S}, \mathrm{S}$ coordination of the Tm ligand as a structural mimic of the active site of Nase.
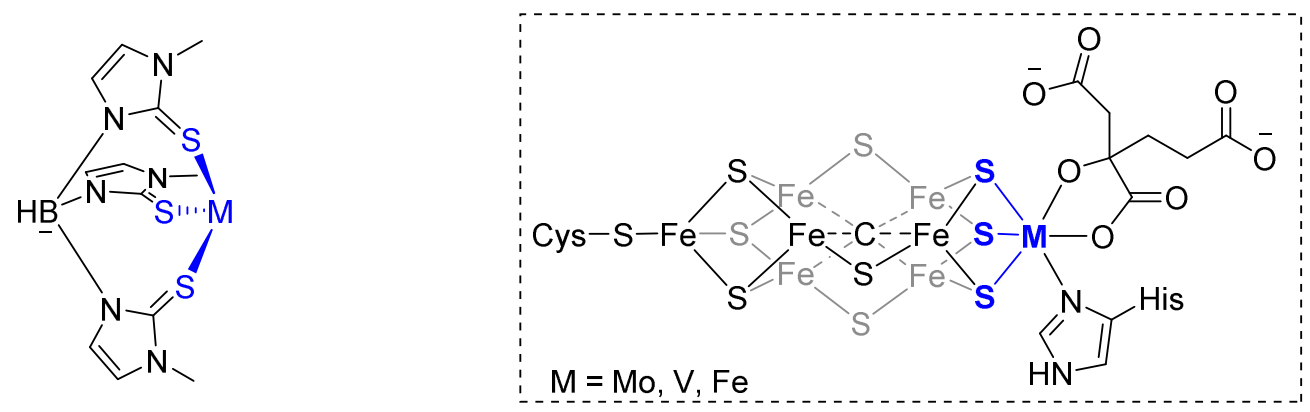

Our goal for developing Nase mimics was to first access monomeric Tm-ligated metal complexes. While other work in our group has focused on TmFe complexes (discussed in Chapter 2.2.1.), vanadium was selected for investigation due to the unique ability of the wildtype VNase to reductively couple $\mathrm{CO}$ to form small-chain hydrocarbons. ${ }^{24}$ Although no TmV complexes have been reported to date, vanadium complexes bearing similar tripodal sulfur ligands are capable of hydrazine reduction. With this in mind, our goal was to synthesize TmV half-sandwich complexes in order to test their ability to mediate reductive transformations similar to those of Nase (Eq. 2).
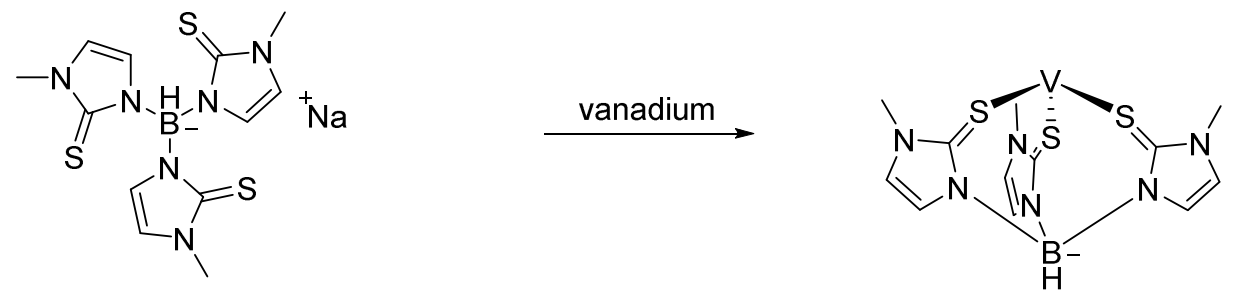

\subsubsection{Vanadium-Tris(methimizolyl)borate Complexes for the Reductive Coupling of Isonitriles}

VNases's ability to reductively couple CO sparked our interest in synthesizing homogeneous complexes capable of similar reactivity. However, due to $\mathrm{CO}$ being a gas and not having a ${ }^{1} \mathrm{H}$ NMR resonance, isonitriles were selected for initial investigations. Precedence exists for vanadium-mediated reductive coupling of both $\mathrm{CO}$ and $\mathrm{CNR}$, as discussed in Chapter 1.1.3. 
(Figure 10). ${ }^{52,65}$ However, these examples are limited and additional examples would make a significant contribution towards understanding the capabilities and requirements of vanadium complexes for performing reductive coupling of $\mathrm{CO}$ and $\mathrm{CNR}$.

Figure 10. Examples of vanadium complexes capable of performing the reductive coupling of $\mathrm{CO}$ or CNR.

Lippard 1991

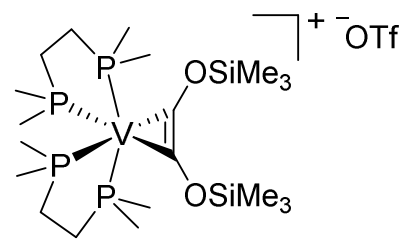

Rheder 1999

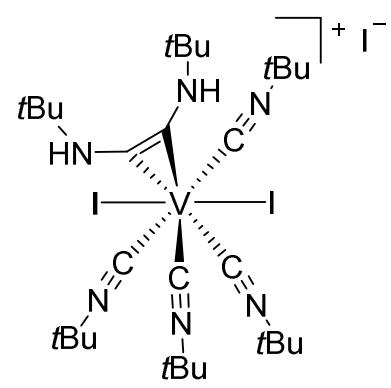

At the onset of this project, we were interested in exploring the possible reductive coupling of $\mathrm{CNR}$ at mononuclear vanadium centers. Our goal was to synthesize $\mathrm{TmV}(\mathrm{CNR})_{\mathrm{n}}$ complexes, and then treat them with reductant and acid in order to induce $\mathrm{C}-\mathrm{C}$ bond formation and ideally release the C-C coupled products (Scheme 12).
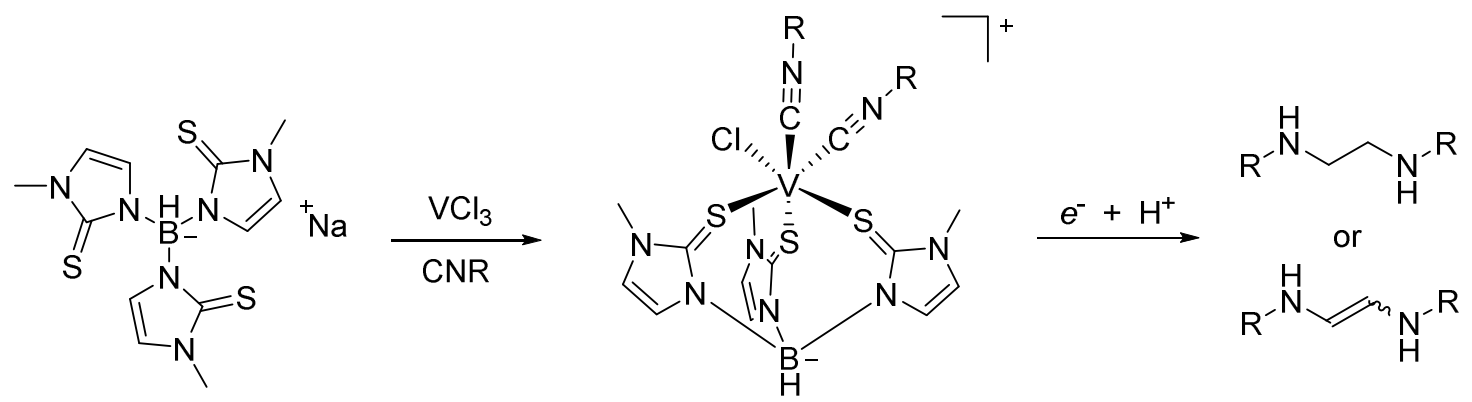

Scheme 12. Plausible route towards accessing $\operatorname{TmV}(\mathrm{CNR})_{\mathrm{n}}$ complexes and generating possible C-C coupled products. 


\subsubsection{Vanadium-Tris(methimizolyl)borate-Hydrazine Complexes and their Reduction Chemistry}

The development of homogeneous Nase mimics towards the goal of $\mathrm{N}_{2}$ reduction to ammonia has been a topic of great interest for a long time due to the difficulty of the transformation. Among these investigations are those involving the reduction of hydrazines, a known intermediate in the reduction of $\mathrm{N}_{2}$. Vanadium mimics are of interest due to their potential to inform us about the role of the heterometal in the Nase active site (discussed in Chapter 1.1.2.). However, relatively few examples of vanadium complexes capable of hydrazine reduction to ammonia exist. ${ }^{34,101}$ In fact, only one example of catalytic $\mathrm{N}_{2}$ or hydrazine reduction by a vanadium complex has been reported to date (Figure 11, Hsu). ${ }^{34}$ Based on this literature precedence that sulfur-ligated complexes are capable of hydrazine binding and reduction, our goal was to develop similar V-Tm complexes with hydrazines and test their ability to cleave the $\mathrm{N}-\mathrm{N}$ bond when treated with a reductant and acid (Scheme 13).

Figure 11. Examples of sulfur-ligated vanadium complexes with hydrazines.
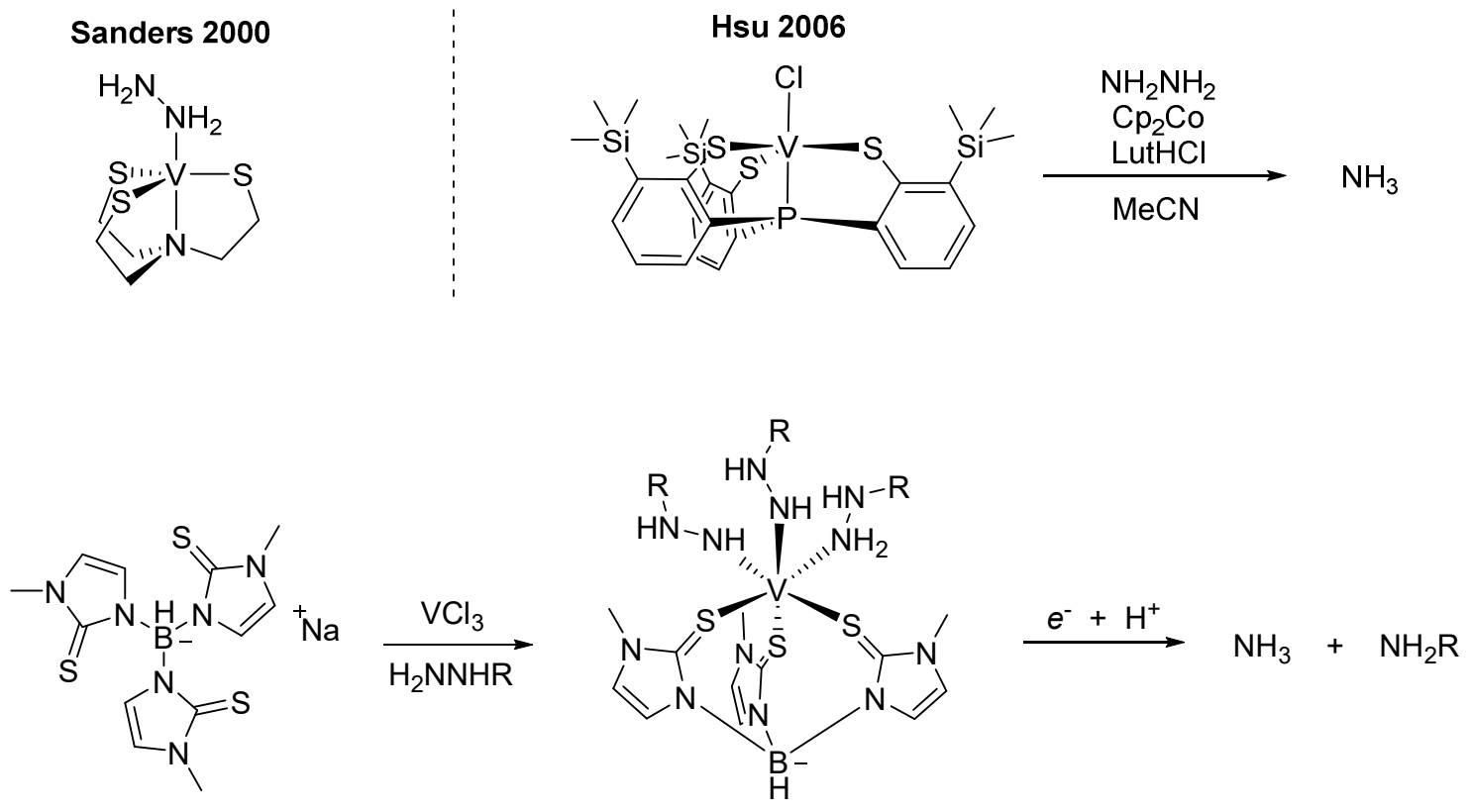

Scheme 13. Plausible route towards accessing VTm complexes with hydrazines and performing reductive cleavage of the N-N bond. 


\subsection{Results and Discussion}

\subsubsection{Synthesis of Vanadium-Tris(imidazole-2-thione)borate Sandwich Complexes}

Sodium tris(methimizolyl)borate (NaTm) was synthesized according to a reported procedure, with modifications. ${ }^{76}$ Methimazole and sodium borohydride $\left(\mathrm{NaBH}_{4}\right)$ were refluxed in xylenes for 18 hours, providing a 74\% yield following recrystallization (Scheme 14). A single reaction in toluene gave a comparable, yet higher yield of $78 \%$. Other variations on this synthesis resulted in lower yields, such as running the reaction neat, altering the reaction time, and using $\mathrm{KBH}_{4}$.

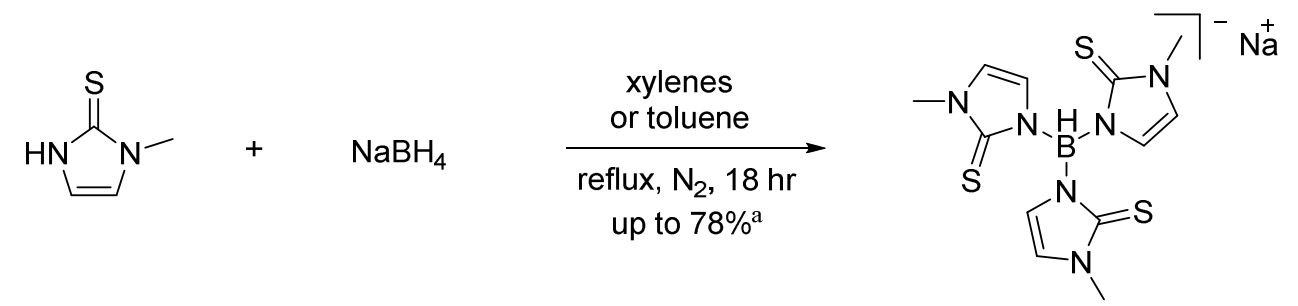

Scheme 14. NaTm synthesis. Reaction conditions: methimazole (20 mmol), $\mathrm{NaBH}_{4}(6.7 \mathrm{mmol})$, degassed xylenes or toluene $(30 \mathrm{~mL})$, reflux, $\mathrm{N}_{2}, 18 \mathrm{~h}$. The product was recrystallized from methanol/diethyl ether.

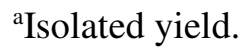

The NaTm salt was found to be much more soluble than KTm, although NaTm only demonstrates good solubility at room temperature in alcohol solvents and highly polar solvents such as dimethyl sulfoxide (DMSO) and dimethylformamide (DMF). However, Tm is not stable in DMSO or DMF, and undergoes decomposition to methimazole within a day. Degradation of Tm and its N-substituted variants $\left(\mathrm{Tm}^{\mathrm{R}}\right)$ is a common issue, ${ }^{69}$ especially throughout the course of the following investigations with vanadium. Tracking the degradation of the $\mathrm{Tm}^{\mathrm{R}}$ ligands was accomplished through ${ }^{1} \mathrm{H}$ NMR studies performed in J. Young style NMR tubes by observing the disappearance of the $\mathrm{Tm}$ resonances and the growth of the methimazole resonances. Tm decomposition led to the formation of methimazole, as the only ${ }^{1} \mathrm{H}$ NMR active degradation product confirmed throughout all investigations involving Tm. It is important to note that methimazole resonances do not shift from their normal values when added to a vanadium(III) trichloride tetrahydrofuran complex $\left(\mathrm{VCl}_{3} \mathrm{THF}_{3}\right)$ in a MeOD- $d_{4}$ solution. Coordination of 
methimazole to vanadium is signaled by a change in the color of the solution from red to green. This could indicate that methimazole-ligated vanadium complexes are the actual products of Tm degradation when vanadium is present.

In order to access other $\mathrm{Tm}^{\mathrm{R}}$ variants, differently $\mathrm{N}$-substituted imidazole-2-thiones were synthesized. $N$-Phenylimidazole-2-thione was prepared according to literature procedures (Scheme 15). ${ }^{102,103}$ Phenyl isothiocyanate and 2,2-diethoxyethylamine were stirred at room temperature for 2 hours, followed by heating at reflux overnight in hydrochloric acid. Upon cooling, the product precipitates from solution, allowing it to be collected via filtration in an $85 \%$ yield without any additional purification needed. Other $N$-substituted imidazole-2-thiones $\left(\mathrm{Tm}^{\mathrm{R}}\right)$ have been prepared through a similar method by our group. For example, sodium tris $(N-$ phenylimidazole-2-thione)borate $\left(\mathrm{NaTm}^{\mathrm{Ph}}\right)$ was accessed from the same method as $\mathrm{NaTm}^{\mathrm{Me}}$, although toluene was used exclusively as the solvent in this case (Scheme 16). Recrystallization of the crude product gave $\mathrm{NaTm}^{\mathrm{Ph}}$ in $64.6 \%$ yield.

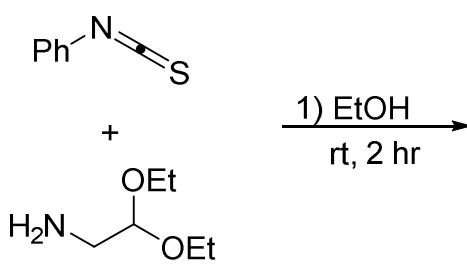<smiles>CCOC(CNC(=S)Nc1ccccc1)OCC</smiles><smiles>S=c1[nH]ccn1-c1ccccc1</smiles>

$84.7 \%$

Scheme 15. $\mathrm{NaTm}^{\mathrm{Ph}}$ synthesis. Reaction conditions: 1) phenyl isothiocyanate (15 mmol), diethoxyethylamine (15 mmol), ethanol (20 mL), rt, 2 h. 2) 10\% $\mathrm{HCl}(20 \mathrm{~mL})$, reflux, $2 \mathrm{~h}$.
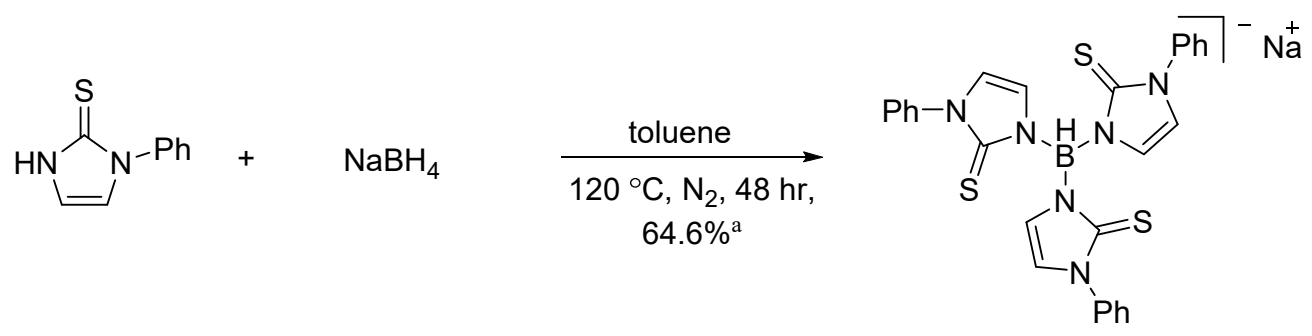

Scheme 16. $\mathrm{NaTm}^{\mathrm{R}}$ synthesis. Reaction conditions: N-phenylimidazole-2-thione ( $\left.8.5 \mathrm{mmol}\right), \mathrm{NaBH}_{4}(5.7$ $\mathrm{mmol}$ ), degassed toluene $(20 \mathrm{~mL}), 120^{\circ} \mathrm{C}, \mathrm{N}_{2}, 48 \mathrm{~h}$. Product was recrystallized from

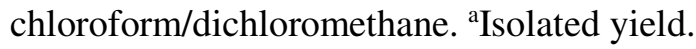


Complexation of $\mathrm{Tm}$ with vanadium was performed with the goal of obtaining half-sandwich complexes (Chapter 1.1.5.1.). However, treatment of $\mathrm{VCl}_{3}$ with $\mathrm{NaTm}$ in methanol $(\mathrm{MeOH})$ forms the bright red sandwich complex bis[tris(methimizolyl)borate] vanadium(III) chloride $\left(\left[\mathrm{Tm}_{2} \mathrm{~V}\right] \mathrm{Cl}\right)$ (1a) (Table 1). Rapid production of a red precipitate occurred immediately, with complete consumption of Tm within 15 minutes (entry 1) based on ${ }^{1} \mathrm{H}$ NMR spectroscopy. Isolation of this product is significant because no examples of $\mathrm{TmV}$ complexes have been reported to date. $\left[\mathrm{Tm}_{2} \mathrm{~V}\right]^{+}$is NMR active despite being paramagnetic, giving two singlets rather than doublets at $12.28 \mathrm{ppm}$ and $10.31 \mathrm{ppm}$ in DMSO- $d_{6}$ for the aromatic imidazole hydrogens.

Although 1a was not the desired half-sandwich complex, its characterization was performed due to it being a new compound. Therefore, the reaction producing $\left[\mathrm{Tm}_{2} \mathrm{~V}\right] \mathrm{Cl}$ was scaled up, providing a bright red powder in 99\% isolated yield (Scheme 17). The assignment of the product as $\left[\mathrm{Tm}_{2} \mathrm{~V}\right] \mathrm{Cl}$ was confirmed through analysis by electrospray ionization mass spectroscopy (ESIMS), which displayed a molecular ion peak of $m / z=753.15$, corresponding to the $\left[\mathrm{Tm}_{2} \mathrm{~V}\right]^{+}$ cation. Furthermore, the reaction with $\mathrm{NaTm}^{\mathrm{Ph}}$ was also performed to obtain the analogous sandwich complex (1) ib in an 84\% yield. A mass-to-charge ratio of $m / z=1125.25$ obtained from the ESI-MS confirmed the mass for the $\left[\mathrm{Tm}^{\mathrm{Ph}}{ }_{2} \mathrm{~V}\right]^{+}$cation. However, slight $\mathrm{Tm}^{\mathrm{Ph}}$ decomposition was observed in an NMR scale experiment, which could account for the lowered yield. Likewise, multiple NMR scale reactions using $\mathrm{NaTm}^{t \mathrm{Bu}}$ demonstrated significant ligand decomposition, generating the analogous imidazole-2-thione as the major species present in the reaction solution and only a minor quantity of $\left[\mathrm{Tm}^{t \mathrm{Bu}}{ }_{2} \mathrm{~V}\right] \mathrm{Cl}$ formed. These results suggest that increased steric bulk of the ligand facilitates ligand degradation in the presence of vanadium.
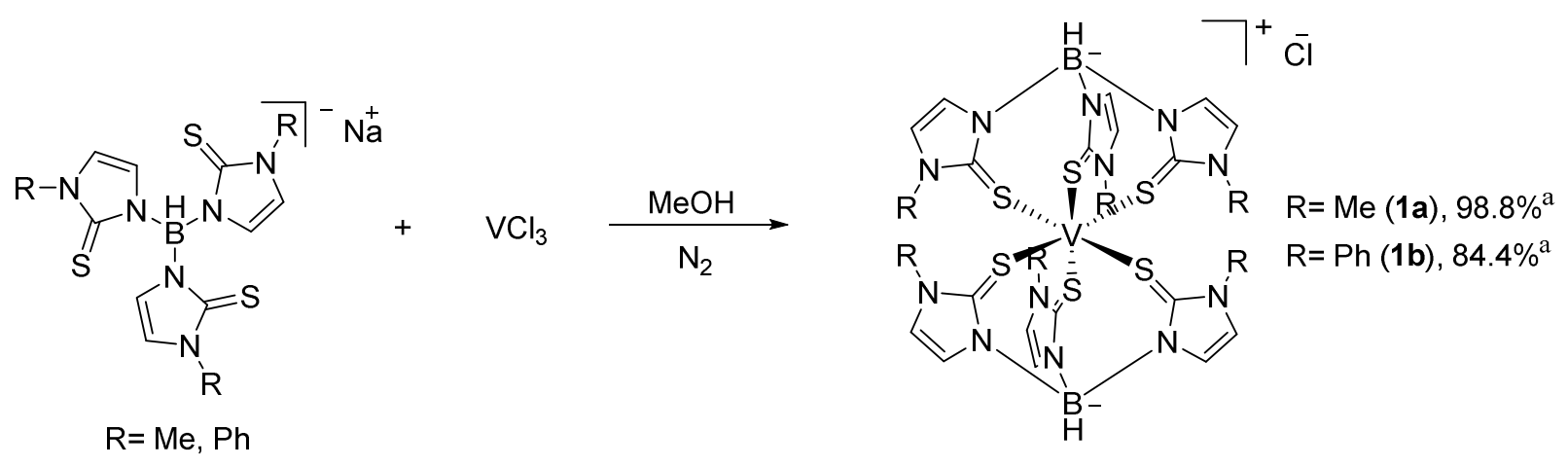

Scheme 17. $\left[\mathrm{Tm}^{\mathrm{R}}{ }_{2} \mathrm{~V}\right] \mathrm{Cl}$ synthesis. Reaction conditions: $\mathrm{NaTm}$ (2.6 mmol), $\mathrm{VCl}_{3}(1.3 \mathrm{mmol}), \mathrm{MeOH}(10$ $\mathrm{mL}$ ), rt, $\mathrm{N}_{2}, 15 \mathrm{~min}$. ${ }^{\mathrm{a}}$ Isolated yield. 
In addition to the chloride complexes, the triflate complex $\left[\mathrm{Tm}_{2} \mathrm{~V}\right](\mathrm{OTf})$ (1c) was also synthesized. Vanadium(III) triflate $\left(\mathrm{V}(\mathrm{OTf})_{3}\right)$ was generated in situ through the addition of silver(I) triflate (AgOTf) to $\mathrm{VCl}_{3}$ in methanol (Scheme 18). Filtration was performed to remove the silver chloride precipitate from the deep violet solution was performed, followed by addition of NaTm to afford $1 \mathrm{c}$ in $73.0 \%$ yield. ESI-MS was again used to verify the mass of the $\left[\mathrm{Tm}_{2} \mathrm{~V}\right]^{+}$ cation $(m / z=753.15)$, and ${ }^{19} \mathrm{~F}$ NMR spectroscopy confirmed the presence of the triflate counterion. Elemental analysis of 1c matched the calculated values as well.

$$
\mathrm{VCl}_{3}+\operatorname{AgOTf} \frac{1) \mathrm{MeOH}}{\mathrm{N}_{2}, 1 \mathrm{~h}} \quad \mathrm{~V}(\mathrm{OTf})_{3} \underset{\mathrm{MeOH}, \mathrm{N}_{2}, 15 \mathrm{~min}}{\stackrel{\text { 2) } \mathrm{NaTm}(2 \text { equiv. }}{\longrightarrow}} \mathrm{Tm}_{2} \mathrm{~V}(\mathrm{OTf})(1 \mathrm{c}) 73.0 \%^{\mathrm{a}}
$$

Scheme 18. $\left[\mathrm{Tm}_{2} \mathrm{~V}\right](\mathrm{OTf})(1 \mathrm{c})$ synthesis. Reaction conditions: (1) $\mathrm{VCl}_{3}(1.1 \mathrm{mmol}), \operatorname{AgOTf}(3.3 \mathrm{mmol})$, $\mathrm{MeOH}(10 \mathrm{~mL}), \mathrm{rt}, \mathrm{N}_{2}, 1 \mathrm{~h}$. Precipitate $(\mathrm{AgCl})$ is filtered off prior to step 2. (2) NaTm (2.2 mmol) added to $\mathrm{V}(\mathrm{OTf})_{3}$ solution. ${ }^{\text {a Isolated yield. }}$

While $\left[\mathrm{Tm}^{\mathrm{Ph}}{ }_{2} \mathrm{~V}\right] \mathrm{Cl}$ and $\left[\mathrm{Tm}_{2} \mathrm{~V}\right](\mathrm{OTf})$ are generally more soluble than $\left[\mathrm{Tm}_{2} \mathrm{~V}\right] \mathrm{Cl}$, obtaining concentrated solutions of any of these is problematic. Despite being highly soluble in DMSO or DMF, the stability of the complexes in these solvents is low, with ligand degradation occurring almost immediately. Moderate to low solubility is observed at room temperature for each in $\mathrm{MeOH}, \mathrm{MeCN}$, dichloromethane (DCM), dichloroethane (DCE), and chloroform $\left(\mathrm{CHCl}_{3}\right)$. Longterm stability in these solutions is not good either, with complete Tm degradation observed over a few weeks in each solvent. However, all of the $\left[\mathrm{Tm}^{\mathrm{R}} 2 \mathrm{~V}\right]^{+}$complexes are stable to oxygen $\left(\mathrm{O}_{2}\right)$, with no observed decomposition after a month of the powder being exposed to air based on ${ }^{1} \mathrm{H}$ NMR spectroscopy.

The dependence of product distribution and yield on solvent was explored. Complete conversion of $\mathrm{NaTm}$ to $\left[\mathrm{Tm}_{2} \mathrm{~V}\right] \mathrm{Cl}$ occurred in acetonitrile as well (entry 2), despite the lower solubility of $\mathrm{NaTm}$ in MeCN. Chlorinated solvents also mediated the formation of $\mathbf{1 a}$ as the sole product, although only partial conversion occurred even when heated to reflux (entries 3-5). Highly polar solvents such as DMSO and DMF were found to completely inhibit $\mathrm{Tm}$ coordination to vanadium, with only free Tm being observed (entries $6 \& 7$ ). Additional protic solvents such as $\mathrm{EtOH}$, and water were also capable of mediating $\left[\mathrm{Tm}_{2} \mathrm{~V}\right] \mathrm{Cl}$ production, water also promoted $\mathrm{Tm}$ 
degradation (entries $8 \& 9$ ). No other products were detected, excluding methimazole formation in select solvents.

Table 1. Screening of solvent and vanadium source for synthesis of $\left[\mathrm{Tm}_{2} \mathrm{~V}\right] \mathrm{Cl}^{\mathrm{a}}$
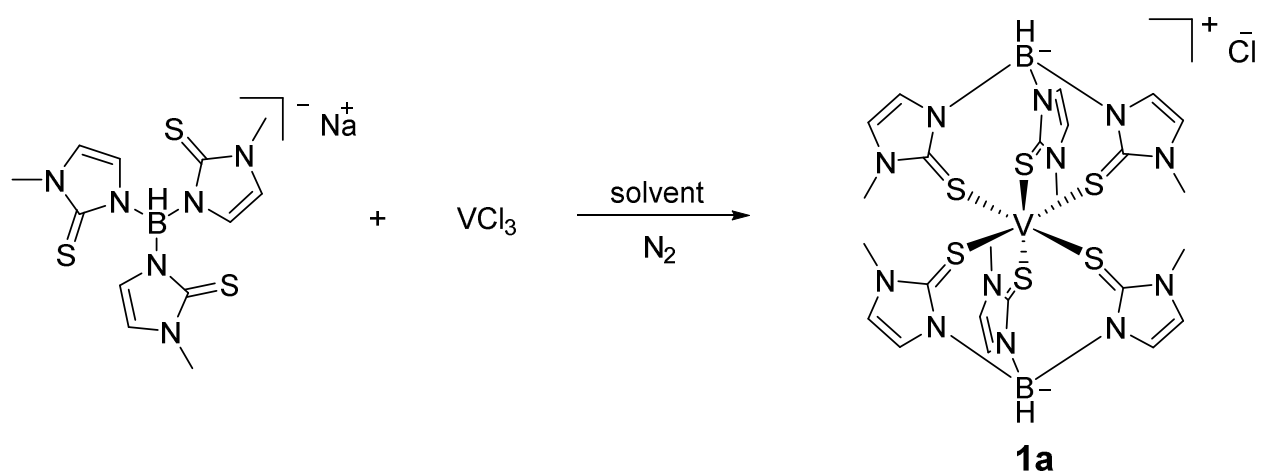

\begin{tabular}{|c|c|c|c|}
\hline Entry & Vanadium Source & Solvent & Formation of $\mathbf{1} \mathbf{a}^{\mathrm{b}}$ \\
\hline 1 & $\mathrm{VCl}_{3}$ & $\mathrm{MeOD}-d_{4}$ & quantitative $^{\mathrm{c}}$ \\
\hline 2 & $\mathrm{VCl}_{3}$ & $\mathrm{MeCN}-d_{3}$ & quantitative $^{c}$ \\
\hline 3 & $\mathrm{VCl}_{3}$ & $\mathrm{DCM}-d_{2}$ & partial $^{\mathrm{d}, \mathrm{e}}$ \\
\hline 4 & $\mathrm{VCl}_{3}$ & $\mathrm{CDCl}_{3}-d_{3}$ & partial $^{\mathrm{d}, \mathrm{e}}$ \\
\hline 5 & $\mathrm{VCl}_{3}$ & DCE & partial $^{\mathrm{d}, \mathrm{e}, \mathrm{f}}$ \\
\hline 6 & $\mathrm{VCl}_{3}$ & DMSO- $d_{6}$ & no reaction ${ }^{\mathrm{e}, \mathrm{g}}$ \\
\hline 7 & $\mathrm{VCl}_{3}$ & $\mathrm{DMF}-d_{7}$ & no reaction ${ }^{\mathrm{e}, \mathrm{g}}$ \\
\hline 8 & $\mathrm{VCl}_{3}$ & $\mathrm{EtOH}$ & quantitative $e^{c}$ \\
\hline 9 & $\mathrm{VCl}_{3}$ & $\mathrm{H}_{2} \mathrm{O}$ & $\operatorname{partial}^{\mathrm{d}, \mathrm{f}, \mathrm{g}}$ \\
\hline 10 & $\mathrm{VCl}_{3}(\mathrm{THF})_{3}$ & $\mathrm{MeOD}-d_{4}$ & quantitative $^{\mathrm{c}}$ \\
\hline 11 & $\mathrm{~V}(\mathrm{acac}) 3^{\mathrm{c}}$ & $\mathrm{MeOD}-d_{4}$ & no reaction ${ }^{\mathrm{e}}$ \\
\hline 12 & $\mathrm{VCl}_{2}{ }^{\mathrm{c}}$ & $\mathrm{MeOD}-d_{4}$ & no reaction ${ }^{\mathrm{e}}$ \\
\hline
\end{tabular}

${ }^{a}$ Reaction conditions unless noted otherwise: NaTm $(0.04 \mathrm{mmol})$, vanadium source $(0.04 \mathrm{mmol})$, solvent $(0.4 \mathrm{~mL}), \mathrm{rt}, \mathrm{N}_{2}, 15 \mathrm{~min}$, J. Young NMR tube. All reactions monitored by ${ }^{1} \mathrm{H}$ NMR spectroscopy. ${ }^{\mathrm{b}} \mathrm{Cannot}$

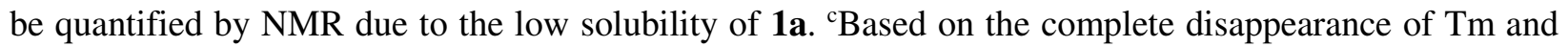
observation of $\mathbf{1 a}$ as the only product. ${ }^{\mathrm{d}} \mathbf{1 a}$ is not the only species present, no degradation. ${ }^{\mathrm{e}} \mathrm{rt}-\mathrm{reflux}, 8 \mathrm{~h}$. ${ }^{\mathrm{f} S}$ Solution removed in vacuo following reaction and ${ }^{1} \mathrm{H}$ NMR of the residue was taken in DMSO- $d_{6} .{ }^{\mathrm{g}} \mathrm{Tm}$ decomposition observed.

Besides $\mathrm{VCl}_{3}$, other commercially available vanadium salts were tested. $\mathrm{VCl}_{3}(\mathrm{THF})_{3}$ exhibited reactivity identical to that of $\mathrm{VCl}_{3}$ (entry 10). Vanadium(III) acetylacetonate (V(acac) 3 ), however, did not bind Tm well, and a mixture composed primarily of unreacted starting 
materials remained (entry 11). No reactivity was observed with the vanadium(II) chloride salt $\left(\mathrm{VCl}_{2}\right)$ (entry 12).

Reduction of 1a was also tested to investigate if $\mathrm{Tm}$ is more labile when coordinated to vanadium(II). Because $\mathrm{Tm}$ is unreactive with $\mathrm{VCl}_{2}$, we hypothesized that the corresponding V(II) complexe, $\mathrm{Tm}_{2} \mathrm{~V}$, may undergo ligand exchange (Table 1, entry 13). Treatment of 1a with $\mathrm{Cp}_{2} \mathrm{Co}$ in an $\mathrm{MeCN}$ solution resulted in a rapid color change from a bright red to a pale yellow, forming the vanadium(II) analog $\mathrm{Tm}_{2} \mathrm{~V}$ (2) (Scheme 19). The absence of peaks in the ${ }^{1} \mathrm{H}$ NMR spectrum of $\mathbf{2}$ suggests it to be a paramagnetic complex. Exposure of $\mathbf{2}$ to air caused an instantaneous color change back to red, as well as the appearance of the $\left[\mathrm{Tm}_{2} \mathrm{~V}\right]^{+}$resonances in the ${ }^{1} \mathrm{H}$ NMR spectrum. Obtaining a mass spectrum for the reduced complex proved problematic, as oxidation occurred upon injection to the instrument giving a red solution. Observation of a molecular ion peak at $m / z=753.15$ suggests the presence of $\left[\mathrm{Tm}_{2} \mathrm{~V}\right]^{+}$rather than $\mathrm{Tm}_{2} \mathrm{~V}$.

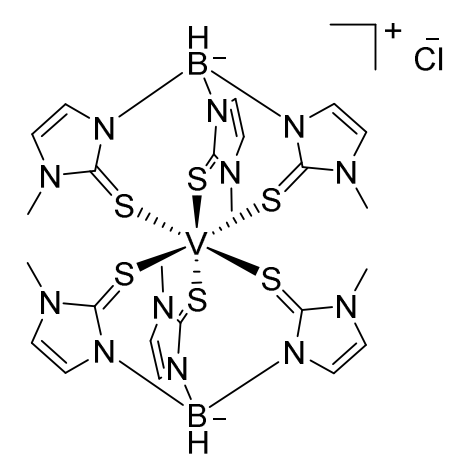

$1 \mathbf{a}$

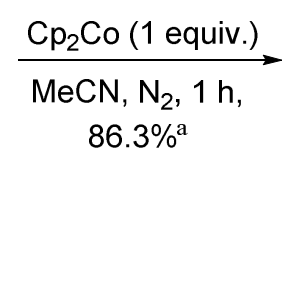

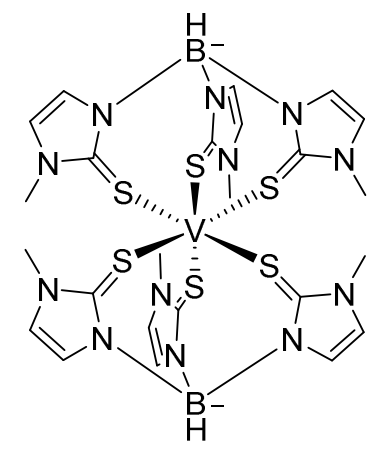

2

Scheme 19. $\mathrm{Tm}_{2} \mathrm{~V}(\mathbf{2})$ synthesis via reduction of 1a. Reaction conditions: $\left[\mathrm{Tm}_{2} \mathrm{~V}\right] \mathrm{Cl}(0.06 \mathrm{mmol}), \mathrm{Cp}_{2} \mathrm{Co}$ (0.06 mmol), $\mathrm{MeCN}(2 \mathrm{~mL}), \mathrm{rt}, \mathrm{N}_{2}, 1 \mathrm{~h}$. ${ }^{\mathrm{a}}$ Isolated yield.

\subsubsection{Attempts at Synthesizing Vanadium-Tris(methimizolyl)borate-Isonitrile Complexes}

Attempts to displace the Tm ligand from 1a were performed on NMR scale reactions (Table 2). Since the objective was to create half-sandwich complexes bearing isonitrile ligands, 1a was treated with tert-butyl isonitrile $(\mathrm{CN} t \mathrm{Bu})$ (entry 1$)$. At room temperature no reaction occurred, while at higher temperatures $\left(60^{\circ} \mathrm{C}\right)$ only Tm decomposition to methimazole was observed. Treatment of $\mathbf{2}$ with $\mathrm{CN} t \mathrm{Bu}$ had the same result (entry 2). Other neutral ligands such as 
monophosphines and 1,10-phenanthroline had the same outcome as with $\mathrm{CN} t \mathrm{Bu}$ (entries 3-5). Benzoate was explored as an anionic ligand to displace Tm due to its similarities to the homocitrate ligand on the heterometal of the nitrogenase active site. Benzoic acid, sodium benzoate, and silver benzoate were examined, although no Tm displacement was observed for any (entries 6-8). Like the previous entries, heating the reactions with benzoate led only to ligand decomposition. In fact, heating $\mathbf{1 a}$ alone in $\mathrm{MeOH}$ had the same result (entry 9).

Table 2. Screening for $\mathrm{Tm}$ ligand displacement from $\mathrm{Tm}_{2} \mathrm{VCl}^{\mathrm{a}}$

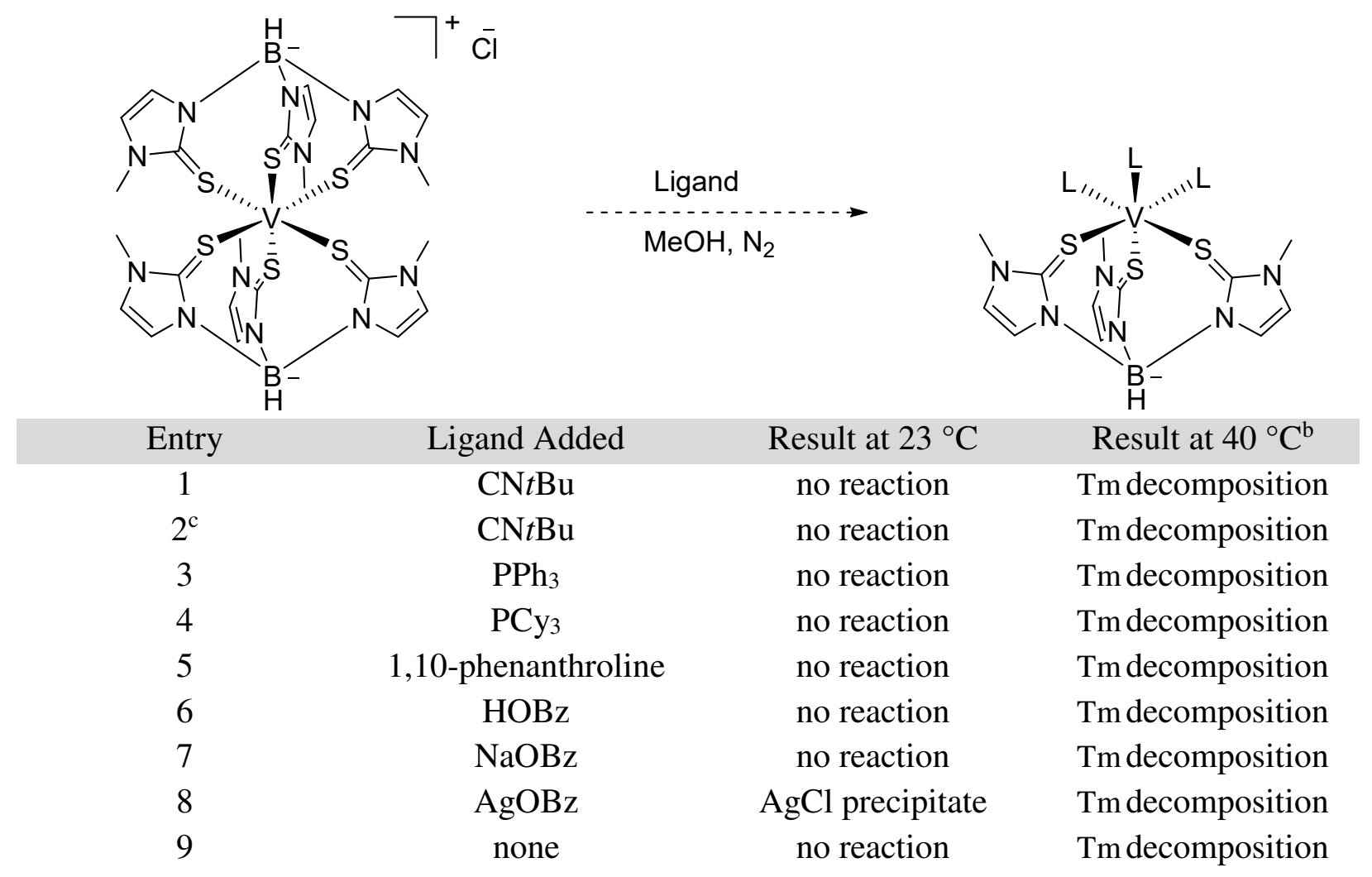

aReaction conditions: $\left[\mathrm{Tm}_{2} \mathrm{~V}\right] \mathrm{Cl}$ (1a) $(0.02 \mathrm{mmol})$, ligand $(0.04 \mathrm{mmol}), \mathrm{d}^{4}-\mathrm{MeOD}(0.4 \mathrm{~mL}), \mathrm{N}_{2}, 12 \mathrm{~h}$ at $\mathrm{rt}$, $4 \mathrm{~h}$ at $40{ }^{\circ} \mathrm{C}$, J. Young NMR tube. All reactions were monitored by ${ }^{1} \mathrm{H}$ NMR spectroscopy. ${ }^{\mathrm{b}} \mathrm{Tm}$ decomposes to form methimazole. ${ }^{\mathrm{C}} \mathrm{Tm} 2 \mathrm{~V}$ was used instead.

After these displacement experiments, it was clear that Tm can only be removed from 1a through degradation. Therefore, a new approach of adding $\mathrm{CN} t \mathrm{Bu}$ to $\mathrm{VCl}_{3}$ prior to $\mathrm{NaTm}$ was employed. Addition of $\mathrm{NaTm}$ to a green $\mathrm{VCl}_{3} / \mathrm{CN} t \mathrm{Bu} \mathrm{MeOH}$ solution at room temperature resulted in several new sets of imidazole signals in the crude ${ }^{1} \mathrm{H}$ NMR spectrum (Figure 12a; Table 3, entry 1). These sets include pairs of broad-singlets in the aromatic region, presumably coming from 
aromatic imidazole hydrogens. However, the dominant species among them belonged to methimazole (Figure 12a, $\mathbf{\Delta}$ ). Other signals in this spectrum have been identified as being from the same species due to always having the same relative intensities to each other regardless of their concentrations. These species have been assigned here as products $\mathbf{X}(\bullet)$ and $\mathbf{Y}(\diamond)$. Performing this same reaction in other solvents lead to the formation of 1a instead, although conversion was incomplete for DCM and $\mathrm{CHCl}_{3}$ (Table 3, entries 2-4). No other Tm resonances were observed in these solvents.

Figure 12. Aromatic region of ${ }^{1} \mathrm{H}$ NMR of reactions in Table 3: (a) entry 1, addition of NaTm to $\mathrm{VCl}_{3} / \mathrm{CN} t \mathrm{Bu}$ solution at room temperature. (b) entry 6 , addition of $\mathrm{NaTm}$ to $\mathrm{VCl}_{3} / \mathrm{CN} t \mathrm{Bu}$ solution at -40 ${ }^{\circ} \mathrm{C}$. (c) entry 9 , addition of $\mathrm{VCl}_{3} / \mathrm{CN} t \mathrm{Bu}$ solution to $\mathrm{NaTm}$ at $-40{ }^{\circ} \mathrm{C}$. Sets of associated signals indicated by symbols.

a) Table 3, entry 1: Addition Method (1) at room temperature.

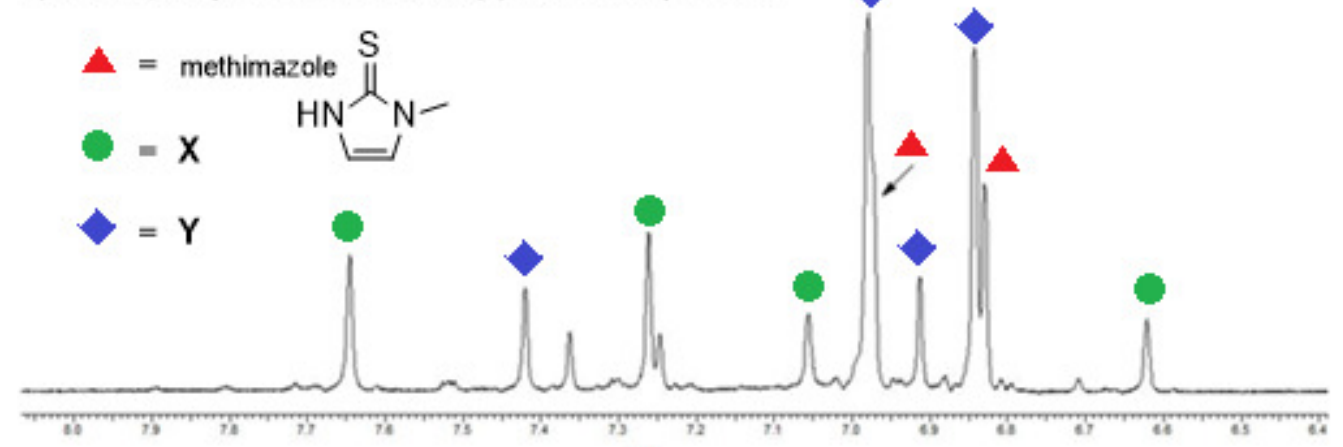

b) Table 3, entry 6: Addition Method (1)

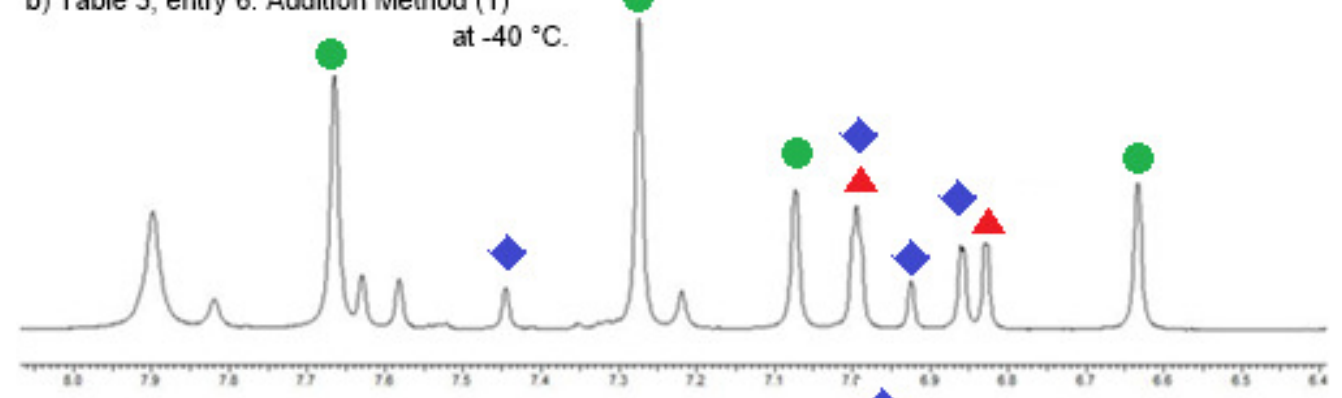

c) Table 3 , entry 9: Addition Method (2) at $-40^{\circ} \mathrm{C}$ 
In order to reduce Tm degradation, the reaction temperature was lowered by placing the flask in an acetone/dry ice bath before the addition of NaTm (Table 3, entry 5). However, the solution color remained green for over an hour, indicating no reaction was taking place. When the temperature was allowed to increase slowly, a color change to a red-brown solution occurred at $40{ }^{\circ} \mathrm{C}$. As the reaction continued to warm to room temperature, the color faded to light brown. Removal of the solvent in vacuo caused a permanent color change to a green/brown residue. This color remained when the residue was dissolved into MeOD- $d_{4}$. The ${ }^{1} \mathrm{H}$ NMR spectrum of this crude sample turned out to contain most of the same signals as the room temperature reaction (entry 1), although the relative integrations are different. Methimazole formation, however, was significantly reduced. More interestingly, two different pairs of the new Tm resonances, with integrations in a 1:1 ratio, grew in area, suggesting that they come from the same Tm species (X). In addition, these two pairs of signals exist in a 2:1 ratio to each other in both the room temperature and the $-78{ }^{\circ} \mathrm{C}$ reactions (Figure 11a). This pattern is consistent with a complex where only two of the Tm arms are equivalent, possibly in a half-sandwich complex with $\mathrm{C}_{\mathrm{v}}$ symmetry or from a $\kappa^{2}-\mathrm{S}, \mathrm{S}$ coordination mode.

Table 3. Reactivity screening for $\mathrm{NaTm}$ with $\mathrm{VCl}_{3} / \mathrm{CN} t \mathrm{Bu}$ solutions ${ }^{\mathrm{a}}$

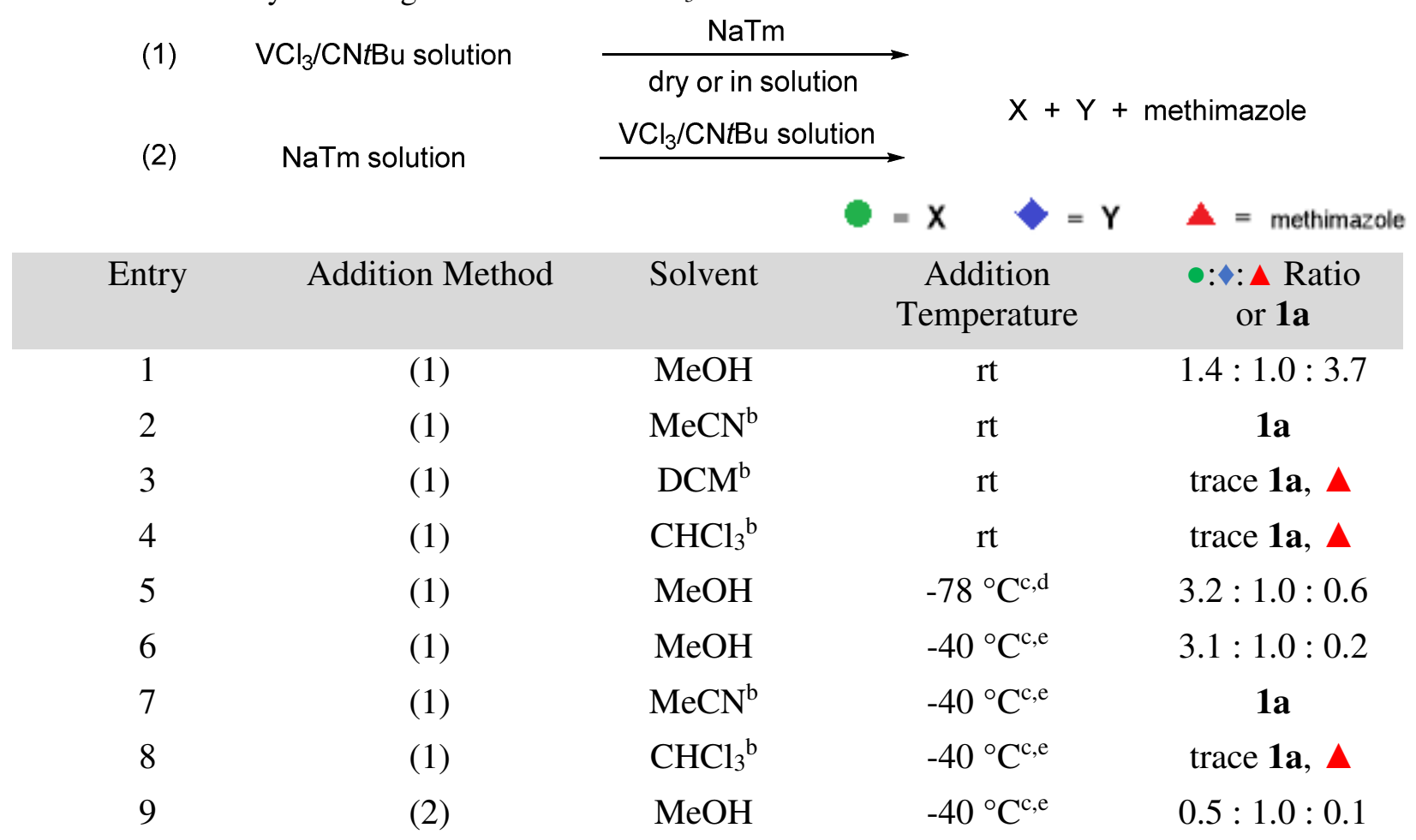

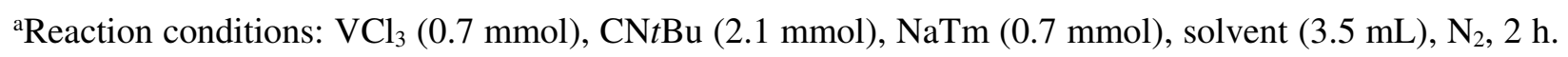
$\mathrm{NaTm}-\mathrm{MeOH}$ solution added via cannulate transfer. ${ }^{\mathrm{b}} \mathrm{NaTm}$ added dry via addition funnel due to insolubility. ${ }^{\mathrm{c}} \mathrm{NaTm}-\mathrm{MeOH}$ solution was added at reduced temperature and allowed to slowly warm to room temperature over 2 hours. ${ }^{\mathrm{d}}$ Cooled in an acetone/dry ice bath. ${ }^{\mathrm{e}} \mathrm{Cooled}$ in an MeCN/dry ice bath. 
Reproduction of this low-temperature addition procedure gave a nearly identical spectrum, although the temperature was held at $-40{ }^{\circ} \mathrm{C}$ during NaTm addition (Figure 11b; Table 3, entry 6). This procedure was performed with $\mathrm{MeCN}$ and DCM as well (entries $7 \& 8$ ), although the outcome was the same as at room temperature for each (entries $2 \& 3$ ). When the $\mathrm{VCl}_{3} / \mathrm{CN} t \mathrm{Bu}$ solution was added to NaTm instead (entry 9), yet another set of Tm signals in a 2:1 ratio were identified $(\mathbf{Y}, \diamond)$ (Figure 11c). When comparing the spectra of the three reactions in Figure 11, it appears that not only can Tm degradation be reduced when running the reaction at lower temperature, but also that the addition method chosen can selectively promote the formation of different TmV products. However, isolation of any products from the crude mixtures through crystallizations were not successful. Further investigations into the formation of $\mathrm{TmV}$ complexes with isonitrile ligands has been suspended due to the difficulties such as the favorability of $\left[\mathrm{Tm}_{2} \mathrm{~V}\right]^{+}$formation, Tm degradation, and inseparable mixtures of products.

\subsubsection{Attempts at Synthesizing Vanadium-Tris(methimizolyl)borate-Hydrazine Complexes and the Acid Assisted Reduction of Hydrazines}

Like with isonitriles, the initial approach for synthesizing half-sandwich V-Tm complexes with hydrazines was to add the hydrazine to a $\mathrm{VCl}_{3}$ solution prior to $\mathrm{NaTm}$ addition (Eq 3).

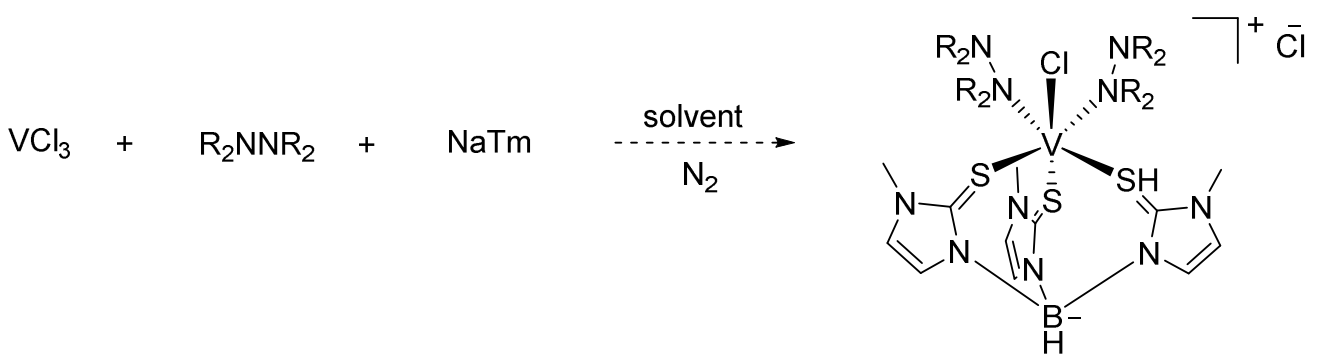

In order to pursue this approach, several differently substituted hydrazines were selected for screening (Table 4). Although coordination of 1,2-diphenylhydrazine occurs based on observed shifts in the diphenylhydrazine ${ }^{1} \mathrm{H}$ NMR spectrum, it is displaced by Tm to form $\mathbf{1 a}$ as the sole 
product in $\mathrm{MeOH}$ (entry 1). The same result is observed for terminal hydrazines in $\mathrm{MeCN}$ (entries 6-9). However, when this procedure is carried out in $\mathrm{MeOH}$ for the terminal hydrazines, an off-white precipitate is formed (3) (entries 6-9). The ${ }^{1} \mathrm{H}$ NMR spectrum of the product resulting from phenylhydrazine (3a) contained new sets of Tm and phenyl resonances, indicating that a new vanadium complex incorporating both ligands was formed. Other terminal hydrazines also gave products with similar Tm resonances (3b-d). Additionally, any precipitate collected from these reactions always displayed a single ${ }^{51} \mathrm{~V}$ NMR signal despite multiple recrystallizations, further supporting this hypothesis. Mass spectral analysis provided spectra that varied significantly between samples and were not assignable to any reasonable vanadiumcontaining structures.

Table 4. Screening for the synthesis of V-Tm complexes with hydrazines ${ }^{a}$

$$
\begin{aligned}
& \mathrm{VCl}_{3}+\mathrm{R}_{-\mathrm{H}^{-}}^{\stackrel{\mathrm{I}^{\prime}}{\mathrm{N}^{\prime}} \mathrm{R}^{\prime \prime}}+\mathrm{NaTm} \underset{\mathrm{N}_{2}, \mathrm{rt}, \mathrm{xh}}{\stackrel{\text { solvent }}{\longrightarrow}} \text { 1a or } \mathbf{3} \\
& \mathrm{R}=\mathrm{H}, \mathrm{Ph} \\
& R^{\prime}, R^{\prime \prime}=H, M e, P h
\end{aligned}
$$

$\begin{array}{cccc}\text { Entry } & \text { Hydrazine } & \text { Solvent } & \text { Product } \\ 1 & \text { PhHNNHPh } & \text { MeOD- } d_{4} & \text { 1a } \\ 2 & \mathrm{H}_{2} \mathrm{NNHPh} & \text { MeOD- } d_{4} & \text { 3a } \\ 3 & \mathrm{H}_{2} \mathrm{NNHMe} & \text { MeOD- } d_{4} & \text { 3b } \\ 4 & \mathrm{H}_{2} \mathrm{NNMe}_{2} & \mathrm{MeOD}-d_{4} & \mathbf{3 c} \\ 5 & \mathrm{H}_{2} \mathrm{NNH}_{2} & \mathrm{MeOD}-d_{4} & \mathbf{3 d} \\ 6 & \mathrm{H}_{2} \mathrm{NNHPh} & \mathrm{MeCN}-d_{3} & \mathbf{1 a} \\ 7 & \mathrm{H}_{2} \mathrm{NNHMe}_{2} & \mathrm{MeCN}-d_{3} & \mathbf{1 a} \\ 8 & \mathrm{H}_{2} \mathrm{NNMe}_{2} & \mathrm{MeCN}-d_{3} & \mathbf{1 a} \\ 9 & \mathrm{H}_{2} \mathrm{NNH}_{2} & \mathrm{MeCN}-d_{3} & \mathbf{1 a}\end{array}$

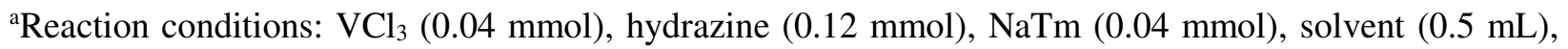
$\mathrm{N}_{2}$, rt, 2 h. Hydrazine was added prior to NaTm.

With the theory that these precipitates were vanadium complexes, screening of reactions with the addition of a reductant and an acid was initiated. Subsequent addition of $\mathrm{Cp}_{2} \mathrm{Co}$ and 2,6lutidinium chloride ( $\mathrm{LutHCl}$ ) to the reaction involving phenylhydrazine described above lead to 
the detection of aniline in a $34 \%$ yield by GC analysis (Scheme 20). This product assignment was confirmed by ${ }^{1} \mathrm{H}$ NMR spectroscopy. Similarly, addition of $\mathrm{Cp}_{2} \mathrm{Co}$ and LutHCl to isolated 3a resulted in the formation of aniline in a $25 \%$ yield (Scheme 21).

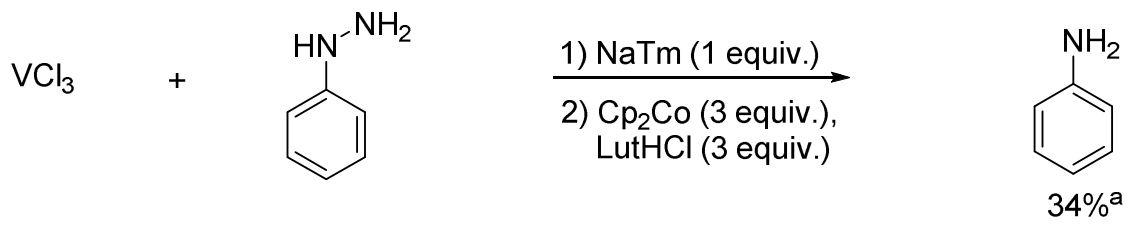

Scheme 20. Subsequent addition of a reductant and an acid generates aniline as a product. Reaction conditions: 1$) \mathrm{VCl}_{3}(0.04 \mathrm{mmol})$, phenylhydrazine $(0.12 \mathrm{mmol}), \mathrm{NaTm}(0.04 \mathrm{mmol}), \mathrm{MeOD}-d_{4}(0.5 \mathrm{~mL})$, $\mathrm{N}_{2}$, rt, $15 \mathrm{~min}$. Hydrazine was added prior to NaTm. 2) $\mathrm{Cp}_{2} \mathrm{Co}(0.12 \mathrm{mmol})$, LutHCl (0.12 mmol), $2 \mathrm{~h}$. Aniline was confirmed by GC analysis and ${ }^{1} \mathrm{H}$ NMR spectroscopy. ${ }^{\mathrm{a}} \mathrm{GC}$ yield using tetradecane as an internal standard.

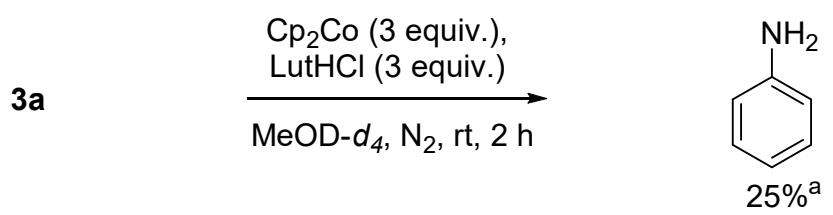

Scheme 21. Addition of a reductant and an acid 3a generates aniline as a product. Reaction conditions: 3a (30 mg), $\mathrm{Cp}_{2} \mathrm{Co}(0.12 \mathrm{mmol})$, LutHCl $(0.12 \mathrm{mmol}), \mathrm{MeOD}-d_{4}(0.5 \mathrm{~mL}), \mathrm{N}_{2}, \mathrm{rt}, 2 \mathrm{~h}$. Aniline was confirmed by GC analysis and ${ }^{1} \mathrm{H}$ NMR spectroscopy. ${ }^{a} \mathrm{GC}$ yield using tetradecane as an internal standard.

Before further optimization of the reduction of phenylhydrazine could be explored, a crystal structure for product 3c was obtained (Figure 13). From this, it was discovered that the precipitates formed were not vanadium complexes, but hydrazonium-Tm salts instead. Protonation of the substituted nitrogen in dimethylhydrazine lead to the precipitation of the less soluble $[\mathrm{Tm}]\left[\mathrm{H}_{2} \mathrm{NNHMe}_{2}\right]$ salt.

In order to properly understand the function of each reagent involved in the formation of $\mathbf{3}$ and the reduction of hydrazines, a series of control reactions excluding $\mathrm{VCl}_{3}$ were performed. (Table 5). Mixing NaTm with phenylhydrazine in methanol did not result in any observable interactions between the two reagents (entry 1). However, addition of $\mathrm{LutHCl}$ to this mixture resulted in a white precipitate forming, which matched the spectra for 3a (entry 2). When NaTm was replaced with $\mathrm{Cp}_{2} \mathrm{Co}$, reduction of phenylhydrazine to aniline still occurred (entry 3), suggesting that Tm 
is only acting as a counter ion. On the other hand, running the same reaction in $\mathrm{MeCN}$ did not facilitate the aniline production (entry 4), revealing that $\mathrm{Cp}_{2} \mathrm{Co}$ is capable of performing the reduction of hydrazines in protic solvents, although an acid is required (entry 5).

Figure 13. X-ray crystal structure of the $[\mathrm{Tm}]\left[\mathrm{H}_{2} \mathrm{NNHMe}_{2}\right]$ salt 3c with thermal ellipsoids drawn at the $50 \%$ probability level.

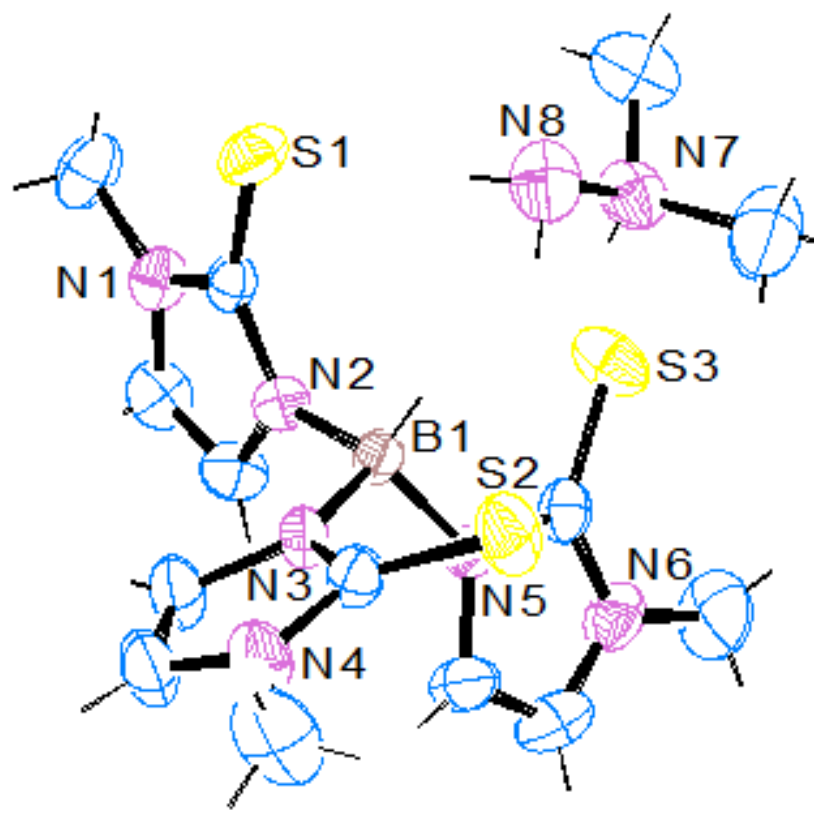

Table 5. Hydrazine screening for the synthesis of $\mathrm{TmVL}_{\mathrm{n}}\left(\mathrm{RHNNHR}^{\prime}\right)_{\mathrm{n}}$ complexes $^{\mathrm{a}}$
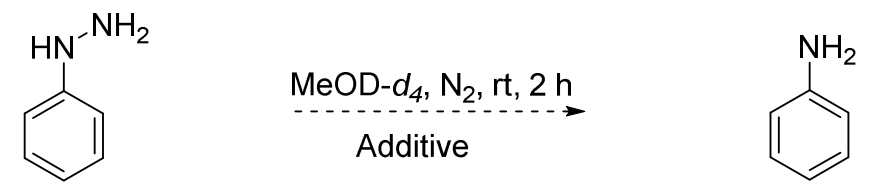

$\begin{array}{ccc}\text { Entry } & \text { Additive } & \text { Result }^{\mathrm{b}} \\ 1 & \mathrm{NaTm} & \text { no reaction } \\ 2 & \mathrm{NaTm}+\mathrm{LutHCl} & {[\mathrm{Tm}]\left[\mathrm{H}_{2} \mathrm{NNH}_{2} \mathrm{Ph}\right](\mathbf{3 a}) 71 \%^{\mathrm{c}}} \\ 3 & \mathrm{Cp} \mathrm{Co}_{2}+\mathrm{LutHCl} & \mathrm{PhNH}_{2} \\ 4^{\mathrm{d}} & \mathrm{Cp} 2 \mathrm{Co}+\mathrm{LutHCl} & \text { no reaction } \\ 5 & \mathrm{Cp}_{2} \mathrm{Co} & \text { no reaction }\end{array}$

${ }^{a}$ Reaction conditions unless noted otherwise: phenylhydrazine ( $\left.0.04 \mathrm{mmol}\right), \mathrm{NaTm}$ ( 1 equiv.), $\mathrm{Cp}_{2} \mathrm{Co}$ (2

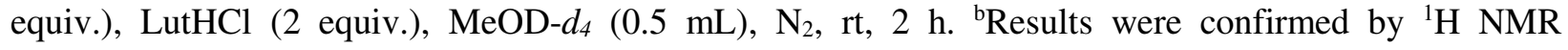
spectroscopy. 'Isolated yield from scaled up reaction: Phenylhydrazine $(0.1 \mathrm{mmol})$, LutHCl (1 equiv.), $\mathrm{MeOH}(2 \mathrm{~mL})$. ${ }^{\mathrm{e}}$ Reaction performed in $\mathrm{MeCN}-d_{3}$. 
With the discovery of the formation of hydrazonium-Tm salts rather than the originally suspected vanadium complexes, it became apparent that synthesis of $\mathrm{TmV}$ half-sandwich complexes would require a different approach. Thus far, the formation of $\mathbf{1 a}$ and inseparable mixtures of products in addition to Tm degradation, have hampered the synthesis of $\mathrm{TmV}$ complexes other than 1a.

\subsection{Conclusions}

A series of new $\mathrm{Tm}^{\mathrm{R}} \mathrm{V}$ sandwich complexes have been successfully isolated and characterized. These complexes are believed to be the first Tm complexes with vanadium, as no other examples have been reported to date. However, Tm was found to be prone to degradation in the presence of vanadium, resulting in unsuccessful attempts to displace a Tm ligand and form a TmV halfsandwich complex.

TmV complexes with isonitrile co-ligands are believed to have been synthesized based on crude ${ }^{1} \mathrm{H}$ NMR data. Low reaction temperature and choice of addition method of the reagents were found to impact the formation of the various products, although isolation of these complexes was unsuccessful. Improved syntheses or purification methods could lead to the isolation of the complexes, which would allow for the investigation of the ability of $\mathrm{TmV}$ complexes to mediate the reductive coupling of isonitriles.

The synthesis of TmV complexes with hydrazine co-ligands was unsuccessful. Products isolated from the reactions between vanadium, Tm, and hydrazines were determined to be Tmhydrazonium salts. While the addition of a reductant and acid to these reaction mixtures resulted in the reduction of the hydrazines to the corresponding amines, vanadium's role was determined to be nothing more than as a Lewis acid. The results of these studies suggest that accessing TmV complexes with hydrazine co-ligands in order to study their reduction chemistry will require the synthesis of alternative $\mathrm{TmV}$ half-sandwich complexes that can undergo subsequent ligand substitution. 


\section{CHAPTER II.}

\section{Coupling of Isonitriles with Bisnucleophiles Mediated by Iron and Cobalt}

\subsection{Iron Mediated Coupling of Isonitriles}

\subsubsection{Coupling of Isonitriles to Form Ureas Mediated by Iron-Tris(methimizolyl)borate Complexes}

In addition to investigating the ability of vanadium to mediate reductive transformations, research in our group has focused on the synthesis and reactivity of iron-isonitrile complexes as nitrogenase mimics. A series of half-sandwich iron(II) tris(2-mercaptoimidazolyl)borate $\left(\mathrm{Tm}^{\mathrm{R}}\right)$ complexes bearing three isonitrile ligands have been successfully isolated (Scheme 22).
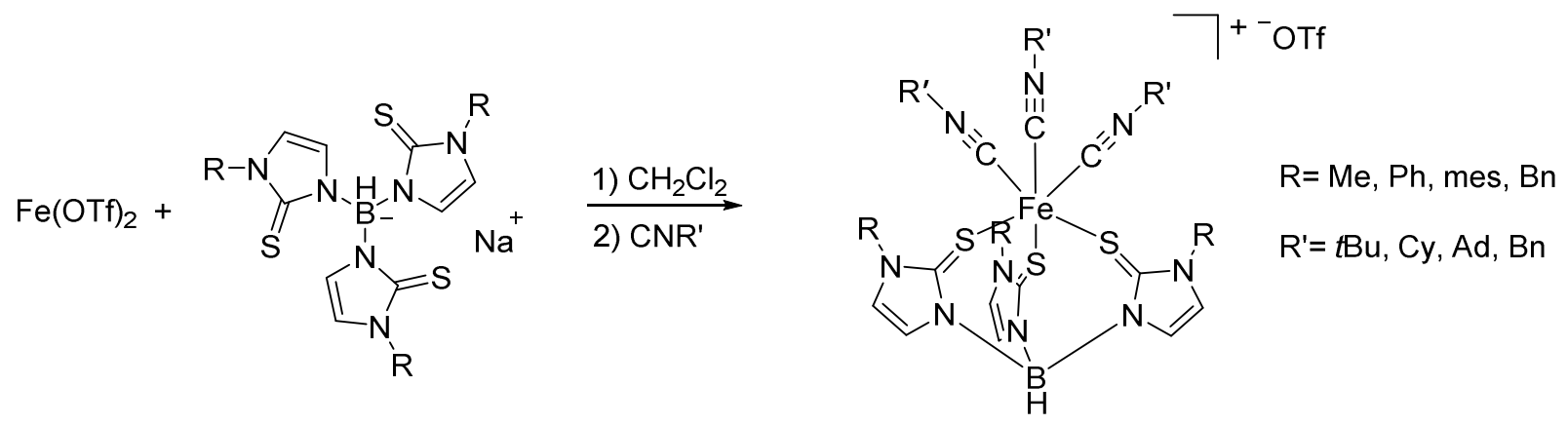

Scheme 22. $\left[\mathrm{Tm}^{\mathrm{R}} \mathrm{Fe}\left(\mathrm{CNR}^{\prime}\right)_{3}\right](\mathrm{OTf})$ complexes isolated by the Hoover group.

With these complexes in hand, their ability to reductively couple the isonitrile ligands was evaluated by treating $\left[\mathrm{Tm}^{\mathrm{Me}} \mathrm{Fe}\left(\mathrm{CN}^{t} \mathrm{Bu}\right)_{3}\right](\mathrm{OTf})$ with a reductant and a proton source. While screening reaction conditions searching for $\mathrm{C}-\mathrm{C}$ coupling products, di-tert-butylurea was frequently detected instead. This piqued our interest because not only are iron-mediated reductive couplings of isonitriles rare (as discussed in Chapter 1.1.3.), but also the conversion of isonitriles to ureas via iron has not previously been demonstrated. Therefore, optimization of its production has been explored. Using potassium graphite $\left(\mathrm{KC}_{8}\right)$ and water as the proton source, urea yields of up to $57 \%$ were achieved (Scheme 23a). Tert-butylamine was also detected under the optimized conditions, prompting the investigation of an amine being involved in urea 
formation. To test its participation, 10 equivalents of tert-butylamine was added under standard conditions, resulting in an increase in urea yield from 57\% to 102\% based on iron (Scheme 23b). Additionally, analogous experiments where the alkyl groups in the isonitriles and amines were different resulted in the formation of the mixed urea as well (Scheme 23c).

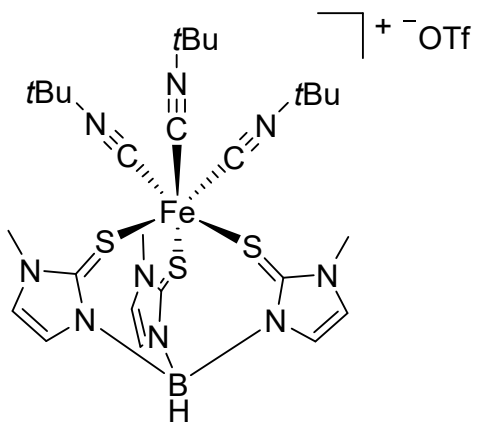

(a)

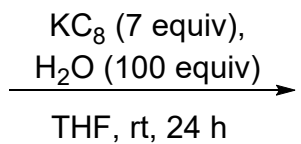

$\mathrm{KC}_{8}$ (7 equiv),

$\mathrm{H}_{2} \mathrm{O}$ (100 equiv),

(b)

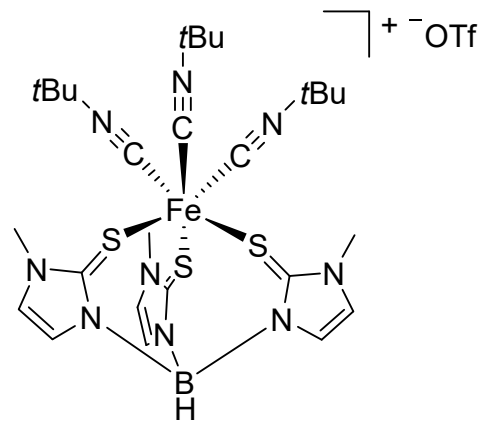<smiles>CC(C)(C)NC(=O)NC(C)(C)C</smiles>

$57 \%$<smiles>CC(C)(C)NC(=O)NC(C)(C)C</smiles>

$102 \%$

(c)

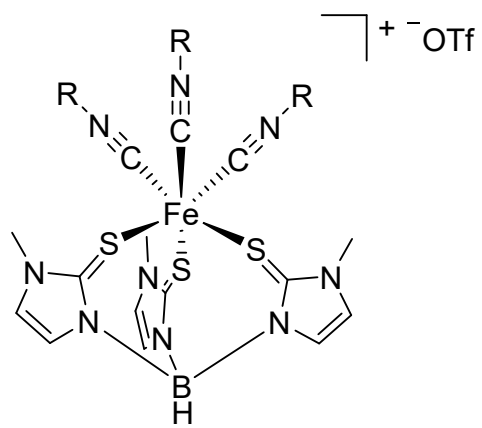

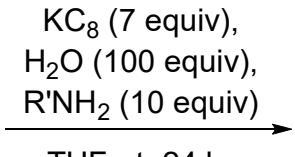

THF, rt, $24 \mathrm{~h}$

Scheme 23. Reactions of FeTm-CNR complexes to produce ureas. a) Standard reaction conditions to produce di-tert-butyl urea. b) Addition of tert-butylamine to standard reaction conditions. c) Mixed urea synthesis through use of isonitriles and amines with differing R-groups. Yields are calculated with respect to iron.

The mechanism was further explored to identify the origin of the oxygen in the urea product. When the reaction workup was performed inside the glovebox no urea was detected by gas 
chromatography (GC). However, subsequent exposure of this sample to air resulted in an $18 \%$ yield, suggesting $\mathrm{O}_{2}$ to be the oxygen source. Additionally, no ${ }^{18} \mathrm{O}$ incorporation into the urea was detected by gas chromatography-mass spectrometry (GC-MS) nor electrospray ionizationmass spectrometry (ESI-MS) when ${ }^{18} \mathrm{O}$ labeled water was used in the reaction, confirming that water is not the oxygen source. While generation of the amine and coupling with an isonitrile ligand both occur under reductive conditions, a final oxidation step by $\mathrm{O}_{2}$ is required to generate urea (Scheme 24).
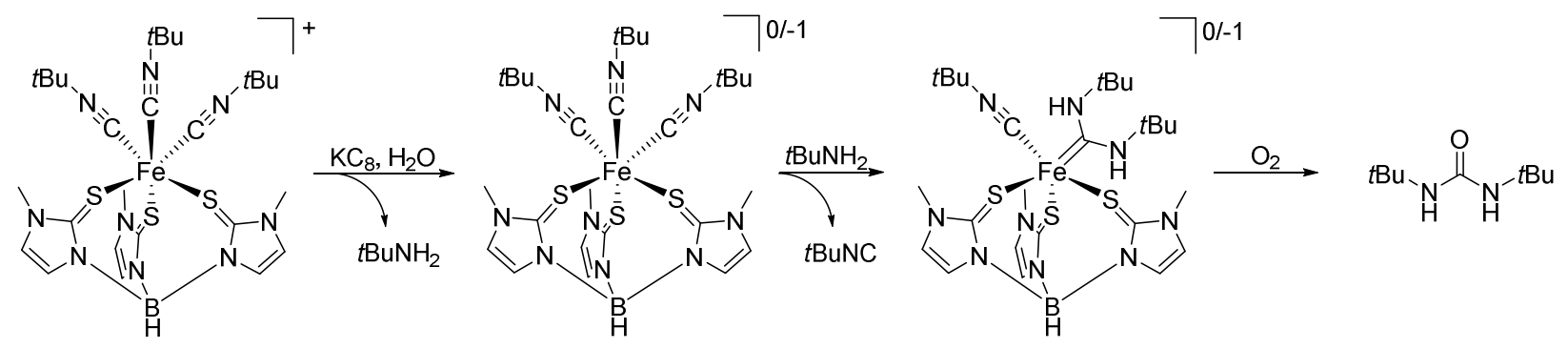

Scheme 24. Possible pathway for the production of urea from $\left[\mathrm{Tm}^{\mathrm{Me}} \mathrm{Fe}(\mathrm{CNtBu})_{3}\right]^{+}$.

Control experiments indicated that tert-butylamine is formed through an iron-mediated reductive cleavage of a tert-butyl isonitrile ligand, although the presence of $\mathrm{KC}_{8}$ and water were found to be necessary as well for amine production to occur. Additionally, urea was not detected when treating the iron complex with amine prior to addition of the reductant, suggesting coupling occurs at a reduced iron species. Due to the requirement of an external reductant and oxidant in order to reach the final product, this system is not likely capable of catalytic production of urea. Alternatively, catalytic oxidative coupling of isonitriles with nucleophiles such as amines performed by group 9 and 10 metals is well established.

\subsubsection{Project Objectives}

Production of urea from the coupling of isonitrile ligands in the $\mathrm{TmFe}(\mathrm{CNR})_{3}$ complexes discussed in Chapter 2.1.1. inspired us to look for similar coupling reactions that can be performed under reductive conditions. The initial hypothesis of how di-tert-butylurea was 
formed was that tandem coupling reactions were occurring between an isonitrile ligand and two nucleophiles, tert-butylamine and water. 2-Aminophenol was selected as a model substrate because it contains both amine and alcohol functionalities, which fill the roles of tert-butylamine and water, respectively. Water would later be ruled out as a coupling partner, however, investigation into the coupling of isonitriles with 2-aminophenol was already well under way. Simple iron salts such as iron(II) triflate $\left(\mathrm{Fe}(\mathrm{OTf})_{2}\right)$ were selected to test for reactivity in the event that synthesis of TmFe complexes is not necessary. Our goal was to identify and optimize the iron-mediated coupling of isonitriles with 2-aminophenol to produce 2-aminobenzoxazoles under reductive conditions (Scheme 25).

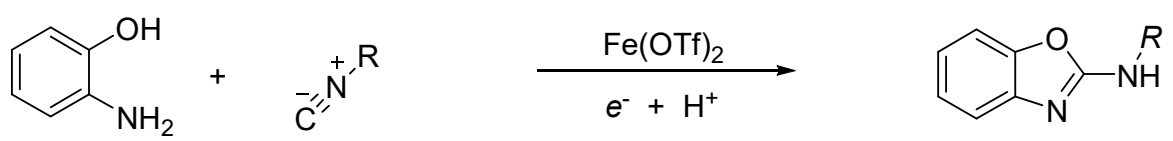

Scheme 25. Desired coupling of 2-aminophenol with isonitriles to produce 2-aminobenzoxazoles, mediated by iron under reductive conditions.

\subsubsection{Results and Discussion}

Initial reaction conditions for identifying reactivity between tert-butyl isonitrile and 2aminophenol were selected based on conditions used to form urea from $\operatorname{TmFe}(\mathrm{CN} t \mathrm{Bu})_{3}$ at the time this project was initiated. These two substrates were treated with iron(II) triflate $\left(\mathrm{Fe}(\mathrm{OTf})_{2}\right.$, potassium graphite $\left(\mathrm{KC}_{8}\right)$ and anhydrous hydrogen chloride $(\mathrm{HCl})$. While no products were detected when 7 equivalents of $\mathrm{HCl}$ was added (Table 6, entry 1), 1 equivalent or no $\mathrm{HCl}$ both resulted in the detection of only trace products by gas chromatography (GC) following a filtration over celite (entries 2-3). Since acid appeared to have an inhibitory effect on the reaction, it was omitted from further screening. The reaction without $\mathrm{HCl}$ was scaled up and the reaction mixture was purified by column chromatography. 2-Amino- $N$-tert-butylbenzoxazole was indeed determined to be the sole isolated product, albeit in only a 3\% yield (Scheme 26). 
Table 6. Reaction screening in search of reactivity

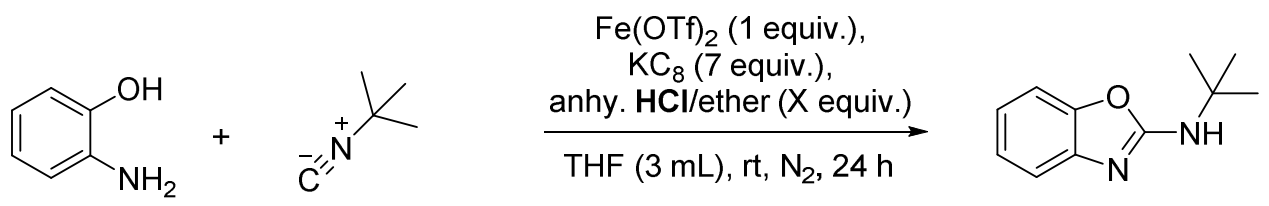

$\begin{array}{ccc}\text { Entry } & \mathrm{HCl}(\text { equiv.) } & \text { Yield }(\%)^{\mathrm{b}} \\ 1 & 7 & 0 \\ 2 & 1 & \text { trace }(<5 \%) \\ 3 & \text { none } & \text { trace }(<5 \%)\end{array}$

${ }^{a}$ Reaction conditions: 2-aminophenol $(0.05 \mathrm{mmol})$, tert-butyl isonitrile $(0.05 \mathrm{mmol}), \mathrm{Fe}(\mathrm{OTf})_{2}(0.05$ mmol), $\mathrm{KC}_{8}(0.35 \mathrm{mmol})$, THF $(3 \mathrm{~mL}), \mathrm{rt}, \mathrm{N}_{2}, 24 \mathrm{~h}, 25 \mathrm{~mL}$ round bottom flask. ${ }^{\text {b } Y i e l d ~ d e t e r m i n e d ~ b y ~ G a s ~}$ Chromatography.
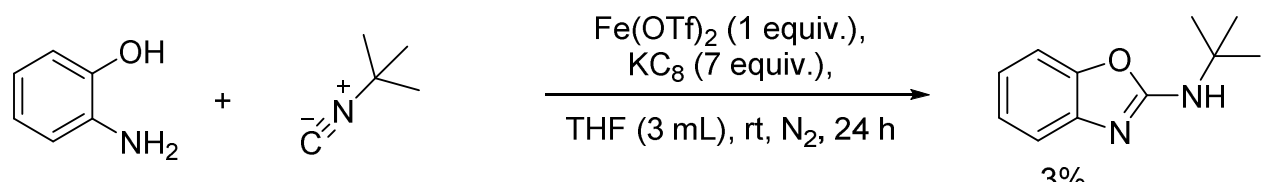

Scheme 26. Isolation of 2-amino- $N$-tert-butylbenzoxazole.

With the desired product confirmed, additional reaction conditions were screened in order to improve the yield. Several iron sources of various oxidation states were tested, although none were able to increase the amount of product formed (Table 7). Additionally, the loading of $\mathrm{Fe}(\mathrm{OTf})_{2}$ was lowered to 0.2 equivalents to test if excess iron was binding substrate and inhibiting reactivity, although no change in the product yield was observed (entry 2).

Several different alterations to the conditions were tested (Table 8). Heating the reaction to reflux or allowing the reaction to run longer did not affect the yield (entries 1-2). Increasing the isonitrile loading to 3 equivalents also did not alter the yield (entry 3). Changing the reaction concentration by lowering the volume of THF had the same result (entries 4-6). Based on the precedence for other metals to perform this coupling under oxidative conditions, $\mathrm{KC}_{8}$ was replaced with air or potassium persulfate $\left(\mathrm{K}_{2} \mathrm{~S}_{2} \mathrm{O}_{8}\right)$ (entries 7-8), ${ }^{104-109}$ however, in both cases no reaction occurred. 
Table 7. Iron screening for the coupling of 2-aminophenol and tert-butyl isonitrile ${ }^{\mathrm{a}}$

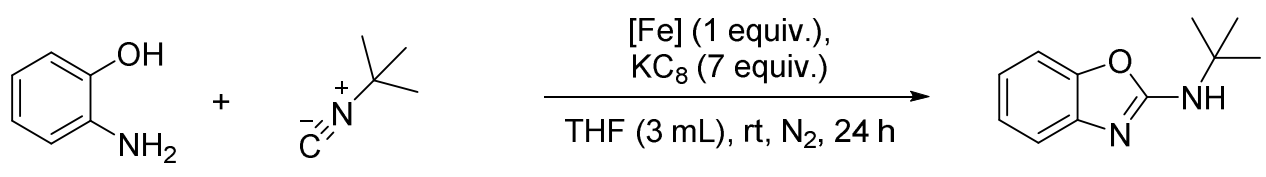

$\begin{array}{ccc}\text { Entry } & \mathrm{Fe} \mathrm{Source} & \text { Yield }(\%)^{\mathrm{b}} \\ 1 & \mathrm{Fe}(\mathrm{OTf})_{2} & \text { trace }(<5 \%) \\ 2 & \mathrm{Fe}(\mathrm{OTf})_{2}{ }^{\mathrm{c}} & \text { trace }(<5 \%) \\ 3 & \mathrm{FeCl}_{2} & \text { trace }(<5 \%) \\ 4 & \mathrm{FeSO}_{4} & \text { trace }(<5 \%) \\ 5 & \mathrm{FeCp}_{2} & \operatorname{trace~}(<5 \%) \\ 6 & \mathrm{FeCl}_{3} & \operatorname{trace~}(<5 \%) \\ 7 & \mathrm{Fe} \mathrm{powder} & \operatorname{trace~}(<5 \%)\end{array}$

${ }^{a}$ Reaction conditions unless noted otherwise: 2-aminophenol $(0.05 \mathrm{mmol})$, tert-butyl isonitrile $(0.05$ $\mathrm{mmol})$, Fe source $(0.05 \mathrm{mmol}), \mathrm{KC}_{8}(0.35 \mathrm{mmol})$, THF $(3 \mathrm{~mL}), \mathrm{rt}, \mathrm{N}_{2}, 24 \mathrm{~h}$. ${ }^{\text {b}}$ Yield determined by Gas Chromatography. ${ }^{\mathrm{c}} \mathrm{Fe}(\mathrm{OTf})_{2}(0.01 \mathrm{mmol})$.

Table 8. Condition screening for the coupling of 2-aminophenol and tert-butyl isonitrile ${ }^{\mathrm{a}}$
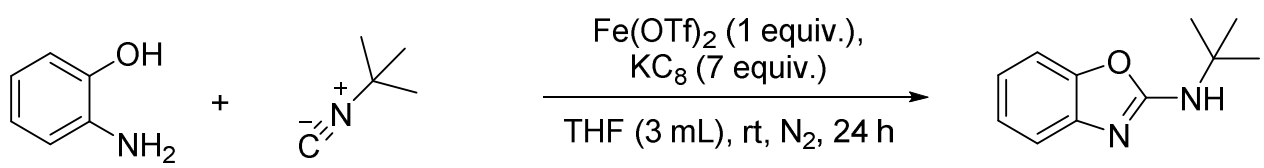

$\begin{array}{ccc}\text { Entry } & \text { Change from Standard Conditions } & \text { Yield }(\%)^{\mathrm{b}} \\ 1 & 75^{\circ} \mathrm{C} & \text { trace }(<5 \%) \\ 2 & 48 \mathrm{~h} & \text { trace }(<5 \%) \\ 3 & \mathrm{CN} t \mathrm{Bu}(3 \mathrm{equiv} .) & \text { trace }(<5 \%) \\ 4 & \mathrm{THF}(0.5 \mathrm{~mL}) & \text { trace }(<5 \%) \\ 5 & \mathrm{THF}(1 \mathrm{~mL}) & \text { trace }(<5 \%) \\ 6 & \mathrm{THF}(2 \mathrm{~mL}) & \text { trace }(<5 \%) \\ 7 & \mathrm{Air}\left(\mathrm{instead} \mathrm{of} \mathrm{KC}_{8}\right) & \text { no reaction } \\ 8 & \mathrm{~K}_{2} \mathrm{~S}_{2} \mathrm{O}_{8}\left(\text { instead of } \mathrm{KC}_{8}\right) & \text { no reaction }\end{array}$

${ }^{a}$ Reaction conditions unless noted otherwise: 2-aminophenol (0.05 mmol), tert-butyl isonitrile (0.05 mmol), $\mathrm{Fe}(\mathrm{OTf})_{2}(0.05 \mathrm{mmol}), \mathrm{KC}_{8}(0.35 \mathrm{mmol})$, THF $(3 \mathrm{~mL}), \mathrm{rt}, \mathrm{N}_{2}, 24 \mathrm{~h}, 20 \mathrm{~mL}$ vial. ${ }^{b}$ Yield determined by Gas Chromatography.

The identity and loading of the reductant were also screened in the event that $\mathrm{KC}_{8}$ was too strong of a reductant. Decreasing the loading of $\mathrm{KC}_{8}$ from 7 to 2 equivalents had no effect on the reaction (Table 9, entries 3-5), although when only 1 equivalent or no reductant was added, no reaction occurred (entries 1-2). Several other metal reductants were also tested in 2, 4, and 7 
equivalents each (entries 6-20). Elemental zinc $(\mathrm{Zn})$, copper $(\mathrm{Cu})$, iron $(\mathrm{Fe})$, manganese $(\mathrm{Mn})$, and magnesium $(\mathrm{Mg})$ all failed to produce the desired product regardless of the amount added. Cobaltocene $\left(\mathrm{Cp}_{2} \mathrm{Co}\right)$ on the other hand was found to cause a significant increase in the amount of product formed. Increasing the amount of $\mathrm{Cp}_{2} \mathrm{Co}$ from 2 to 7 equivalents resulted in an increase in the observed yield (entries 21-23). However, when iron was excluded from the reaction, no significant change was observed (entry 24). This result revealed that $\mathrm{Cp}_{2} \mathrm{Co}$ was mediating the reaction.

Table 9. Reductant screening for the coupling of 2-aminophenol and tert-butyl isonitrile ${ }^{\mathrm{a}}$

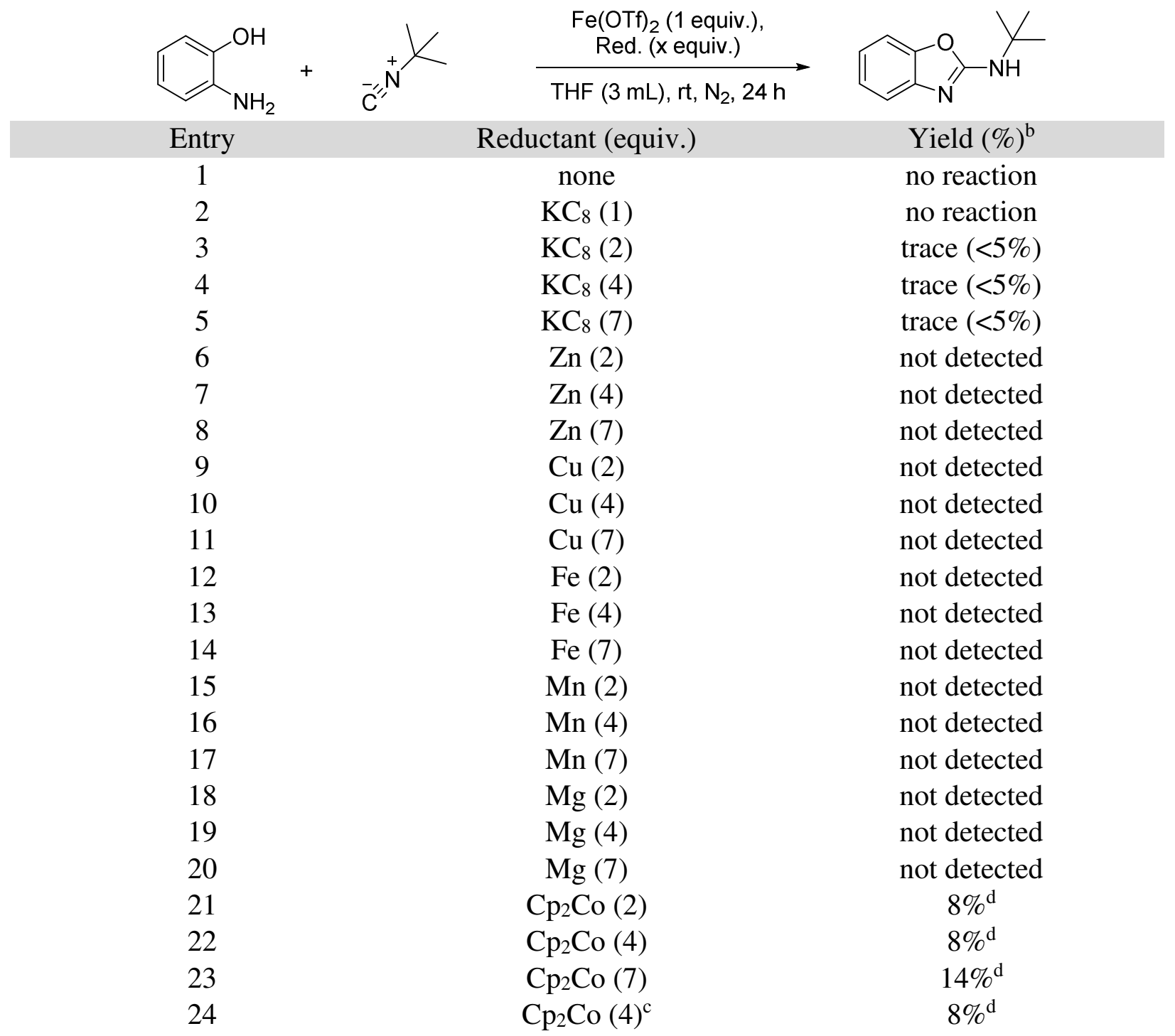

${ }^{a}$ Reaction conditions: 2-aminophenol $(0.05 \mathrm{mmol})$, tert-butyl isonitrile $(0.05 \mathrm{mmol}), \mathrm{Fe}(\mathrm{OTf})_{2}(0.05$

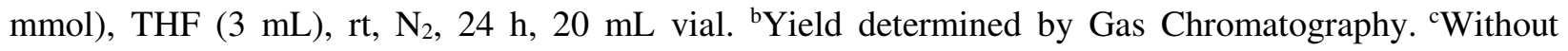
$\mathrm{Fe}(\mathrm{OTf})_{2} \cdot{ }^{\mathrm{d}}$ Uncalibrated $\mathrm{GC}$ yield. 
Additional cobalt sources were tested to determine if this reactivity is limited to $\mathrm{Cp}_{2} \mathrm{Co}$ (Table 10). Cobalt(II) acetate $\left(\mathrm{Co}(\mathrm{OAc})_{2}\right)$ and cobalt(II) carbonate $\left(\mathrm{CoCO}_{3}\right)$ were both found to mediate the coupling as well, while other sources did not perform well under these conditions. Interestingly, when the reaction using $\mathrm{Cp}_{2} \mathrm{Co}$ (entry 1) was worked up in the glovebox, the desired product was not observed by GC. However, when this sample was subsequently exposed to air, the 2-aminobenzoxazole product was detected. This demonstrates that while cobalt is performing the coupling in these reactions, a final oxidation by air is needed to form the product.

Table 10. Cobalt screening for the coupling of 2-aminophenol and tert-butyl isonitrile ${ }^{\mathrm{a}}$
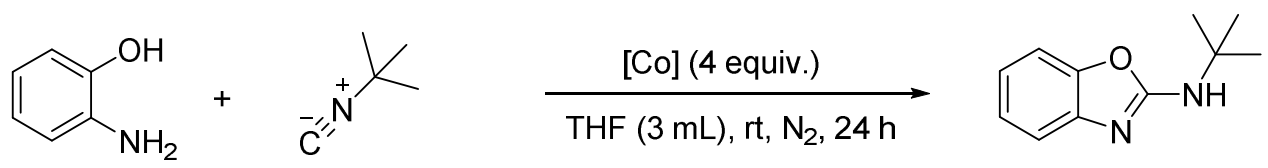

$\begin{array}{ccc}\text { Entry } & \text { Co Source } & \text { Yield }(\%)^{\mathrm{b}} \\ 1 & \mathrm{Cp}_{2} \mathrm{Co} & 8 \%^{\mathrm{c}} \\ 2 & \mathrm{Co}(\mathrm{OAc})_{2} & 23 \%^{\mathrm{c}} \\ 3 & \mathrm{CoCO}_{3} & 28 \%^{\mathrm{c}} \\ 4 & \mathrm{CoCl}_{2} & \text { trace }(<5 \%) \\ 5 & \mathrm{Co}(\mathrm{acac})_{2} & \text { not detected } \\ 6 & \mathrm{CpCo}(\mathrm{CO})_{2} & \text { not detected } \\ 7 & \mathrm{Co} \mathrm{powder} & \text { not detected }\end{array}$

${ }^{a}$ Reaction conditions: 2-aminophenol $(0.05 \mathrm{mmol})$, tert-butyl isonitrile $(0.05 \mathrm{mmol}), \mathrm{Fe}(\mathrm{OTf})_{2}(0.05$ mmol), [Co] (0.2 mmol), THF (3 mL), rt, $\mathrm{N}_{2}, 24 \mathrm{~h}, 20 \mathrm{~mL}$ vial. ${ }^{\text {b}}$ Yield determined by Gas Chromatography. ${ }^{\mathrm{c}}$ Uncalibrated GC yield.

\subsection{Oxidative Transition Metal-Catalyzed Coupling of Isonitriles and Nucleophiles}

Isonitriles are a class of substrates frequently used in multi-component coupling reactions, such as the Passerini and Ugi reactions, for the synthesis of a wide range of organic compounds. ${ }^{110-112}$ While much of these reactions are metal-free, transition metal-catalysis has allowed access to many additional transformations involving isonitriles. ${ }^{113}$ Although examples exist of isonitrile couplings mediated by a large range of transition metals, catalytic coupling with nucleophiles remains limited to only a few different metals, primarily palladium. ${ }^{114}$ The majority of the palladium catalyzed reactions developed to date are redox-neutral overall, although many reports 
of oxidative systems have emerged in the past five years. Similarly, several examples employing both cobalt and nickel as catalysts for the oxidative coupling of isonitriles with nucleophiles have recently been developed.

\subsubsection{Palladium-Catalyzed Coupling of Isonitriles and Nucleophiles}

Since the first report of isonitrile insertion by the Saegusa group in 1974 (Scheme 27), ${ }^{115}$ many different palladium-catalyzed isonitrile coupling reactions utilizing various types of nucleophiles have been developed. ${ }^{116}$
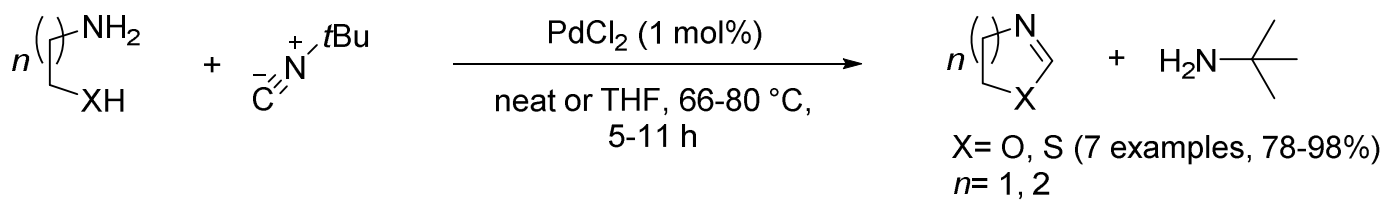

Scheme 27. Palladium-catalyzed coupling of tert-butyl isonitrile with amino alcohols and amino thiols.

Although few developments were made over the next decade, Migita's 1986 report of the coupling of isonitriles with aryl bromides and organotin reagents led the way in the development of a large array of palladium-catalyzed couplings of isonitriles with both an organohalide and a nucleophile (Scheme 28). ${ }^{117}$ Following this report, many similar tandem-coupling reactions were developed with a range of other nucleophiles, such as primarily amines, ${ }^{118,119}$ alcohols, ${ }^{120}$ and water. $^{121}$ Organohalides remain the most common type of electrophilic coupling partner employed in these redox-neutral systems. However, a handful of examples exist employing substrates that undergo a loss of $\mathrm{CO}_{2}$ or $\mathrm{N}_{2}$ upon activation by palladium, such as cyclic carbonates, ${ }^{122}$ allyl esters, ${ }^{123}$ lactones, ${ }^{124,125}$ and benzotriazinones. ${ }^{126}$ This activation step, typically occurring through an oxidative-addition by $\operatorname{Pd}(0)$, is a common requirement for initiation of the catalytic cycle (Scheme 25). Isonitrile insertion and reductive elimination can then occur sequentially to afford the final product. 

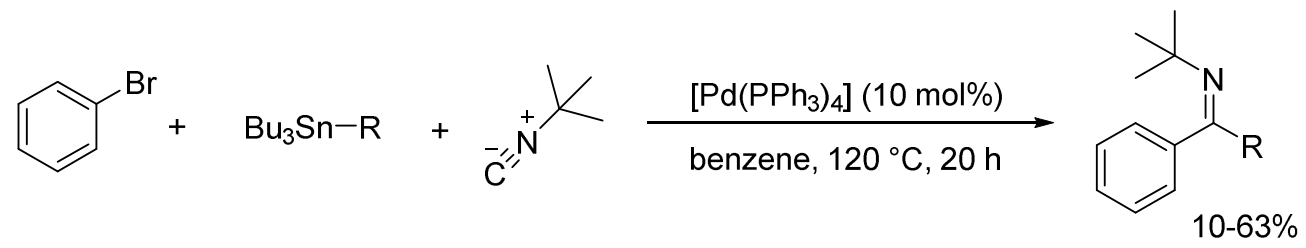

Scheme 28. Palladium-catalyzed coupling of tert-butyl isonitrile with phenyl bromide and organotin reagents.

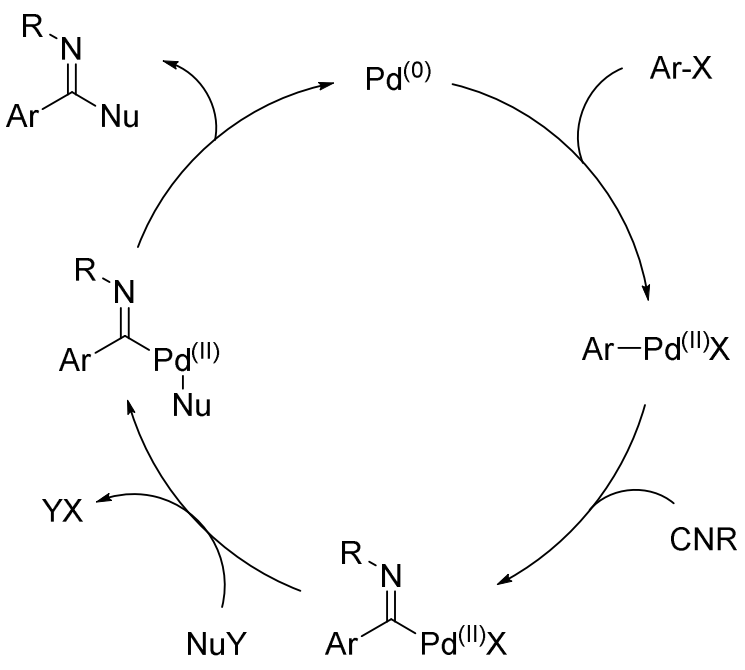

Scheme 29. Typical catalytic cycle for redox-neutral palladium-catalyzed coupling of isonitriles with an aryl halide and a nucleophile.

Alternatively, inclusion of an external oxidant has allowed for the development of more atomeconomical transformations utilizing less-functionalized coupling partners. Oxidative systems present an attractive alternative to the redox-neutral systems mentioned above due to requirement of significantly less functionalized substrates. These reactions proceed through an initial H-bond activation by a $\mathrm{Pd}(\mathrm{II})$ catalyst during the first step, while losing only protons during the course of the reaction. Although the Saegusa group first demonstrated catalytic oxidative coupling of isonitriles with primary amines to generate carbodiimides in 1975 (Scheme 30), ${ }^{127}$ reports of oxidative isonitrile insertion reactions have been scarce until very recently.

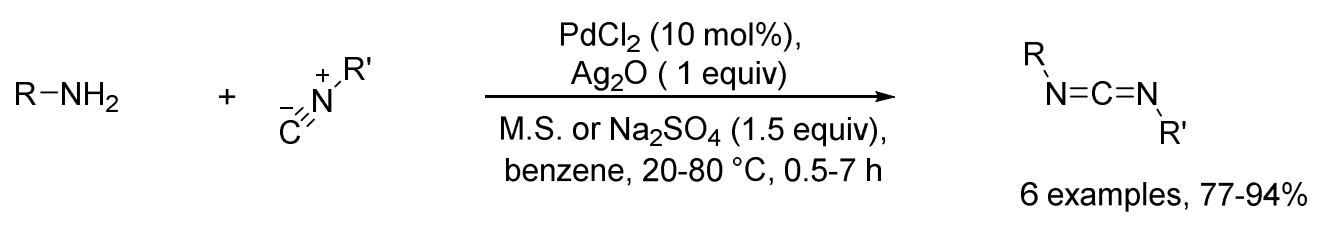

Scheme 30. Oxidative palladium-catalyzed coupling of isonitriles with amines to produce carbodiimides. 


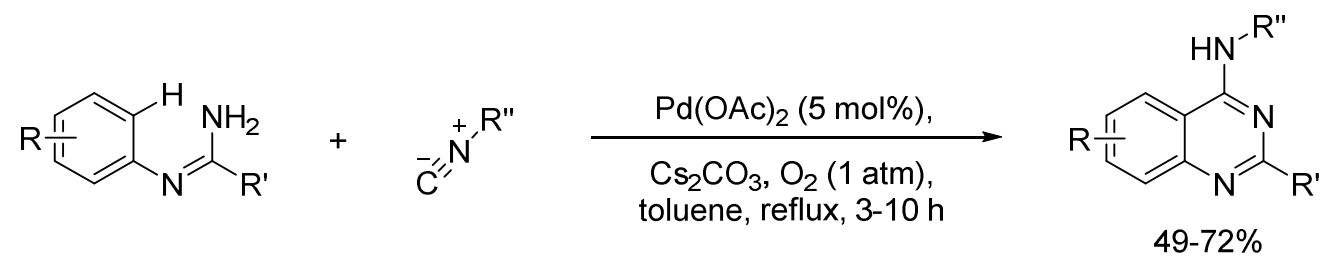

Scheme 31. Oxidative palladium-catalyzed coupling of isonitriles with $\mathrm{N}$-aryl amidines to produce 4aminoquinazolines.

Zhu's 2011 publication on the synthesis of 4-aminoquinazolines from aryl amidines was the first of several from the group involving $\mathrm{C}-\mathrm{H}$ activations as the initiating step (Scheme 31 ). ${ }^{128}$ On the other hand, Orru et al. have developed methodology proceeding through an initial N-H activation instead. ${ }^{104,105}$ This capability of palladium to insert isonitriles into an amine ligand allows for the use of bisnucleophiles as coupling partners for the synthesis of various heterocycles (Scheme 32a). Although an amino group is necessary for initiation, it was demonstrated that a wide range of nucleophilic functional groups bearing $\mathrm{NH}, \mathrm{OH}$, and $\mathrm{SH}$ moieties can be employed (Scheme $32 b)$.

a)

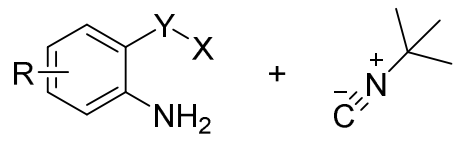
$\mathrm{X}=\mathrm{NH}, \mathrm{OH}, \mathrm{SH}$

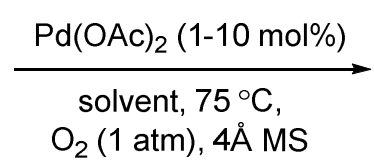

1.2 equiv

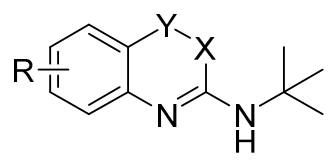<smiles>NCc1ccccc1N</smiles>

b)<smiles>Nc1ccccc1N</smiles><smiles>Nc1ccccc1C(=O)O</smiles><smiles>Nc1ccccc1S</smiles><smiles>NC(=O)c1ccccc1N</smiles><smiles>Nc1ccccc1O</smiles><smiles>Nc1ccccc1S(N)(=O)=O</smiles>

Scheme 32. (a) Palladium catalyzed coupling of isonitriles with aniline-based bisnucleophiles. (b) Selection of bisnucleophiles successfully coupled with isonitriles.

Unlike most of the aforementioned systems, coupling with a nucleophilic group is not limited to the final step (Scheme 33). Following coordination of both partners to $\operatorname{Pd}(\mathrm{II})$ (B), the isonitrile is inserted into the $\mathrm{Pd}-\mathrm{N}$ bond. Reductive elimination from intermediate $\mathbf{C}$ involving the second 
nucleophilic group then occurs, releasing heterocycle E. After tautomerization, the final product F is obtained. Finally, $\operatorname{Pd}(0)$ is oxidized back to $\operatorname{Pd}(\mathrm{II})$ by the external oxidant to turn over the cycle.
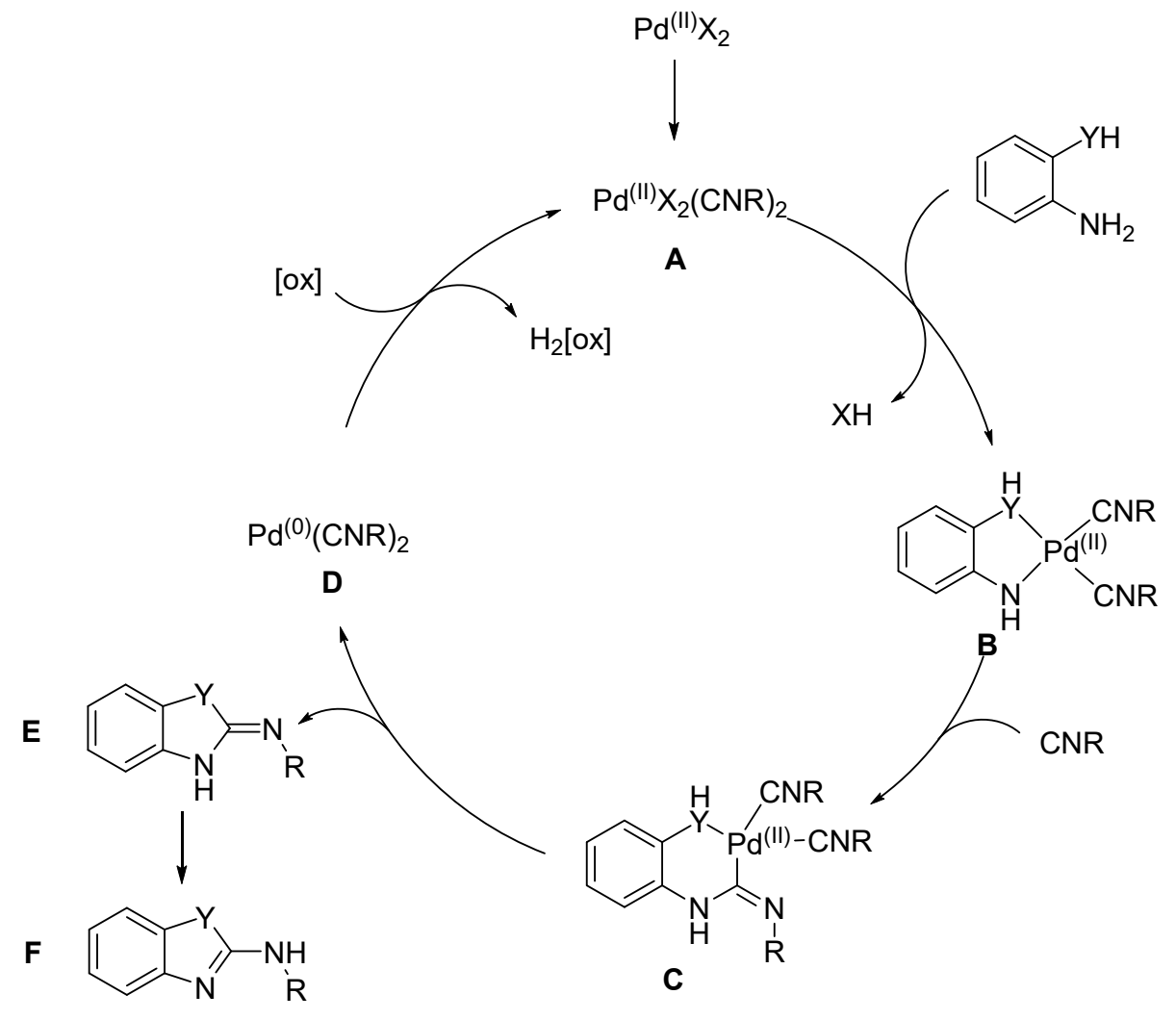

Scheme 33. Catalytic cycle for palladium-catalyzed coupling of isonitriles with bisnucleophiles.

In addition, the Jiang group showed that when using $o$-amino alcohol substrates there are multiple products accessible from this catalytic cycle. Single or tandem isonitrile insertion was found to be selective based on the choice of palladium precatalyst and isonitrile loading. Both the 2-aminobenzoxazole and 3-amino-2H-benzoxazine products were found to be optimizable to achieve excellent yields (Scheme 34). ${ }^{106}$ 
a)<smiles>[R]=[N+]=[N-]</smiles>

1.2 equiv.

b)<smiles>[R][N+]#[C-]</smiles>

2.4 equiv

$$
\underset{\text { 1,4-dioxane, rt- } 80^{\circ} \mathrm{C},}{\mathrm{Pd}\left(\mathrm{PPh}_{3}\right)_{4}(5 \mathrm{~mol} \%)}
$$$$
\text { air, 2-12 } \mathrm{h}
$$

$$
\begin{aligned}
& \underset{\text { 1,4-dioxane, } 50^{\circ} \mathrm{C},}{\stackrel{\mathrm{PdCl}_{2}(5 \mathrm{~mol} \%)}{\longrightarrow}} \\
& \text { air, } 2 \mathrm{~h}
\end{aligned}
$$

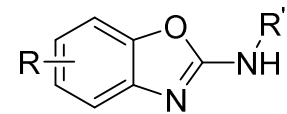

$75-96 \%$

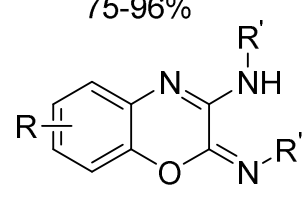

$77-97 \%$

Scheme 34. Optimized conditions for obtaining a) 2-aminobenzoxazoles and b) 3-amino-2 $\mathrm{H}$ benzoxazines.

\subsubsection{Oxidative First-Row Transition Metal-Catalyzed Coupling of Isonitriles with Bisnucleophiles}

Despite the propensity for palladium to perform isonitrile insertion reactions, it is desirable to develop methodology involving first row transition metals due to their lower costs and their potential for accessing additional transformations that are incompatible with palladium systems. Currently, there are only a handful of examples of first row transition metals performing coupling reactions with isonitriles. Of those, only cobalt and nickel have been shown to be competent catalysts for the coupling of isonitriles with nucleophiles. Over recent years, the Ji group has been at the forefront of cobalt-catalyzed isonitrile coupling reactions with several publications involving a range of amine nucleophiles. In their initial work on the subject published in 2013, aniline-based bisnucleophiles were selected including $o$-aminoanilines, $o$ aminophenols, and $o$-aminobenzenethiols (Scheme 35a). ${ }^{129}$ Cobalt(II) acetate tetrahydrate $\left(\mathrm{Co}(\mathrm{OAc})_{2} \cdot 4 \mathrm{H}_{2} \mathrm{O}\right)$ was found to be the best precatalyst when paired with potassium persulfate $\left(\mathrm{K}_{2} \mathrm{~S}_{2} \mathrm{O}_{8}\right)$ as the oxidant. These substrates coupled with isonitriles to produce 2aminobenzimidazoles, 2-aminobenzoxazoles, and 2-aminobenzthiazoles, respectively, in moderate to good yields. In addition, they reported ultrasound conditions using cobalt(II) acetylacetonate $\left(\mathrm{Co}(\mathrm{acac})_{2}\right)$ as the precatalyst for the same transformation, although yields were at best the same as the previous conditions, if not worse (Scheme 35b). ${ }^{130}$ 
a)

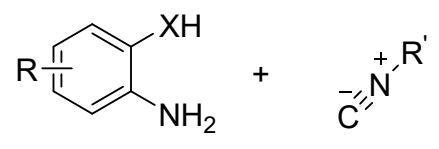

1.2 equiv.

b)

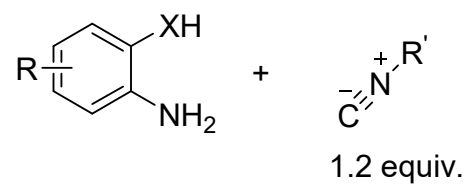

$\mathrm{X}=\mathrm{O}, \mathrm{S}, \mathrm{NR} "$
$\mathrm{Co}(\mathrm{OAc})_{2} \cdot 4 \mathrm{H}_{2} \mathrm{O}(10 \mathrm{~mol} \%)$, $\mathrm{NaOAc}$ (2 equiv.), $\mathrm{K}_{2} \mathrm{~S}_{2} \mathrm{O}_{8}$ (1 equiv.) 1,4-dioxane, $100^{\circ} \mathrm{C}, 18 \mathrm{~h}$<smiles>[R]NC1=[R1]([X])C=CC2=CC=[N+]C2=N1</smiles>

O: $67-95 \%$ (11 examples) S: $45-90 \%$ (7 examples)

$\mathrm{N}: 45-91 \%$ (13 examples)

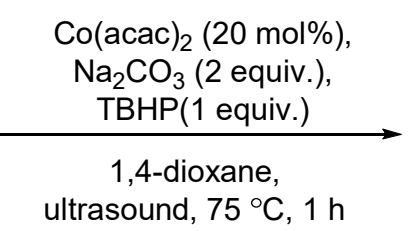

O: $25-84 \%$ (11 examples) S: $72-87 \%$ (2 examples) N: $69-89 \%$ (2 examples)

Scheme 35. Cobalt-catalyzed coupling of isonitriles with aniline-based bisnucleophiles. (a) Initial conditions using $\mathrm{Co}(\mathrm{OAc})_{2} \cdot 4 \mathrm{H}_{2} \mathrm{O}$ as the precatalyst. (b) Ultrasound conditions using $\mathrm{Co}(\mathrm{acac})_{2}$.

At the same time, the Ji group also developed a nickel-catalyzed system promoting the coupling of isonitriles and bisnucleophiles (Scheme 36a). ${ }^{131}$ Using the same selection of substrates as the cobalt system, nickel was shown to be capable of coupling the partners to generate the same benzazole derivatives. While the reactivity of many of the pairs was equally effective as with cobalt, overall performance of nickel was worse, especially with thiol-containing substrates. However, cyclization with the bisnucleophile 2-aminobenzyl alcohol to generate a 2aminobenzoxazine was shown to be successful (Scheme 36b).

a)<smiles>[R][X]=[N+]=[Ni]</smiles>
1.2 equiv $\mathrm{X}=\mathrm{O}, \mathrm{S}, \mathrm{NR} "$

b)<smiles>Nc1ccccc1CO</smiles>
1.2 equiv

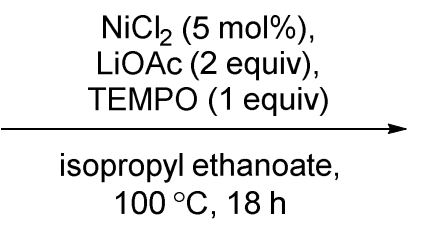

$\mathrm{NiCl}_{2}(5 \mathrm{~mol} \%)$,

$\mathrm{LiOAc}$ (2 equiv), TEMPO (1 equiv)

isopropyl ethanoate, $100^{\circ} \mathrm{C}, 18 \mathrm{~h}$<smiles>[R]Nc1[X]c2c[nH]ccc-2n1</smiles>

O: $30-95 \%$ (11 examples) S: $39-65 \%$ (4 examples) N: $80-89 \%$ (3 examples)<smiles>CC(C)(C)NC1=Nc2ccccc2CO1</smiles>

Scheme 36. Nickel-catalyzed coupling of isonitriles with aniline-based bisnucleophiles. (a) Coupling to produce various benzazole products. (b) Coupling of tert-butyl isonitrile with 2-aminobenzyl alcohol to form the corresponding benzoxazine product. 
Despite mediating the same overall transformations, the proposed mechanisms for the cobaltand nickel-catalyzed transformations are quite different. Nickel is thought to proceed through a catalytic cycle analogous to that of palladium, with coupling occurring through successive isonitrile insertion and reductive elimination steps (Scheme 29). However, the pathway for cobalt-catalyzed coupling is believed to involve an organoradical species and an off-cycle coupling with the second nucleophile to complete the reaction (Scheme 37). It is not yet known exactly how the initial coupling is performed, although it is likely that it proceeds through either a migratory insertion of the isonitrile into the amine (Path I), or through nucleophilic attack by the amine on a coordinated isonitrile (Path II). Either pathway would result in Co-carbene intermediate $\mathbf{B}$, which is proposed to undergo homlytic cleavage of the Co-carbene bond to release radical species D. A subsequent single-electron transfer then occurs to oxidize the radical, forming an amino methylidyneaminium intermediate $(\mathbf{E})$ that can be trapped by attack of the second nucleophile.

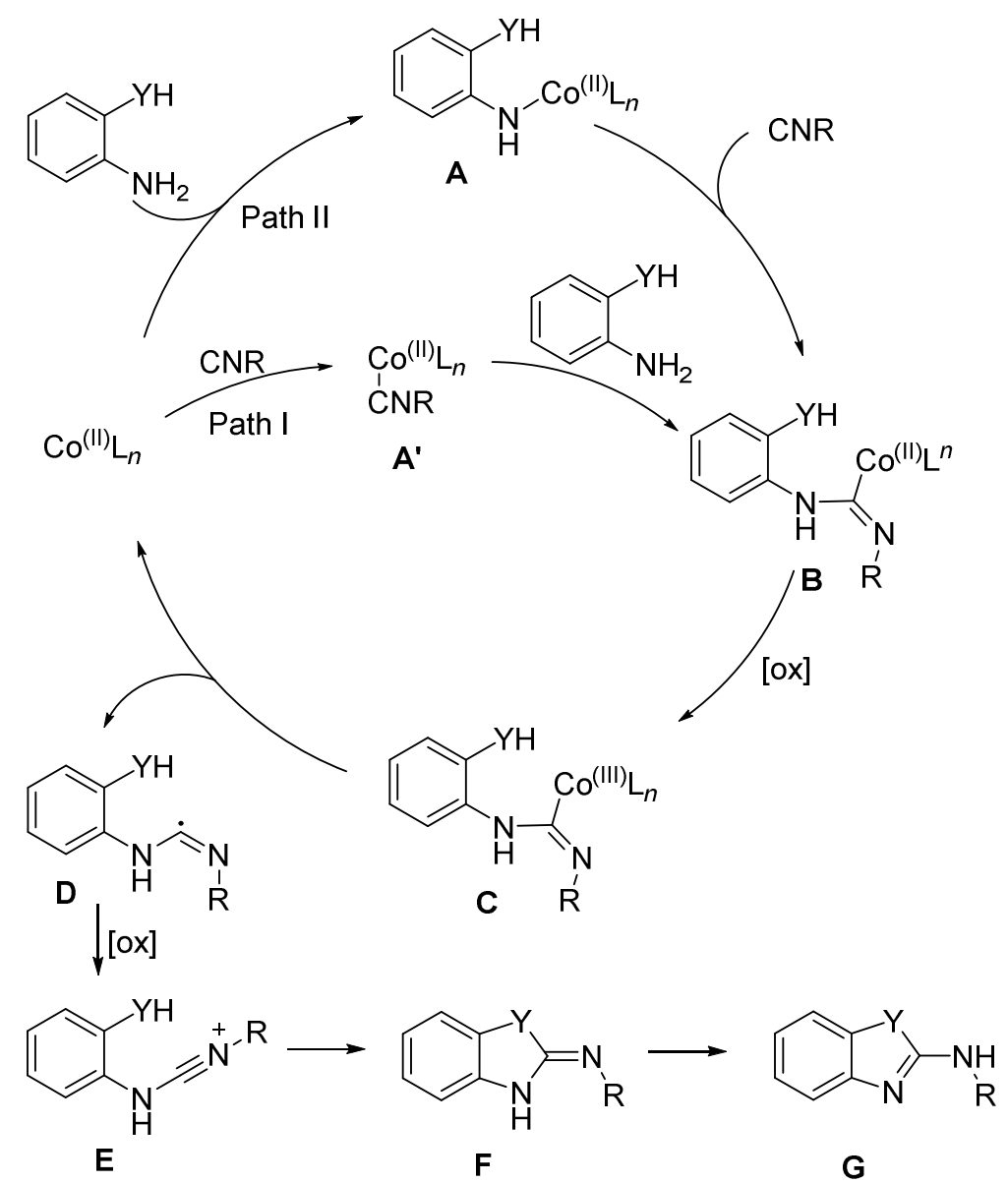

Scheme 37. Proposed mechanistic pathways for the cobalt-catalyzed coupling of isonitriles with anilinebased bisnucleophiles. 
In addition to the substrates discussed above, the Ji group was able to extend the scope of nucleophilic coupling partners for isonitriles under their ultrasound conditions to mixed-mononucleophile pairs (Scheme 38). ${ }^{130,132}$ By pairing an isonitrile with an aniline and a second nucleophile, mixed ureas were obtained using an aqueous reaction solution (Scheme 38a), mixed thioureas were generated from elemental sulfur (Scheme 38b), and guanidines were synthesized with the inclusion of a second amine (Scheme 38c).

a)

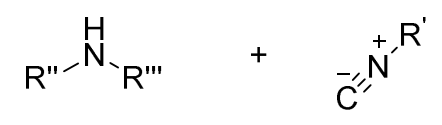

$$
\mathrm{R}^{\prime \prime}=\text { Alkyl, Aryl }
$$$$
\mathrm{R}^{\prime \prime}=\mathrm{H}, \text { Alkyl }
$$

b)

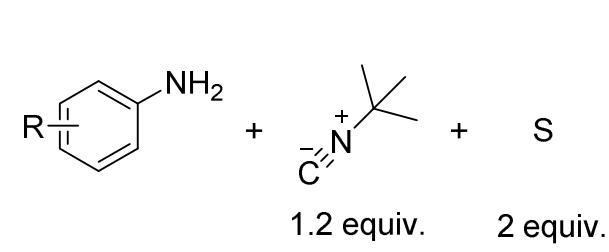

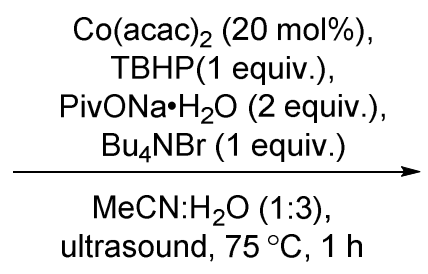

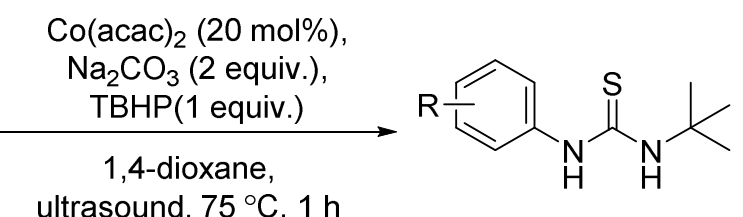

ultrasound, $75^{\circ} \mathrm{C}, 1 \mathrm{~h}$<smiles>[R]NC(=O)N([R7])[R]</smiles>

c)

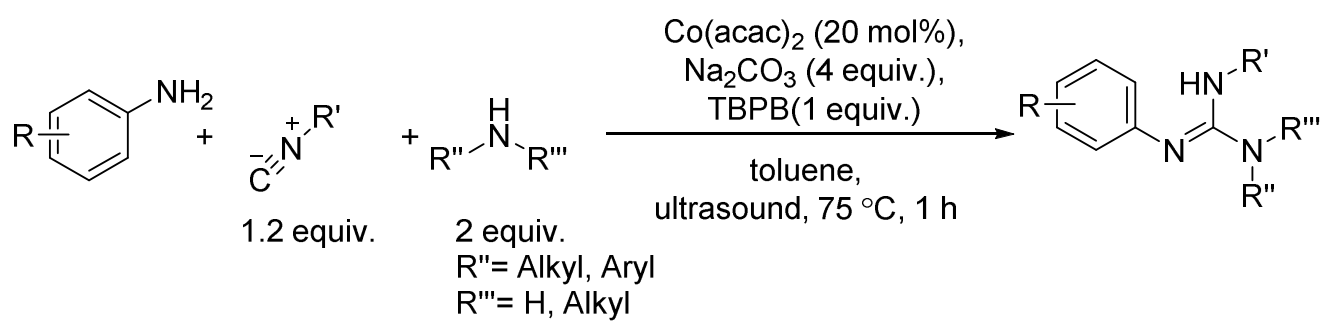

Scheme 38. Cobalt-catalyzed coupling of isonitriles with amines under ultrasound irradiation. (a) Synthesis of ureas from primary and secondary amines and water. (b) Synthesis of thioureas from primary anilines and elemental sulfur. (c) Synthesis of guanidines from a primary aniline and an amine. 


\subsubsection{Project Objectives}

Discovering that cobaltocene is much more competent than iron at coupling isonitriles with 2aminophenol to form 2-aminobenzoxazoles prompted us to switch our focus from investigating iron to cobalt for related reactions. The precedence for cobalt performing this reaction under oxidative conditions, discussed in the previous section, ${ }^{129,130}$ demonstrated the viability of cobalt for performing similar couplings of isonitriles with bisnucleophiles. However, only a few different classes of bisnucleophiles have been reported to be compatible with cobalt so far. ${ }^{104-106}$ While a broad range of substrates have been demonstrated to be compatible with the palladiumcatalyzed reaction, cobalt could prove to access different substrates or transformations due to the differences in reaction mechanisms. Considering that exposure to air was required for the previously mentioned cobaltocene reactions to complete the formation of 2-aminobenzoxazole, our goal became to develop new cobalt-catalyzed coupling reactions of isonitriles with a broad range of bisnucleophiles under oxidative conditions (Scheme 39).
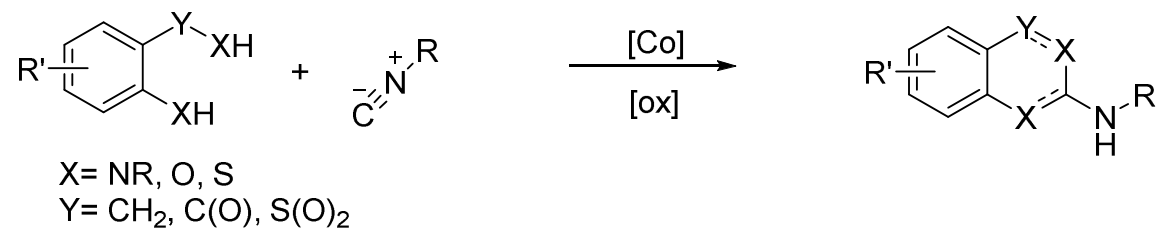

Scheme 39. Goal for the optimization of the coupling between isonitriles and 2-aminobenzylamines to produces 2-aminoquinazolines.

\subsubsection{Results and Discussion}

The results establishing that cobalt(II) salts are capable of mediating the coupling of tert-butyl isonitrile and 2-aminophenol without an external reductant demonstrates that cobalt is much more promising than iron for promoting the coupling of isonitriles with bisnucleophiles in general. Since the coupling of 2-aminophenol and similar ortho-substituted anilines with isonitriles has already been reported with cobalt under oxidative conditions by the Ji group (Chapter 2.1.2.2.), ${ }^{129,130,132}$ our focus is on expanding the reactivity to include additional classes 
of bisnucleophiles. Several substrates were selected for screening for reactivity with $\mathrm{Co}(\mathrm{OAc})_{2}$ using air as an oxidant (Scheme 40). Of these, only 2-aminobenzylamine was found to form the desired heterocycle, 2-amino- $N$-tert-butylquinazoline, under these conditions.

(a)

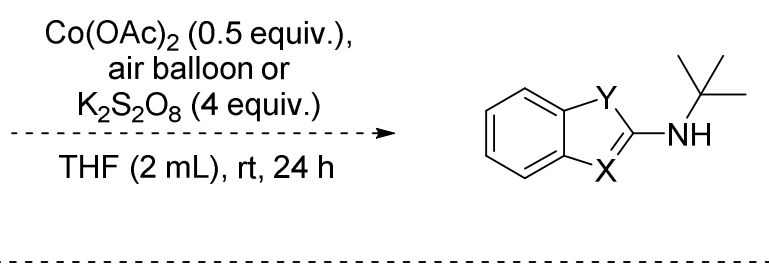

(b)<smiles>NCc1ccccc1N</smiles><smiles>NC(=O)c1ccccc1N</smiles><smiles>Nc1ccccc1CO</smiles><smiles>Nc1ccccc1C(=O)O</smiles><smiles>Oc1ccccc1O</smiles>

Scheme 40. (a) Reaction conditions for screening the coupling of bisnucleophiles with tert-butyl isonitrile mediated by cobalt under oxidative conditions. (b) Substrates screened.

Heterocyclic groups are commonly found in biologically active compounds, including a large range of pharmaceuticals containing a quinazoline moiety. Furthermore, several marketed drugs feature a 2-amino-substituted quinazoline. ${ }^{133}$ These include Alfuzosin and Bunazosin, which are used to treat benign prostatic hyperplasia, and Prazosin, used to treat high blood pressure (Figure $14)$.

Figure 14. Currently marketed drugs containing a 2-aminoqunazoline moiety.<smiles>COc1cc2nc(N(C)CCCCC(=O)C3CCCO3)nc(N)c2cc1OC</smiles>

Alfuzosin<smiles>COc1cc2nc(N3CCN(C(=O)c4ccco4)CC3)nc(N)c2cc1OC</smiles><smiles>CCCC(=O)N1CCCN(c2nc(N)c3cc(OC)c(OC)cc3n2)CC1</smiles>

Bunazosin 
The cobalt source and oxidant were further investigated for the coupling reaction of tert-butyl isonitrile and 2-aminobenzylamine (Table 11). Cobalt(II) acetylacetonate $\left(\mathrm{Co}(\mathrm{acac})_{2}\right), \mathrm{CoCO}_{3}$, and cobalt(II) chloride $\left(\mathrm{CoCl}_{2}\right)$ were all found to be capable of mediating the reaction, although none were as effective as $\mathrm{Co}(\mathrm{OAc})_{2}$ regardless of the cobalt loading or the oxidant choice. While air and $\mathrm{K}_{2} \mathrm{~S}_{2} \mathrm{O}_{8}$ both promoted the reaction, air was shown to be the better of the two oxidants with each cobalt salt. When the loading of $\mathrm{Co}(\mathrm{OAc})_{2}$ was lowered to $10 \mathrm{~mol} \%$, the yield increased, demonstrating catalytic activity (entry 2). Additional time was allowed for the reaction in case 24 hours is not long enough (entry 3). This resulted in an increase in yield of the quinazoline product up to $96 \%$. However, more recent reactions have failed to reproduce these yields, resulting in yields below $30 \%$ (Table 16, Apendix A).

Table 11. Cobalt and oxidant screening for the coupling of 2-aminobenzylamine and tert-butyl isonitrile ${ }^{\mathrm{a}}$

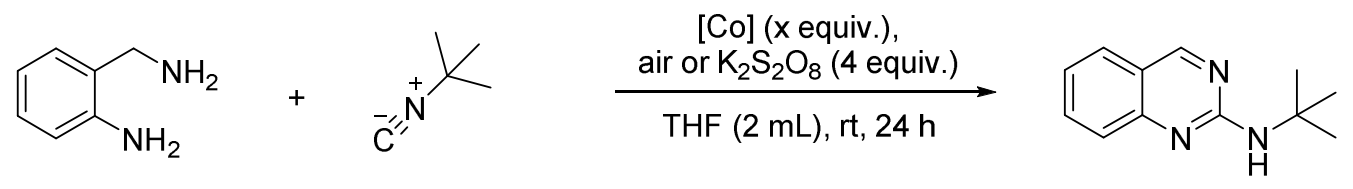

$\begin{array}{ccccc}\text { Entry } & \text { Co Source } & \text { Co equiv. } & \text { Oxidant } & \text { Yield }(\%)^{\mathrm{b}} \\ 1 & \mathrm{Co}(\mathrm{OAc})_{2} & 0.5 & \text { air } & 52 \\ 2 & & 0.1 & \text { air } & 63^{\mathrm{c}} \\ 3^{\mathrm{d}} & & 0.1 & \text { air } & 94^{\mathrm{e}} \\ 4 & & 0.5 & \mathrm{~K}_{2} \mathrm{~S}_{2} \mathrm{O}_{8} & 20 \\ 5 & \mathrm{Co}(\mathrm{acac})_{2} & 0.5 & \text { air } & 40 \\ 6 & & 0.1 & \text { air } & 18 \\ 7 & & 0.5 & \mathrm{~K}_{2} \mathrm{~S}_{2} \mathrm{O}_{8} & 40 \\ 8 & \mathrm{CoCO}_{3} & 0.5 & \text { air } & 7 \\ 9 & & 0.1 & \text { air } & 1 \\ 10 & & 0.5 & \mathrm{~K}_{2} \mathrm{~S}_{2} \mathrm{O}_{8} & \text { not detected } \\ 11 & \mathrm{CoCl}_{2} & 0.5 & \text { air } & 16 \\ 12 & & 0.1 & \text { air } & 40 \\ 13 & & 0.5 & \mathrm{~K}_{2} \mathrm{~S}_{2} \mathrm{O}_{8} & 15\end{array}$

${ }^{a}$ Reaction conditions: 2-aminobenzylamine $(0.2 \mathrm{mmol})$, tert-butyl isonitrile $(0.2 \mathrm{mmol})$, [Co] (x mmol),

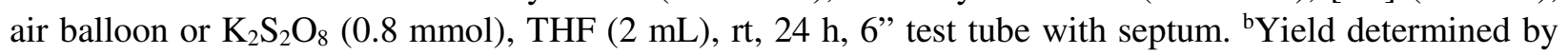
${ }^{1} \mathrm{H}$ NMR spectroscopy with dimethyl sulfone as the internal standard. ${ }^{\mathrm{c}}$ Average of 3 reactions ${ }^{\mathrm{d}} 72$ hours. ${ }^{\mathrm{e}}$ Average of 2 reactions. 
The temperature of the reaction was elevated to $75{ }^{\circ} \mathrm{C}$ in order to decrease reaction time (Table 12), however, only trace product was observed in the crude reaction mixture and the overall mass balance was poor (entry 2). Performing the reaction in a $25 \mathrm{~mL}$ round bottom flask with a reflux condenser as opposed to a 6-inch test tube did not influence the yield (entry 3). Conversely, running the reaction in a pressure tube resulted in moderate yields, although still lower than those obtained when the reaction is conducted at room temperature (entry 4). These results gave rise to the hypothesis that $\mathrm{CN} t \mathrm{Bu}$ is being lost under reflux conditions due to its low boiling point ( $\mathrm{bp}=$ $\left.91^{\circ} \mathrm{C}\right)$. This does not seem to be the case, as $\mathrm{CNCy}\left(\mathrm{bp}=173{ }^{\circ} \mathrm{C}\right)$ also gave only trace yields under reflux (entry 5). Additionally, no decomposition occurred when submitting the product to the reaction conditions in place of 2-aminobenzylamine.

Table 12. Temperature screening for coupling of 2-aminobenzylamine and tert-butyl isonitrile ${ }^{\mathrm{a}}$

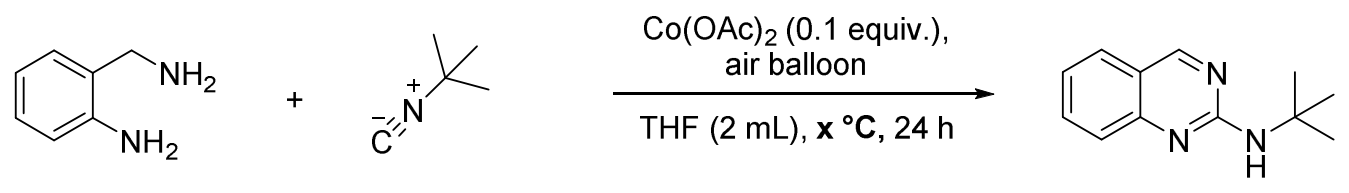

$\begin{array}{ccc}\text { Entry } & \text { Temperature }\left(^{\circ}\right) & \text { Yield }(\%)^{\mathrm{b}} \\ 1 & \mathrm{rt} & 63 \\ 2 & 75 & \text { trace }(<5 \%) \\ 3 & 75^{\mathrm{c}} & \text { trace }(<5 \%) \\ 4 & 75^{\mathrm{d}} & 60 \\ 5 & 75^{\mathrm{e}} & \text { trace }(<5 \%) \\ 6^{\mathrm{f}} & 75 & \text { no reaction }\end{array}$

${ }^{a}$ Reaction conditions: 2 -aminobenzylamine $(0.2 \mathrm{mmol})$, tert-butyl isonitrile $(0.2 \mathrm{mmol}), \mathrm{Co}(\mathrm{OAc})_{2}(0.02$ mmol), air balloon, THF $(2 \mathrm{~mL}), \mathbf{x}{ }^{\circ} \mathbf{C}, 24 \mathrm{~h}, 6$ " test tube with septum. ${ }^{\text {b} Y i e l d ~ d e t e r m i n e d ~ b y ~}{ }^{1} \mathrm{H}$ NMR spectroscopy with dimethyl sulfone as the internal standard. ${ }^{~}$ Reaction performed in a $25 \mathrm{~mL}$ round bottom flask with a reflux condenser. ${ }^{\mathrm{d}}$ Reaction performed in a $9 \mathrm{~mL}$ pressure tube. ${ }^{\mathrm{e}} \mathrm{CNCy}$ was used in place of $\mathrm{CNtBu}$. ${ }^{\mathrm{f}}$-amino- $\mathrm{N}$-tert-butylquinazoline was added in place of 2-aminobenzylamine.

Other isonitriles have been screened for the coupling with 2-aminobenzylamine at room temperature (Table 13). Alkyl isonitriles such as cyclohexyl and adamantyl gave yields of $31 \%$ and 25\% after 24 hours, respectively. Aryl isonitriles such as 2,6-dimethyl isonitrile and 4methoxy isonitrile produced even lower yields. While benzyl isonitrile reacted, no quinazoline product was discernible from the crude reaction mixture. These preliminary results suggest that tert-butyl isonitrile is the most reactive of the isonitriles investigated so far. 
Table 13. Isonitrile screening for the coupling with 2-aminobenzylamine ${ }^{a}$

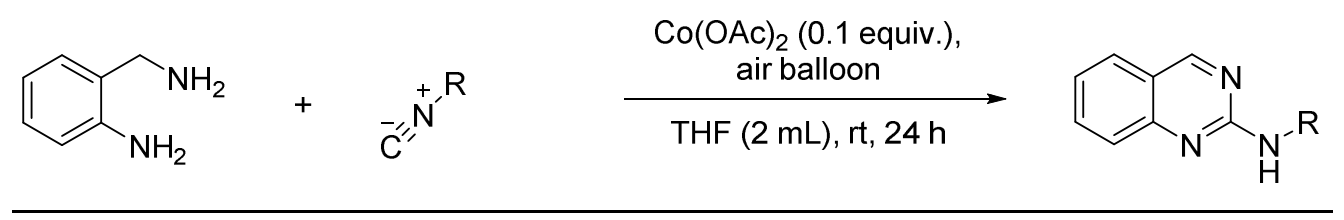<smiles>c1ccc2nc(NC3CCCCC3)ncc2c1</smiles>

$31 \%$

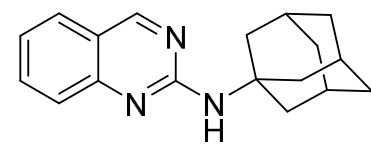

$25 \%$<smiles>c1ccc(CNc2ncc3ccccc3n2)cc1</smiles>

not detected<smiles>Cc1cccc(C)c1Nc1ncc2ccccc2n1</smiles>

$17 \%$<smiles>COc1ccc(Nc2ncc3ccccc3n2)cc1</smiles>

$21 \%$

aReaction conditions: 2-aminobenzylamine ( $0.2 \mathrm{mmol})$, isonitrile $(0.2 \mathrm{mmol}), \mathrm{Co}(\mathrm{OAc})_{2}(0.02 \mathrm{mmol})$, air balloon, THF ( $2 \mathrm{~mL}), \mathrm{rt}, 24 \mathrm{~h}, 6$ " test tube with septum. Yields determined by ${ }^{1} \mathrm{H}$ NMR spectroscopy with dimethyl sulfone as the internal standard.

Table 14. Projected scope of isonitriles to be investigated ${ }^{a}$<smiles>CC(C)(C)Nc1ncc2ccccc2n1</smiles><smiles>CCCCCNc1ncc2ccccc2n1</smiles><smiles>c1ccc(CNc2ncc3ccccc3n2)cc1</smiles><smiles>Cc1cccc(C)c1Nc1ncc2ccccc2n1</smiles><smiles>CC(C)Nc1ncc2ccccc2n1</smiles><smiles>CC(C)(C)CC(C)(C)Nc1ncc2ccccc2n1</smiles><smiles>c1ccc2nc(NCCN3CCOCC3)ncc2c1</smiles><smiles>COc1ccc(Nc2ncc3ccccc3n2)cc1</smiles><smiles>c1ccc2nc(NC3CCCCC3)ncc2c1</smiles><smiles>c1ccc2nc(NC34CC5CC(CC(C5)C3)C4)ncc2c1</smiles><smiles>CCOC(=O)CNc1ncc2ccccc2n1</smiles><smiles>Fc1ccc(Nc2ncc3ccccc3n2)cc1</smiles>

A range of additional isonitriles, including both alkyl and aryl substrates, will be investigated as well (Table 14). Additionally, substituted 2-aminobenzylamines are not commercially available and will be prepared for use in coupling with isonitriles. Reduction of 2-aminobenzonitriles 
using borane-tetrahydrofuran adduct $\left(\mathrm{BH}_{3} \cdot \mathrm{THF}\right)$ has been reported for the synthesis of various 2aminobenzylamines (Scheme 41). ${ }^{134}$
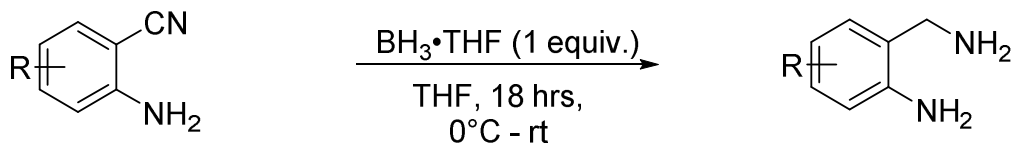

Scheme 41. Reduction of 2-aminobenzonitriles to 2-aminobenzylamines.

A range of functional groups and substitution patterns will be prepared (Table 15). Methylsubstituted substrates at the 3,4, 5, and 6 positions will all be obtained. Also, substrates containing various functional groups in the para-position to the amino group will be employed, such as halogens, nitro, and methoxy. $N$-methyl and $\alpha$-methyl substituted substrates will be investigated as well.

Table 15. Projected scope of 2-aminobenzylamines to be investigated ${ }^{\mathrm{a}}$<smiles>Cc1cccc2cnc(NC(C)(C)C)nc12</smiles><smiles>Cc1ccc2cnc(NC(C)(C)C)nc2c1</smiles><smiles>Cc1ccc2nc(NC(C)(C)C)ncc2c1</smiles><smiles>Cc1cccc2nc(NC(C)(C)C)ncc12</smiles><smiles>CC(C)(C)Nc1ncc2cc(Cl)ccc2n1</smiles><smiles>COc1ccc2nc(NC(C)(C)C)ncc2c1</smiles><smiles>CC(C)(C)Nc1ncc2cc(C(F)(F)F)ccc2n1</smiles><smiles>CC(C)(C)Nc1ncc2cc(Br)ccc2n1</smiles><smiles>CC(C)(C)Nc1ncc2cc(F)ccc2n1</smiles><smiles>CC(C)(C)Nc1ncc2cc([N+](=O)[O-])ccc2n1</smiles><smiles>Cn1c(=NC(C)(C)C)ncc2ccccc21</smiles><smiles>Cc1nc(NC(C)(C)C)nc2ccccc12</smiles>

\subsection{Conclusions}

The coupling of tert-butyl isonitrile with 2-aminophenol mediated by iron to for 2-amino- $N$-tertbutylbenzoxazole under reductive conditions was found to be successful, although only trace yields could be obtained. However, cobaltocene was found to be much more effective at 
performing this reaction while screening reductants. Furthermore, exposure to air was discovered to be required for the completion of the transformation, demonstrating the impracticality of the use of a reductant.

Oxidative cobalt-catalyzed coupling of isonitriles with 2-aminobenzylamine to form 2aminoquinazolines was also found to be successful. While optimization is ongoing, there is much promise for the success of this reaction. Ultimately, a series of both coupling partners will be studied in order to synthesize a wide range of 2-aminoquinazolines. Future investigations within the group will focus on expanding the scope of bisnucleophiles tolerated by cobalt for the coupling with isonitriles. It is believed that not only can the scope of substrates be expanded, but that there is also the possibility of accessing substrates and/or transformations not tolerated by palladium or nickel. 


\section{Experimental Procedures}

\subsection{General Information}

Unless stated otherwise, reagents were used as received from commercial suppliers. All reactions were carried out using standard Schlenk or glovebox techniques under an atmosphere of dinitrogen. Solvents were dried in a Pure Process Technology Glass Contour solvent purification system or used as received from commercial vendors. Deuterated solvents were purchased from Cambridge Isotopes Laboratories, Inc. Column chromatography was performed using Silicycle Silia Flash P60 silica gel. ${ }^{1} \mathrm{H},{ }^{13} \mathrm{C},{ }^{19} \mathrm{~F}$, and ${ }^{51} \mathrm{~V}$ spectra were obtained at room temperature on Varian $400 \mathrm{MHz}$ and $600 \mathrm{MHz}$ spectrometers. ${ }^{1} \mathrm{H}$ and ${ }^{13} \mathrm{C}$ spectra were referenced to residual solvent resonances. Chemical shifts $(\delta)$ are given in ppm and coupling constants $(J)$ are given in hertz $(\mathrm{Hz})$. Resonances are described as s (singlet), br (broad singlet), d (doublet), t (triplet), dt (doublet of triplet), td (triplet of doublet), and m (multiplet). ESI-MS data were collected using an Ion Trap LCQ DECA XP spectrometer. GC analysis was performed using a Shimadzu GC2014 instrument with a Crossbond ${ }^{\mathrm{TM}}$ 5\% diphenyl / 95\% dimethyl polysiloxane column and a flame ionization detector. Elemental analyses were performed by Atlanta Microlab, Inc. X-ray diffraction data were collected on a Bruker AXS D8 Venture single crystal X-ray diffractometer. The data were processed using the ORTEP-3 software.

\subsection{Procedures for $\mathrm{NaTm}^{\mathrm{R}}$ Synthesis}

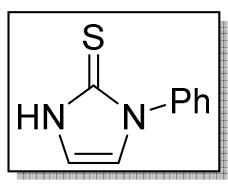

Synthesis of N-phenylimidazole-2-thione: A $50 \mathrm{~mL}$ round bottom flask was charged with phenyl isothiocyanate $(2.03 \mathrm{~g}, 15.0 \mathrm{mmol})$ and aminoacetaldehyde diethyl acetal $(2.00 \mathrm{~g}, 15.0 \mathrm{mmol})$. EtOH $(20 \mathrm{~mL})$ was added and the mixture was stirred for 2 hours at room temperature. After this time the solvent was removed by rotary evaporation, and $10 \%$ aqueous $\mathrm{HCl}(20 \mathrm{~mL})$ was added to the reaction flask. A reflux condenser was attached to the flask and the reaction was heated to reflux in an oil bath for 2 hours. The flask was allowed to cool to room temperature and then was placed in an ice bath to encourage complete precipitation of the 
product. The product was collected via filtration using a Büchner funnel and washed with cool methanol (3 mL), providing a white powder $(2.24 \mathrm{~g}, 12.7 \mathrm{mmol}, 84.7 \%)$ without any additional purification needed.

${ }^{1} \mathrm{H}$ NMR $\left(\mathrm{CD}_{3} \mathrm{CN}, 400 \mathrm{MHz}\right): \delta=10.38(\mathrm{br}, 1 \mathrm{H}), 7.60(\mathrm{dt}, J=8.0 \mathrm{~Hz}, 2.0 \mathrm{~Hz}, 2 \mathrm{H}), 7.50(\mathrm{td}, J=$ $7.2 \mathrm{~Hz}, 2.0 \mathrm{~Hz}, 2 \mathrm{H}), 7.43$ (td, $J=7.2 \mathrm{~Hz}, 2.0 \mathrm{~Hz}, 1 \mathrm{H}), 7.00$ (d, $J=2.4 \mathrm{~Hz}, 1 \mathrm{H}), 6.88$ (d, $J=2.4$ $\mathrm{Hz}, 1 \mathrm{H}) \mathrm{ppm} .{ }^{13} \mathrm{C}$ NMR $\left(\mathrm{CD}_{3} \mathrm{CN}, 100 \mathrm{MHz}\right): \delta=138.2(\mathrm{C}), 128.8(\mathrm{CH}), 128.1(\mathrm{CH}), 126.0$ $(\mathrm{CH}), 119.5(\mathrm{CH}), 114.6(\mathrm{CH})$ ppm. IR (neat): $v_{\max }\left(\mathrm{cm}^{-1}\right) 3070(\mathrm{~m}), 3004(\mathrm{~m}), 2891(\mathrm{~m}), 2724$ (w), 1597 (w), 1575 (m), 1500 (s), 1475 (s), 1455 (m), 1417 (m), 1326 (s), 1309 (s), 1273 (s), 1253 (s), 1140 (m), 1090 (m), 1070 (m), 1031 (w), 1003 (w), 978 (w), 910 (s), 839 (w), 798 (s), $764(\mathrm{~s}), 713$ (s), 695 (s), $674(\mathrm{~s})$. The spectroscopic data are consistent with those reported in the literature. ${ }^{102}$

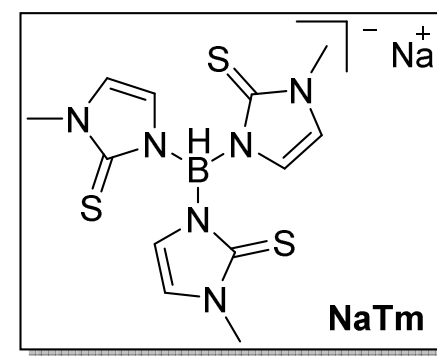

Synthesis of sodium tris(methimizolyl)borate (NaTm): A $100 \mathrm{~mL}$ round bottom flask was charged with methimazole $(4.57 \mathrm{~g}, 40.0 \mathrm{mmol})$ and $\mathrm{NaBH}_{4}(504 \mathrm{mg}$, $13.3 \mathrm{mmol})$, followed by xylenes or toluene $(30 \mathrm{~mL})$. The flask was fitted with a reflux condenser and the solution was degassed under vacuum. After that, the flask was placed under an $\mathrm{N}_{2}$ atmosphere and heated at reflux in an oil bath for 18 hours. Once that time had paced, the flask was allowed to cool to room temperature and placed in an ice bath. Hexanes $(10 \mathrm{~mL})$ was added to the solution to help induce precipitation of the product. The precipitate was then collected via filtration using a Büchner funnel and washed with hexanes $(10 \mathrm{~mL})$. This crude sample was then purified by recrystallization from $\mathrm{MeOH} / \mathrm{Et}_{2} \mathrm{O}$ to provide a white powder (3.89 $\mathrm{g}, 10.4 \mathrm{mmol}, 78.0 \%)$.

${ }^{1} \mathrm{H}$ NMR (DMSO- $\left.d_{6}, 400 \mathrm{MHz}\right): \delta=6.79(\mathrm{~d}, J=2.0 \mathrm{~Hz}, 1 \mathrm{H}), 6.40(\mathrm{~d}, J=2.0 \mathrm{~Hz}, 1 \mathrm{H}), 3.38(\mathrm{~s}$, $3 \mathrm{H}) \mathrm{ppm} .{ }^{13} \mathrm{C}$ NMR (DMSO-d $\left.6,100 \mathrm{MHz}\right): \delta=120.8(\mathrm{CH}), 116.3(\mathrm{CH}), 33.4\left(\mathrm{CH}_{3}\right) \mathrm{ppm} . \mathrm{IR}$ (neat): $v_{\max }\left(\mathrm{cm}^{-1}\right) 3354(\mathrm{w}), 3296(\mathrm{w}), 3127(\mathrm{~m}), 3016(\mathrm{w}), 2935$ (w), $2480(\mathrm{w}), 1576(\mathrm{w}), 1559$ (w), 1451 (m), 1403 (m), 1374 (s), 1293 (m), 1198 (s), 1164 (w), 1093 (s), 998 (w), 740 (m), 721 
(m), $691(\mathrm{~m}), 678(\mathrm{~m})$. The spectroscopic data are consistent with those reported in the literature. $^{73}$

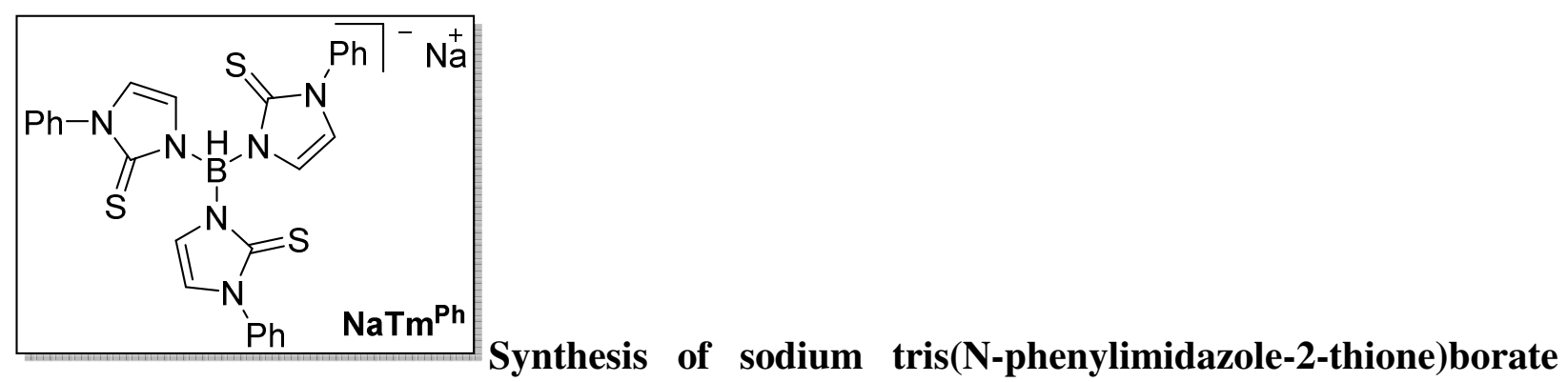

$\left(\mathbf{N a T m}{ }^{\mathrm{Ph}}\right)$ : A $50 \mathrm{~mL}$ round bottom flask was charged with $\mathrm{N}$-phenylimidazole-2-thione $(1.50 \mathrm{~g}$, $8.5 \mathrm{mmol}$.) and $\mathrm{NaBH}_{4}(214 \mathrm{mg}, 5.7 \mathrm{mmol})$, followed by toluene $(20 \mathrm{~mL})$. The flask was fitted with a reflux condenser and the solution was degassed under vacuum. After that, the flask was placed under an $\mathrm{N}_{2}$ atmosphere and refluxed in an oil bath for 48 hours. Once that time had passed, the flask was allowed to cool to room temperature and placed in an ice bath. Hexanes (10 $\mathrm{mL}$ ) was added to the solution to help induce precipitation of the product. The precipitate was then collected via filtration using a Büchner funnel and washed with hexanes $(10 \mathrm{~mL})$. This crude sample was then purified by recrystallization from $\mathrm{CHCl}_{3} / \mathrm{CH}_{2} \mathrm{Cl}_{2}$ to provide a white powder (1.03 g, $1.83 \mathrm{mmol}, 64.6 \%)$.

${ }^{1} \mathrm{H}$ NMR $\left(\mathrm{CD}_{3} \mathrm{OD}, 400 \mathrm{MHz}\right): \delta=7.61(\mathrm{~d}, J=8.0 \mathrm{~Hz}, 2 \mathrm{H}), 7.47(\mathrm{t}, J=7.2 \mathrm{~Hz}, 2 \mathrm{H}), 7.43(\mathrm{~d}, J=$ $7.2 \mathrm{~Hz}, 1 \mathrm{H}), 7.02(\mathrm{~d}, J=2.4 \mathrm{~Hz}, 1 \mathrm{H}), 6.99(\mathrm{~d}, J=2.4 \mathrm{~Hz}, 1 \mathrm{H}) \mathrm{ppm} .{ }^{13} \mathrm{C} \mathrm{NMR}\left(\mathrm{CD}_{3} \mathrm{OD}, 100\right.$ MHz): $\delta=162.1(\mathrm{C}), 139.2(\mathrm{C}), 128.3(\mathrm{CH}), 127.4(\mathrm{CH}), 126.5(\mathrm{CH}), 122.8(\mathrm{CH}), 118.0(\mathrm{CH})$ ppm. IR (neat): $v_{\max }\left(\mathrm{cm}^{-1}\right) 3370(\mathrm{w}), 3136(\mathrm{w}), 3070(\mathrm{w}), 2504$ (w), 1598 (m), 1497 (s), 1458 (w), 1416 (s), 1352 (s), 1326 (m), 1253 (s), 1187 (s), 1156 (s), 1080 (s), 1027 (m), 1003 (m), 956 (m), $906(\mathrm{w}), 824(\mathrm{w}), 747(\mathrm{~s}), 716(\mathrm{~s}), 689(\mathrm{~s}), 672(\mathrm{~s})$. 


\subsection{Procedures for the Synthesis of Vanadium-Tris(methimizolyl)borate Sandwich Complexes}

General procedure for the screening of the reaction between tris(methimizolyl)borate and vanadium sources (Table 1):

NaTm (15.0 mg, $0.04 \mathrm{mmol})$ and the corresponding vanadium source $(0.04 \mathrm{mmol})$ were added to a J. Young NMR tube, followed by the appropriate solvent $(0.4 \mathrm{~mL})$. These reactions were allowed to proceed for 15 minutes at room temperature with occasional shaking. ${ }^{1} \mathrm{H}$ NMR spectra were then obtained for each reaction. If a proteo-solvent was used, it was removed under vacuum and DMSO- $d_{6}$ was added in order to obtain an NMR spectrum. Any reactions where little to no reaction was observed were heated to reflux in an oil bath for 8 hours.

\section{Synthesis of bis[tris(imidazole-2-thione)borate] vanadium(III) chloride $\left(\left[\mathrm{Tm}^{\mathrm{R}}{ }_{2} \mathrm{~V}\right] \mathrm{Cl}\right)$ complexes:}

A $25 \mathrm{~mL}$ round bottom flask was charged with $\mathrm{VCl}_{3}$ (205 mg, $1.3 \mathrm{mmol}, 1$ equiv.) and the corresponding $\mathrm{NaTm}^{\mathrm{R}}$ (2.6 mmol, 2 equiv.). Dry $\mathrm{MeOH}(10 \mathrm{~mL})$ was added to the flask and the reaction was stirred for 15 minutes. After this time, $\mathrm{Et}_{2} \mathrm{O}(5 \mathrm{~mL})$ was added to increase precipitation of the product. The product was then collected via filtration using a Büchner funnel and washed with 1:1 $\mathrm{MeOH}_{\mathrm{Et}} \mathrm{O}(3 \mathrm{~mL})$, providing a bright red powder without any additional purification needed.

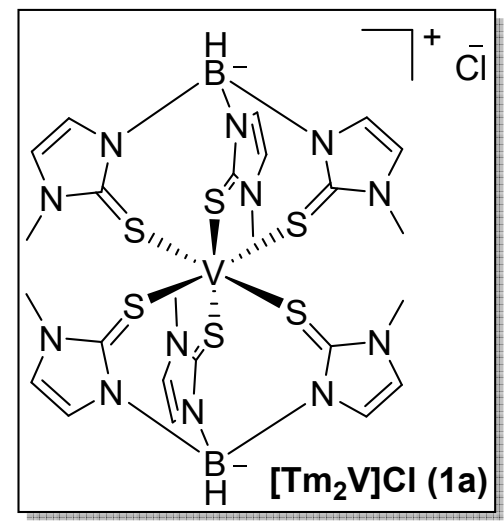

[Tm2V]Cl (1a): Yield: ${ }^{1} \mathrm{H}$ NMR (DMSO- $\left.d_{6}, 400 \mathrm{MHz}\right): \delta=12.28$

(s, 2H), 10.31 (s, 2H), 3.01 (s, 6H) ppm. ${ }^{13} \mathrm{C}$ NMR (DMSO- $\left.d_{6}, 100 \mathrm{MHz}\right): \delta=136.1(\mathrm{CH}), 128.2$ 
(CH), $90.4\left(\mathrm{CH}_{3}\right)$ ppm. IR (neat): $v_{\max }\left(\mathrm{cm}^{-1}\right) 3318(\mathrm{w}), 3132(\mathrm{w}), 3120(\mathrm{~m}), 3080(\mathrm{w}), 3012(\mathrm{w})$, 2943 (w), 2401 (w), 2221 (w), 1619 (w), 1559 (m), 1462 (s), 1420 (m), 1376 (s), 1332 (m), 1302 (m), 1200 (s), 1143 (m), 1097 (m), 1052 (m), 1035 (m), 1017 (m), 776 (m), 735 (s), 695 (s). ESIMS (MeOH): $m / z 753.15\left([\mathrm{M}]^{+}\right)$.

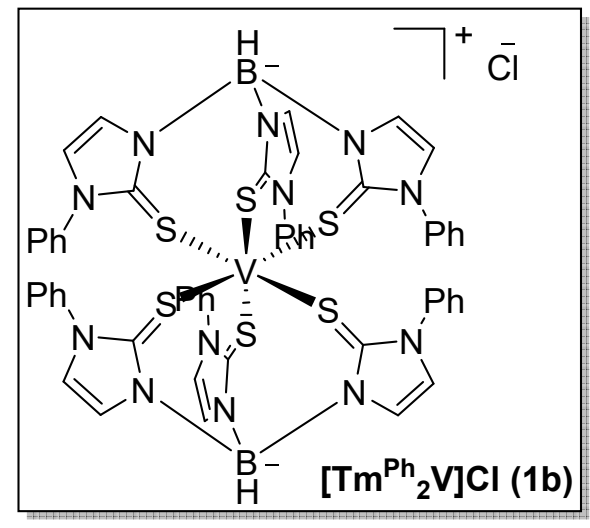

$\left[\mathbf{T m}^{\mathrm{Ph}_{2}} \mathbf{V}\right] \mathbf{C l}(\mathbf{1 b}):{ }^{1} \mathrm{H}$ NMR (DMSO- $\left.d_{6}, 400 \mathrm{MHz}\right): \delta=12.56$

(s, 2H), $9.82(\mathrm{~s}, 2 \mathrm{H}), 7.51(\mathrm{~m}, 6 \mathrm{H}), 7.07$ (t, $J=27.2 \mathrm{~Hz} 4 \mathrm{H}) \mathrm{ppm}$. IR (neat): $v_{\max }\left(\mathrm{cm}^{-1}\right) 3389(\mathrm{w})$, 3063 (w), 2442 (w), 1597 (w), 1557 (w), 1497 (s), 1430 (m), 1366 (s), 1324 (m), 1248 (w), 1191 (s), 1099 (m), 1072 (w), 1047 (w), 1026 (w), 1003 (w), 956 (w), $914(w), 833$ (w), 758 (s), 725 (s), 690 (s). ESI-MS (MeOH): $m / z 1125.25\left([\mathrm{M}]^{+}\right)$.

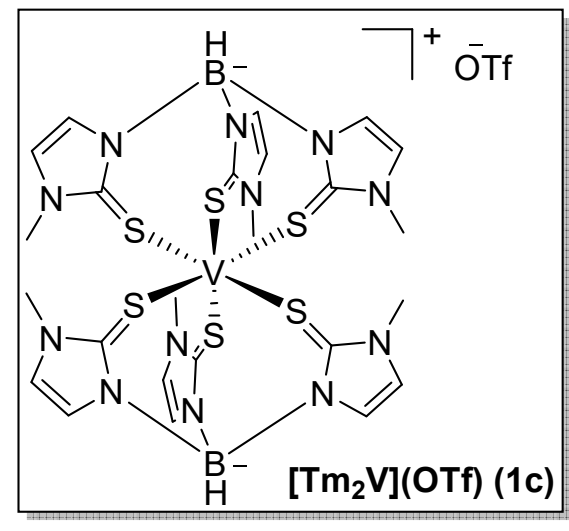

triflate ([Tm2V](OTf), 1c): A $25 \mathrm{~mL}$ round bottom flask was charged with $\mathrm{VCl}_{3}(175 \mathrm{mg}, 1.1$ $\mathrm{mmol})$ and AgOTf $(856 \mathrm{mg}, 3.3 \mathrm{mmol})$. Dry MeOH $(10 \mathrm{~mL})$ was added to the flask creating a deep violet solution, which was stirred for 1 hour. During this time a white precipitate $(\mathrm{AgCl})$ formed, which was then be filtered off using a Hirsch funnel. NaTm (831 mg, $2.2 \mathrm{mmol}$ ) was 
added to the fitrate and stirred for 15 minutes. After this time, $\mathrm{Et}_{2} \mathrm{O}(5 \mathrm{~mL})$ was added to the flask to increase precipitation of the product. The product was then collected via filtration using a Büchner funnel and washed with 1:1 $\mathrm{MeOH}: \mathrm{Et}_{2} \mathrm{O}(3 \mathrm{~mL})$, providing an orange/red powder (731 $\mathrm{mg}, 0.8 \mathrm{mmol}, 73 \%$ ) without any additional purification needed.

${ }^{1} \mathrm{H}$ NMR (DMSO- $\left.d_{6}, 400 \mathrm{MHz}\right): \delta=12.28(\mathrm{~s}, 2 \mathrm{H}), 10.29(\mathrm{~s}, 2 \mathrm{H}), 3.00(\mathrm{~s}, 6 \mathrm{H}) \mathrm{ppm} .{ }^{13} \mathrm{C}$ NMR (DMSO-d $\left.d_{6}, 100 \mathrm{MHz}\right): \delta=136.1(\mathrm{CH}), 128.2(\mathrm{CH}), 90.4\left(\mathrm{CH}_{3}\right)$ ppm. ${ }^{19} \mathrm{~F}\left(\mathrm{DMSO}-d_{6}, 282 \mathrm{MHz}\right)$ : $\delta=77.79$ ppm. IR (neat): $v_{\max }\left(\mathrm{cm}^{-1}\right) 3130(\mathrm{w}), 2334(\mathrm{w}), 1562(\mathrm{w}), 1466(\mathrm{~m}), 1415(\mathrm{w}), 1384$ (m), 1328 (w), 1300 (w), 1270 (s), 1207 (s), 1140 (s), 1093 (w), 1049 (w), 1031 (s), 1013 (m), $773(\mathrm{~m}), 733$ (s), 691 (s). ESI-MS $(\mathrm{MeOH}): \mathrm{m} / \mathrm{z}=753.15\left([\mathrm{M}]^{+}\right)$. Anal. Calc. for $\mathrm{C}_{25} \mathrm{H}_{32} \mathrm{~B}_{2} \mathrm{~F}_{3} \mathrm{~N}_{12} \mathrm{O}_{3} \mathrm{~S}_{7} \mathrm{~V}$ (902.04): C 33.27, $\mathrm{H}$ 3.57, N 18.62; found: C33.49, H 3.51, N 18.63.

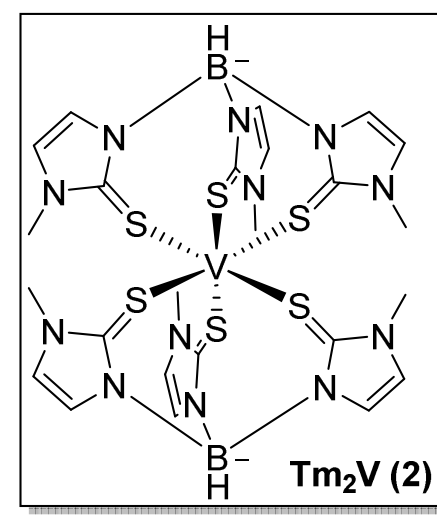

Synthesis of bis[tris(methimizolyl)borate] vanadium(II) (2): A 10

$\mathrm{mL}$ round bottom flask was charged with $1 \mathrm{a}(50 \mathrm{mg}, 0.063 \mathrm{mmol})$ and $\mathrm{Cp}_{2} \mathrm{Co}(13 \mathrm{mg}, 0.067$ $\mathrm{mmol}$ ). Dry MeCN (2 mL) was added and the reaction was stirred at room temperature for 1 hour. After this time the precipitate was collected via filtration using a Hirsch funnel and washed with 1:1 MeCN:Et $2 \mathrm{O}(1 \mathrm{~mL})$, providing a pale yellow powder (41 mg, $0.05 \mathrm{mmol}, 86.3 \%$ ) without any additional purification needed. IR (neat): $v_{\max }\left(\mathrm{cm}^{-1}\right) 3160(\mathrm{w}), 3113(\mathrm{~m}), 3075(\mathrm{~m})$, 2925 (s), 2854 (s), 2391 (m), 2321 (w), 2227 (w), 1606 (w), 1563 (m), 1458 (s), 1412 (s), 1377 (s), 1325 (m), 1301 (m), 1208 (s), 1137 (m), 1108 (w), 1096 (w), 1052 (w), 1028 (w), 778 (m), 730 (m), 695 (m). 


\subsection{Procedures for Reactions Involving Isonitriles as Ligands}

\section{General procedure for the displacement of tris(methimizolyl)borate from 1 (Table 2):}

Complex 1 (16 mg, $0.02 \mathrm{mmol})$ and the corresponding ligand (0.04 mmol) were combined into a J. Young NMR tube, followed by the addition of the appropriate solvent $(0.4 \mathrm{~mL})$. These reactions were monitored by ${ }^{1} \mathrm{H}$ NMR spectroscopy at room temperature over the course of 1 day. Following this, the reactions were heated to reflux in an oil bath for 8 hours and analyzed again by ${ }^{1} \mathrm{H}$ NMR.

\section{General procedure for the addition of tris(methimizolyl)borate and vanadium/isonitrile solutions (Table 3):}

A $25 \mathrm{~mL}$ 2-neck round bottom flask was charged with $\mathrm{VCl}_{3}(110 \mathrm{mg}, 0.7 \mathrm{mmol})$. Dry solvent (3.5 mL) was added to the flask, followed by $\mathrm{CN} t \mathrm{Bu}$ or $\mathrm{CNCy}(2.1 \mathrm{mmol})$. When using $\mathrm{MeOH}$ as the solvent, $\mathrm{NaTm}(262 \mathrm{mg}, 0.7 \mathrm{mmol})$ was dissolved in $\mathrm{MeOH}$ in a separate $25 \mathrm{~mL}$ round bottom flask, and the vanadium solution was reduced to $2 \mathrm{~mL}$. Alternatively, when other solvents were used, NaTm was placed in an addition funnel connected to the 2-neck flask.

The reaction flask was then brought out of the glovebox and set up on a Schlenk line. If the reaction was initiated at reduced temperature, then both the reaction flask and the NaTm solution (if used) were then cooled in an acetone (for $-78^{\circ} \mathrm{C}$ ) or $\mathrm{MeCN}$ (for $-40{ }^{\circ} \mathrm{C}$ ) dry ice bath. Once at the appropriate temperature, NaTm addition was performed. Addition of the NaTm solution was performed via cannulate transfer. If the reaction was performed at reduced temperature, then that temperature was held for 2 hours before being allowed to slowly warm to room temperature. After the reactions were complete, the solvent was removed in vacuo to provide an olive green residue.

Purification of the crude residue was attempted through several different crystallizations. Slow evaporation of solvent from $\mathrm{MeOH}, \mathrm{MeCN}$, and DCM solutions of the crude mixture were performed. Additionally, slow vapor diffusion of ethyl ether into each of the three solutions was carried out. However, none of these attempts resulted in the precipitation of any material. 


\subsection{Procedures for Reactions Involving Hydrazines}

\section{General procedure for the addition of tris(methimizolyl)borate to vanadium/hydrazine solutions (Table 4):}

A $3 \mathrm{~mL}$ vial was charged with $\mathrm{VCl}_{3}(6 \mathrm{mg}, 0.04 \mathrm{mmol})$ followed by the appropriate deuterated solvent $(0.5 \mathrm{~mL})$ and the corresponding hydrazine $(0.12 \mathrm{mmol})$. NaTm $(15 \mathrm{mg}, 0.04 \mathrm{mmol})$ was then added and the solution was allowed to stir for 2 hours, during which an off-white precipitate (3) formed. After this time, the reactions were transferred to a J. Young NMR tube for analysis. Isolation of the 3 was done by performing the reaction on a $1.5 \mathrm{mmol}$ scale. The precipitate was then collected via filtration using a Hirsch funnel and washed with 1:1 $\mathrm{MeOH}_{\mathrm{Et}} \mathrm{O}(1 \mathrm{~mL})$. Yields listed are crude yields, containing a vanadium impurity detected by ${ }^{51} \mathrm{~V}$ NMR.

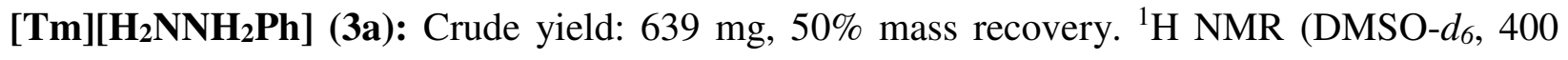
$\mathrm{MHz}): \delta=7.27(\mathrm{t}, J=9.2 \mathrm{~Hz}, 2 \mathrm{H}), 6.91(\mathrm{~m}, 3 \mathrm{H}), 6.81(\mathrm{~d}, J=2.0 \mathrm{~Hz}, 3 \mathrm{H}), 6.38(\mathrm{~d}, J=2.0 \mathrm{~Hz}$, 3H) ppm.

[Tm][H $\left.\mathbf{H}_{2} \mathbf{N N H}_{2} \mathrm{Me}\right](\mathbf{3 b}):$ Crude yield: $466 \mathrm{mg}, 46 \%$ mass recovery. ${ }^{1} \mathrm{H}$ NMR (DMSO- $d_{6}, 400$ $\mathrm{MHz}): \delta=6.79(\mathrm{~s}, 3 \mathrm{H}), 6.40(\mathrm{~s}, 3 \mathrm{H}), 3.38(\mathrm{~s}, 9 \mathrm{H}), 2.55(\mathrm{~s}, 3 \mathrm{H}) \mathrm{ppm}$.

[Tm][H2NNHMe2] (3c): Crude yield: $417 \mathrm{mg}, 39 \%$ mass recovery. ${ }^{1} \mathrm{H}$ NMR (DMSO- $d_{6}, 400$ $\mathrm{MHz}): \delta=6.80(\mathrm{~d}, J=1.6 \mathrm{~Hz}, 3 \mathrm{H}), 6.38(\mathrm{~d}, J=1.6 \mathrm{~Hz}, 3 \mathrm{H}), 3.38(\mathrm{~s}, 9 \mathrm{H}), 2.72(\mathrm{~s}, 6 \mathrm{H}) \mathrm{ppm}$.

[Tm][H $\left.\mathbf{H}_{2} \mathbf{N N H}_{3}\right](\mathbf{3 d}):$ Crude yield: $851 \mathrm{mg}, 90 \%$ mass recovery. ${ }^{1} \mathrm{H}$ NMR (DMSO-d 6 , 400 $\mathrm{MHz}): \delta=6.81(\mathrm{~s}, 3 \mathrm{H}), 6.38(\mathrm{~s}, 3 \mathrm{H}), 3.38(\mathrm{~s}, 9 \mathrm{H}) \mathrm{ppm}$.

\section{Procedure for the reduction of phenylhydrazine to aniline via in situ formation of 3a:}

A $3 \mathrm{~mL}$ vial was charged with $\mathrm{VCl}_{3}(6 \mathrm{mg}, 0.04 \mathrm{mmol})$ followed by $\mathrm{CD}_{3} \mathrm{OD}(0.5 \mathrm{~mL})$ and the phenylhydrazine $(12 \mu \mathrm{L}, 0.12 \mathrm{mmol})$. Next, NaTm (15 mg, $0.04 \mathrm{mmol}), \mathrm{Cp}_{2} \mathrm{Co}$ (8 mg, 0.04 $\mathrm{mmol})$, and LutHCl $(6 \mathrm{mg}, 0.04 \mathrm{mmol})$ were added to the vial. The solution was allowed to stir for 2 hours. After this time, the reaction was filtered through celite and transferred to a J. Young NMR tube for analysis. Further analysis of this sample was performed via GC, detecting aniline in a $34 \%$ yield with tetradecane as the internal standard. 


\section{Procedure for the reduction of $3 a$ to aniline:}

A $3 \mathrm{~mL}$ vial was charged with $3 \mathrm{a}$ (30 mg, $0.04 \mathrm{mmol})$, followed by $\mathrm{CD}_{3} \mathrm{OD}(0.5 \mathrm{~mL})$. $\mathrm{Cp}_{2} \mathrm{Co}(8$ $\mathrm{mg}, 0.04 \mathrm{mmol})$, and $\mathrm{LutHCl}(6 \mathrm{mg}, 0.04 \mathrm{mmol})$ were then added to the vial. The solution was allowed to stir for 2 hours. After this time, the reaction was filtered through celite and transferred to a J. Young NMR tube for analysis. Further analysis of this sample was performed via GC, detecting aniline in a $25 \%$ yield with tetradecane as the internal standard.

\section{General procedure for the control reactions involving phenylhydrazine (Table 5):}

A $3 \mathrm{~mL}$ vial was charged with the appropriate selection of $\mathrm{NaTm}(15 \mathrm{mg}, 0.04 \mathrm{mmol}), \mathrm{Cp}_{2} \mathrm{Co}$ (16 mg, $0.08 \mathrm{mmol})$ and $\mathrm{LutHCl}(12 \mathrm{mg}, 0.08 \mathrm{mmol})$, followed by $\mathrm{CD}_{3} \mathrm{OD}(0.5 \mathrm{~mL})$. Phenylhydrazine $(4 \mu \mathrm{L}, 0.04 \mathrm{mmol})$ was then added to the vial and allowed to stir for 2 hours. After this time, the reaction was filtered through celite (if needed) and transferred to a J. Young NMR tube for analysis.

The reaction omitting $\mathrm{Cp}_{2} \mathrm{Co}$ (entry 2) was also performed on a larger scale employing Phenylhydrazine (30 $\mu \mathrm{L}, 0.3 \mathrm{mmol})$, NaTm (112 mg, $0.3 \mathrm{mmol})$, LutHCl (43 mg, $0.3 \mathrm{mmol})$, and $\mathrm{MeOH}(2 \mathrm{~mL})$. Ethyl ether $(2 \mathrm{~mL})$ was added to induce further precipitation of the product, which was collected via Hirsch funnel filtration and washed with ethyl ether $(1 \mathrm{~mL})$, providing 3a (98 mg, $0.21 \mathrm{mmol}, 71 \%)$ without any additional purification needed.

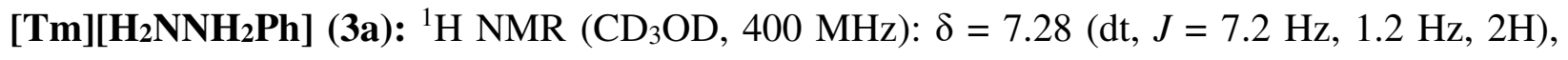
$7.00(\mathrm{~m}, 3 \mathrm{H}), 6.88(\mathrm{~d}, J=2.0 \mathrm{~Hz}, 3 \mathrm{H}), 6.38(\mathrm{~d}, J=2.0 \mathrm{~Hz}, 3 \mathrm{H}), 3.52(\mathrm{~s}, 9 \mathrm{H}) \mathrm{ppm}$. 


\section{Appendix A}

Table 16. Recent attempts for reproducing the cobalt-catalyzed coupling of 2-aminobenzylamine and tert-butyl isonitrile ${ }^{\mathrm{a}}$
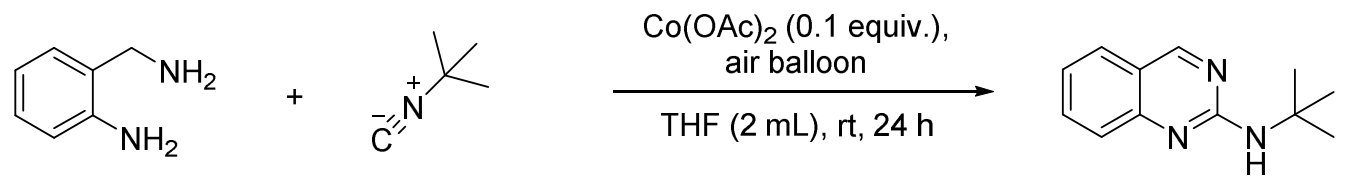

$\begin{array}{ccc}\text { Entry } & \text { Workup Method } & \text { Yield }(\%) \\ 1^{\mathrm{c}} & \text { silica filtration } & 14 \\ 2 & \text { silica filtration } & 21^{\mathrm{d}} \\ 3^{\mathrm{e}} & \text { silica filtration } & 24 \\ 4 & \text { EDTA wash } & 22^{\mathrm{f}}\end{array}$

${ }^{a}$ Reaction conditions: 2-aminobenzylamine $(0.20 \mathrm{mmol})$, tert-butyl isonitrile $(0.22 \mathrm{mmol}), \mathrm{Co}(\mathrm{OAc})_{2}$ (0.02 mmol), air balloon, THF ( $2 \mathrm{~mL}), \mathrm{rt}, 24 \mathrm{~h}, 6$ " test tube with septum. ${ }^{\text {b}}$ Yield determined by ${ }^{1} \mathrm{H}$ NMR spectroscopy with dimethyl sulfone as the internal standard. ${ }^{\mathrm{c}}$ Tert-butyl isonitrile $(0.20 \mathrm{mmol})$. ${ }^{\mathrm{d}}$ Average of 3 reactions. ${ }^{\mathrm{e}} \mathrm{O}_{2}$ balloon. ${ }^{\mathrm{f}}$ Average of 4 reactions. 


\section{References}

(1) Hoffman, B. M.; Dean, D. R.; Seefeldt, L. C.; Acc. Chem. Res. 2009, 42, 609-619.

(2) Hu, Y.; Ribbe, M. W.; J. Biol. Inorg. Chem. 2014, 19, 731-736.

(3) Hoffman, B. M.; Lukoyanov, D.; Dean, D. R.; Seefeldt, L. C.; Acc. Chem. Res. 2013, 46, 587-595.

(4) Hoffman, B. M.; Lukoyanov, D.; Yang, Z.-Y.; Dean, D. R.; Seefeldt, L. C.; Chem. Rev. 2014, 114, 4041-4062.

(5) Yandulov, D. V.; Schrock, R. R.; Science 2003, 301, 76-78.

(6) Anderson, J. S.; Rittle, J.; Peters, J. C.; Nature 2013, 501, 84-88.

(7) Creutz, S. E.; Peters, J. C.; J. Am. Chem. Soc. 2014, 136, 1105-1115.

(8) Kuriyama, S.; Arashiba, K.; Nakajima, K.; Tanaka, H.; Kamaru, N.; Yoshizawa, K.; Nishibayashi, Y.; J. Am. Chem. Soc. 2014, 136, 9719-9731.

(9) Arashiba, K.; Kinoshita, E.; Kuriyama, S.; Eizawa, A.; Nakajima, K.; Tanaka, H.; Yoshizawa, K.; Nishibayashi, Y.; J. Am. Chem. Soc. 2015, 137, 5666-5669.

(10) Barney, B. M.; Yang, T.-C.; Igarashi, R. Y.; Dos Santos, P. C.; Laryukhin, M.; Lee, H.-I.; Hoffman, B. M.; Dean, D. R.; Seefeldt, L. C.; J. Am. Chem. Soc. 2005, 127, 1496014961.

(11) Barney, B. M.; McClead, J.; Lukoyanov, D.; Laryukhin, M.; Yang, T.-C.; Lee, H.-I.; Dean, D. R.; Hoffman, B. M.; Seefeldt, L. C.; Biochemistry 2007, 46, 6784-6794.

(12) Danyal, K.; Inglet, B. S.; Vincent, K. A.; Barney, B. M.; Hoffman, B. M.; Armstrong, F. A.; Dean, D. R.; Seefeldt, L. C.; J. Am. Chem. Soc. 2010, 132, 13197-13199.

(13) Shaw, S.; Lukoyanov, D.; Danyal, K.; Dean, D. R.; Hoffman, B. M.; Seefeldt, L. C.; J. Am. Chem. Soc. 2014, 136, 12776-12783.

(14) Seefeldt, L. C.; Yang, Z.-Y.; Duval, S.; Dean, D. R.; Biochim. Biophys. Acta 2013, 1827, 1102-1111.

(15) Fisher, K.; Dilworth, M. J.; Newton, W. E.; Biochemistry 2006, 45, 4190-4198.

(16) Eady, R. R.; Robson, R. L.; Richardson, T. H.; Miller, R. W.; Hawkins, M.; Biochem. J. 1987, 249, 745-751.

(17) Pau, R. N.; Eldridge, M. E.; Lowe, D. J.; Mitchenall, L. A.; Eady, R.; Biochem. J. 1993, 293, 101-107.

(18) Schneider, K.; Gollan, U.; Selsemeiervoigt, S.; Plass, W.; Muller, A.; Naturwissenschaften 1994, 81, 405-408. 
(19) Dilworth, M. J.; Eady, R. R.; Eldridge, M. E.; Biochem. J. 1988, 249, 745-751.

(20) Ashby, G. A.; Dilworth, M. J.; Thorneley, R. N. F.; Biochem. J. 1987, 247, 547-554.

(21) McKenna, C. E.; McKenna, M. C.; Higa, M. T.; J. Am. Chem. Soc. 1976, 98, 4657-4659.

(22) Seefeldt, L. C.; Rasche, M. E.; Ensign, S. A.; Biochemistry 1995, 5382-5389.

(23) Hu, Y.; Lee, C. C.; Ribbe, M. W.; Science, 2011, 333, 753-755.

(24) Lee, C. C.; Hu, Y.; Ribbe, M. W.; Science, 2010, 329, 642.

(25) Yang, Z.-Y.; Dean, D. R.; Seefeldt, L. C.; J. Biol. Chem. 2011, 286, 19417-19421.

(26) Schlögl, R.; Angew. Chem., Int. Ed. 2003, 42, 2004 -2008.

(27) Ertl, G.; Angew. Chem., Int. Ed. 2008, 47, $3524-3535$.

(28) Wu, B.; Gramigna, K. M.; Bezpalko, M. W.; Foxman, B. M.; Thomas, C. M.; Inorg. Chem. 2015, 54, 10909-10917.

(29) Schrock, R. R.; Glassman, T. E.; Vale, M. G.; J. Am. Chem. Soc. 1991, 113, 725-726.

(30) Block, E.; Ofori-Okai, G.; Kang, H.; Zubieta, J.; J. Am. Chem. Soc. 1992, 114, 758-759.

(31) Chen, Y.; Zhou, Y.; Chen, P.; Tao, Y.; Li, Y.; Qu, J.; J. Am. Chem. Soc. 2008, 130, $15250-15251$.

(32) Yuki, M.; Miyake, Y.; Nishibayashi, Y.; Organometallics 2012, 31, 2953-2956.

(33) Hitchcock, P. B.; Hughes, D. L.; Maguire, M. J.; Marjani, K.; Richards, R. L.; J. Am. Chem. Soc. 1992, 114, 758-759.

(34) Chu, W.-C.; Wu, C.-C.; Hsu, H.-F.; Inorg. Chem. 2006, 45, 3164-3166.

(35) Chang, Y.-H.; Chan, P.-M.; Tsai, Y.-F.; Lee, G.-H.; Hsu, H.-F.; Inorg. Chem. 2014, 53, 664-666.

(36) Davies, S. C.; Hughes, D. L.; Janas, Z.; Jerzykiewicz, L. B.; Richards, R. L.; Sanders, J. R.; Silverston, J. E.; Sobota, P.; Inorg. Chem. 2000, 39, 3485-3498.

(37) Davies, S. C.; Hughes, D. L.; Konkol, M..; Richards, R. L.; Sanders, J. R.; Sobota, P.; J. Chem. Soc., Dalton Trans., 2002, 2811-2814.

(38) Seino, H.; Masumori, T.; Hidai, M.; Mizobe, Y.; Organometallics 2003, 22, 3424-3431.

(39) Coucouvanis, D.; Mosier, P. E.; Demadis, K. D.; Patton, S.; Malinak, S. M.; Kim, C. G.; Tyson, M. A.; J. Am. Chem. Soc. 1993, 115, 12193-12194.

(40) Malinak, S. M.; Demadis, K. D.; Coucouvanis, D.; J. Am. Chem. Soc. 1995, 117, 31263133.

(41) Seefeldt, L. C.; Dance, I. G.; Dean, D. R.; Biochemistry 2004, 43, 1401-1409. 
(42) Khodakov, A. Y.; Chu, W.; Fongarland, P.; Chem. Rev. 2007, 107, 1692-1744.

(43) Maitlis, P. M.; Zanotti, V.; Chem. Commun., 2009, 13, 1619-1634.

(44) West, N. M.; Miller, A. J. M.; Labinger, J. A.; Bercaw, J. E.; Coord. Chem. Rev. 2011, 255, 881-898.

(45) Wu, J.; Fanwick, P. E.; Kubiak, C. P.; J. Am. Chem. Soc. 1988, 110, 1319-1321.

(46) Okazaki, M.; Suto, K.; Kudo, N.; Takano, M.; Ozawa, F.; Organometallics 2012, 31, 4110-4113.

(47) Marchetti, F.; Zacchini, S.; Zanotti, V.; Organometallics 2014, 33, 3990-3997.

(48) Lam, C. T.; Corfield, P. W. R.; Lippard, S. J.; J. Am. Chem. Soc. 1977, 99, 617-618.

(49) Giandomenico, C. M.; Lam, C. T.; Lippard, S. J.; J. Am. Chem. Soc. 1982, 104, 12631271.

(50) Acho, J. A.; Lippard, S. J.; Organometallics 1994, 13, 1294-1299.

(51) Collazo, C.; Rodewald, D.; Schmidt, H.; Rehder, D.; Organometallics 1996, 15, 48844887.

(52) Rehder, D.; Böttcher, C.; Collazo, C.; Hedelt, R.; Schmidt, H.; J. Organomet. Chem. 1999, 585, 294-307.

(53) Ojo, W.-S.; Pétillon, F. Y.; Schollhammer, P.; Talarmin, J.; Organometallics 2008, 27, 4207-4222.

(54) Shen, J.; Yap, G. P. A.; Theopold, K. H.; J. Am. Chem. Soc. 2014, 136, 3382-3384.

(55) Wayland, B. B.; Sherry, A. E.; Coffin, V. L.; Chem. Commun. 1989, 10, 662-663.

(56) Miller, A. J. M.; Labinger, J. A.; Bercaw, J. E.; J. Am. Chem. Soc. 2008, 130, 1187411875.

(57) Sazama, G. T.; Betley, T. A.; Organometallics 2011, 30, 4315-4319.

(58) Suess, D. L. M.; Peters, J. C.; J. Am. Chem. Soc. 2013, 135, 12580-12583.

(59) Manriquez, J. M.; McAlister, D. R.; Sanner, R. D.; Bercaw, J. E.; J. Am. Chem. Soc. 1976, 98, 6733-6735.

(60) Wolczanski, P. T.; Bercaw, J. E.; Acc. Chem. Res. 1980, 13, 121-127.

(61) Toreki, R.; LaPointe, R. E.; Wolczanski, P. T.; J. Am. Chem. Soc. 1987, 109, 7558-7560.

(62) Wantanabe, T.; Ishida, Y.; Matsuo, T.; Kawaguchi, H.; J. Am. Chem. Soc. 2009, 131, 3474-3475.

(63) Kurogi, T.; Ishida, Y.; Hatanaka, T.; Kawaguchi, H.; Dalton Trans. 2013, 42, 7510-7513. 
(64) Bianconi, P. A.; Williams, I. D.; Engeler, M. P.; Lippard, S. J.; J. Am. Chem. Soc. 1986, 108, 311-313.

(65) Protasiewicz, J. D.; Lippard, S. J.; J. Am. Chem. Soc. 1991, 113, 6564-6510.

(66) Carnahan, E. M.; Lippard, S. J.; J. Am. Chem. Soc. 1990, 112, 3230-3231.

(67) Buss, J. A.; Agapie, T.; Nature 2016, 7584, 72-75.

(68) Lee, C. C.; Fay, A. W.; Weng, T. C.; Krest, C. M.; Hedman, B.; Hodgson, K. O.; Hu, Y.; Ribbe, M. W.; Proc. Natl. Acad. Sci. USA 2015, 112, 13845 - 13849.

(69) Spicer, M. D.; Reglinski, J.; Eur. J. Inorg. Chem. 2009, 1553-1574.

(70) Garner, M.; Lehmann, M.-A.; Reglinski, J.; Spicer, M.D.; Organometallics 2001, 20, 5233-5236.

(71) Garner, M.; Lewinski, K.; Pattek-Janczyk, A.; Reglinski, J.; Sieklucka, B.; Spicer, M. D.; Szaleniec, M.; Dalton Trans. 2003, 1181-1185.

(72) Jesson, J. P.; Trofimenko, S.; Eaton, D. R.; J. Am. Chem. Soc. 1967, 89, 3158-3164.

(73) Garner, M.; Kennedy, A. R.; Cassidy, I.; Reglinski, J.; Spicer, M. D.; Chem. Commun. 1996, 1975-1976.

(74) Reglinski, J.; Garner, M.; Cassidy, I. D.; Slavin, P. A.; Spicer, M. D.; Armstrong, D. R.; J. Chem. Soc., Dalton Trans. 1999, 2119-2126.

(75) Kimblin, C.; Bridgewater, B. M.; Churchill, D. G.; Parkin, G.; Chem. Commun. 1999, 2301-2302.

(76) Hill, A. F.; Owen, G. R.; White, A. J. P.; Williams, D. J.; Angew. Chem., Int. Ed. 1999, $38,2759-2761$.

(77) Kimblin, C.; Hascall, T.; Parkin, G.; Inorg. Chem. 1997, 36, 5680-5681.

(78) Kimblin, C.; Bridgewater, B. M.; Hascall, T.; Parkin, G.; J. Chem. Soc., Dalton Trans. 2000, 891-897.

(79) Santini, C.; Lobbia, G. G.; Pettinari, C.; Pellei, M.; Valle, G.; Calogero, S.; Inorg. Chem. 1998, 37, 890-900.

(80) Tesmer, M.; Shu, S.; Vahrenkamp, H.; Inorg. Chem. 2001, 40, 4022-4029.

(81) Bakbak, S.; Bhatia, V. K.; Incarvito, C. D.; Rheingold, A. L.; Rabinovich, D.; Polyhedron 2001, 20, 3343-3348.

(82) Bailey, P. J.; Dawson, A.; McCormack, C.; Moggach, S. A.; Oswald, I. D. H.; Parsons, S.; Rankin, D. W. H.; Turner, A.; Inorg. Chem. 2005, 44, 8884-8898.

(83) Ibrahim, M. M.; Shu, M.; Vahrenkamp, H.; Eur. J. Inorg. Chem. 2005, 1388-1397. 
(84) Docrat, A.; Morlok, M. M.; Bridgewater, B. M.; Churchill, D. G.; Parkin, G.; Polyhedron 2004, 23, 481-488.

(85) Ibrahim, M. M.; Olmo, C. P.; Tekeste, T.; Seebacher, J.; He, G.; Maldonado Calvo, J. A.; Bohmerle, K.; Steinfeld, G.; Brombacher, H.; Vahrenkamp, H.; Inorg. Chem. 2006, 45, 7493-7502.

(86) Kimblin, C.; Churchill, D. G.; Bridgewater, B. M.; Girard, J. N.; Quarless, D. A.; Parkin, G.; Polyhedron 2001, 20, 1891-1896.

(87) Dodds, C. A.; Lehmann, M.-A.; Ojo, J. F.; Reglinski, J.; Spicer, M.D.; Inorg. Chem. 2004, 23, 4927-4934.

(88) Hill, A. F.; Smith, M. K.; Dalton Trans. 2007, 3363-3364.

(89) Figueroa, J. S.; Melnick, J. G.; Parkin, G.; Inorg. Chem. 2006, 45, 7056-7058.

(90) Foreman, M. R. St.-J.; Hill, A. F.; White, A. J. P.; Williams, D. J.; Organometallics 2004, 23, 913-916.

(91) Mihalcik, D. J.; White, J. L.; Tanski, J. M.; Zakharov, L. N.; Yap, G. P. A.; Incarvito, C. D.; Rheingold, A. L.; Rabinovich, D.; Dalton Trans. 2004, 1626-1634.

(92) Crossley, I. R.; Foreman, M. R. St.-J.; Hill, A. F.; White, A. J. P.; Williams, D. J.; Chem. Commun. 2005, 221-223.

(93) Crossley, I. R.; Hill, A. F.; Willis, A. C.; Organometallics 2005, 24, 1062-1064.

(94) Senda, S.; Ohki, Y.; Hirayama, T.; Toda, D.; Chen, J.-L.; Matsu-moto, T.; Kawaguchi, H.; Tatsumi, K.; Inorg. Chem. 2006, 45, 9914-9925.

(95) Pang, K.; Quan, S. M.; Parkin, G.; Chem. Commun. 2006, 5015-5017.

(96) Crossley, I. R.; Hill, A. F.; Organometallics 2004, 23, 5656-5658.

(97) Tesmer, M.; Shu, S.; Vahrenkamp, H.; Inorg. Chem. 2001, 40, 4022-4029.

(98) Buccella, D.; Shultz, A.; Melnick, J. G.; Kanopka, F.; Parkin, G.; Organometallics 2006, 25, 5496-5499.

(99) Wallace, D.; Gibson, L. T.; Reglinski, J.; Spicer, M. D.; Inorg. Chem. 2007, 46, 38043806.

(100) Tran, B. L.; Carrano, C. J. Inorg. Chem. 2007, 46, 5429-5438.

(101) Davies, S. C.; Hughes, D. L.; Janas, Z.; Jerzykiewicz, L. B.; Richards, R. L.; Sanders, J. R.; Silverston, J. E.; Sobota, P.; Inorg. Chem. 2000, 39, 3485-3498.

(102) Matsuda, K.; Yanagisawa, I.; Isomura, Y.; Mase, T.; Shibanuma, T.; Synth. Commun. 1997, 27, 3565-3571. 
(103) Cassidy, C. S.; Reinhardt, L. A.; Cleland, W.W.; Frey, P. A.; J. Chem. Soc., Perkin Trans. 2 1999, 635-641.

(104) Vlaar, T.; Cioc, R. C.; Mampuys, P.; Maes, B. U. W.; Orru, R. V. A.; Ruijter, E.; Angew. Chem. Int. Ed. 2012, 51, 13058-13061.

(105) Vlaar, T.; Orru, R. V. A.; Maes, B. U. W.; Ruijter, E.; J. Org. Chem. 2013, 78, 1046910475.

(106) Liu, B.; Yin, M.; Gao, H.; Wu, W.; Jiang, H.; J. Org. Chem. 2013, 78, 3009-3020.

(107) Zhu, T.-H.; Wang, S.-Y.; Wang, G.-N.; Ji, S.-J.; Chem.-Eur. J. 2013, 19, 5850-5853.

(108) Zhu, T.-H.; Xu, X.-P.; Cao, J.-J.; Wei, T.-Q.; Wang, S.-Y.; Ji, S.-J.; Adv. Synth. Catal. 2014, 356, $509-518$.

(109) Wang, G.-N.; Zhu, T.-H.; Wang, S.-Y.; Wei, T.-Q.; Ji, S.J.; Tetrahedron 2014, 70, 80798083.

(110) Lygin, A. V.; Meijere, A.; Angew. Chem. Int. Ed. 2010, 49, 9094 - 9124.

(111) Qiu, G.; Ding, Q.; Wu, J.; Chem. Soc. Rev., 2013, 42, 5257-5269.

(112) Bode, M. L.; Gravestock, D.; Rousseau, A. L.; Org. Prep. Proc. Int. 2016, 48, 89-221.

(113) Boyarskiy, V. P.; Bokach, N. A.; Luzyanin, K. V.; Kukushkin, V. Y.; Chem. Rev. 2015, $115,2698-2779$.

(114) Chakrabarty, S.; Choudhary, S.; Doshi, A.; Liu, F.-Q.; Mohan, R.; Ravindra, M. P.; Shah, D.; Yang, X.; Fleming, F. F.; Adv. Synth. Catal. 2014, 356, 2135 - 2196.

(115) Ito, Y.; Ito, I.; Hirao, T.; Saegusa, T.; Synth. Commun. 1974, 4, 97-103.

(116) Vlaar, T.; Ruijter, E.; Maes, B. U.W.; Orru, R. V. A.; Angew. Chem. Int. Ed. 2013, 52, $7084-7097$.

(117) Kosugi, M.; Ogata, T.; Tamura, H.; Sano, H.; Migita, T.; Chem. Lett. 1986, 15, 11971200.

(118) Saluste, C. G.; Whitby, R. J.; Furber, M.; Angew. Chem., Int. Ed. 2000, 39, 4156-4158.

(119) van Baelen, G.; Kuijer, S.; Rýček, L.; Sergeyev, S.; Janssen, E.; de Kanter, F. J. J.; Maes, B. U. W.; Ruijter, E.; Orru, R. V. A.; Chem. Eur. J. 2011, 17, 15039-15044.

(120) Boissarie, P. J.; Hamilton, Z. E.; Lang, S.; Murphy, J. A.; Suckling, C. J.; Org. Lett. 2011, 13, 6256-6259.

(121) Jiang, H.; Liu, B.; Li, Y.; Wang, A.; Huang, H.; Org. Lett. 2011, 13, 1028-1031. 
(122) Ohe, K.; Matsuda, H.; Ishihara, T.; Ogoshi, S.; Chatani, N.; Murai, S.; J. Org. Chem. 1993, 58, 1173-1177.

(123) Kamijo, S.; Jin, T.; Yamamoto, Y.; J. Am. Chem. Soc. 2001, 123, 9453-9454.

(124) Kamijo, S.; Yamamoto, Y.; J. Am. Chem. Soc. 2002, 124, 11940-11945.

(125) Park, S.; Shintani, R.; Hayashi, T.; Chem. Lett. 2009, 38, 204-205.

(126) Miura, T.; Nishida, Y.; Morimoto, M.; Yamauchi, M.; Murakami, M.; Org. Lett. 2011, $13,1429-1431$.

(127) Ito, Y.; Hirao, T.; Saegusa, T.; J. Org. Chem. 1975, 40, 2981-2982.

(128) Wang, Y.; Wang, H.; Peng, J.; Zhu, Q.; Org. Lett. 2011, 13, 4604-4607.

(129) Zhu, T.-H.; Wang, S.-Y.; Wang, G.-N.; Ji, S.-J.; Chem.-Eur. J. 2013, 19, 5850-5853.

(130) Zhu, T.-H.; Xu, X.-P.; Cao, J.-J.; Wei, T.-Q.; Wang, S.-Y.; Ji, S.-J.; Adv. Synth. Catal. 2014, 356, $509-518$.

(131) Wang, G.-N.; Zhu, T.-H.; Wang, S.-Y.; Wei, T.-Q.; Ji, S.J.; Tetrahedron 2014, 70, 80798083.

(132) Zhu, T.-H.; Wang, S.-Y.; Wei, T.-Q.; Ji, S.J.; Adv. Synth. Catal. 2015, 357, 823-828.

(133) Selvam, T, P.; Kumar, P.V.; Res. Pharm. 2011, 1, 1-21.

(134) Primik, M. F.; Göschi, S.; Jakupec, M.A.; Roller, A.; Keppler, B. K.; Arion, V. B.; Inorg. Chem. 2010, 49, 11084-11095. 